\title{
GCU
}

Glasgow Caledonian

University

University for the Common Good

\section{Interventions for post-stroke fatigue}

Wu, Simiao; Kutlubaev, Mansur A.; Chun, Ho-Yan Y.; Cowey, Eileen; Pollock, Alex; MacLeod, Malcolm R.; Dennis, Martin; Keane, Elizabeth; Sharpe, Michael; Mead, Gillian E. Published in:

Cochrane Database of Systematic Reviews

DOI:

10.1002/14651858.CD007030.pub3

Publication date:

2015

Document Version

Publisher's PDF, also known as Version of record

Link to publication in ResearchOnline

Citation for published version (Harvard):

Wu, S, Kutlubaev, MA, Chun, H-YY, Cowey, E, Pollock, A, MacLeod, MR, Dennis, M, Keane, E, Sharpe, M \& Mead, GE 2015, 'Interventions for post-stroke fatigue', Cochrane Database of Systematic Reviews, vol. 2015, no. 7. https://doi.org/10.1002/14651858.CD007030.pub3

\section{General rights}

Copyright and moral rights for the publications made accessible in the public portal are retained by the authors and/or other copyright owners and it is a condition of accessing publications that users recognise and abide by the legal requirements associated with these rights.

Take down policy

If you believe that this document breaches copyright please view our takedown policy at https://edshare.gcu.ac.uk/id/eprint/5179 for details of how to contact us. 


\section{(E) Cochrane Library}

Cochrane Database of Systematic Reviews

\section{Interventions for post-stroke fatigue (Review)}

Wu S, Kutlubaev MA, Chun HYY, Cowey E, Pollock A, Macleod MR, Dennis M, Keane E, Sharpe M, Mead GE

Wu S, Kutlubaev MA, Chun HYY, Cowey E, Pollock A, Macleod MR, Dennis M, Keane E, Sharpe M, Mead GE.

Interventions for post-stroke fatigue.

Cochrane Database of Systematic Reviews 2015, Issue 7. Art. No.: CD007030.

DOI: 10.1002/14651858.CD007030.pub3.

www.cochranelibrary.com 
TABLE OF CONTENTS

HEADER

ABSTRACT

PLAIN LANGUAGE SUMMARY

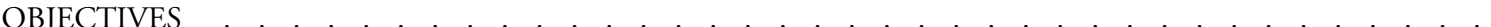

METHODS . . .

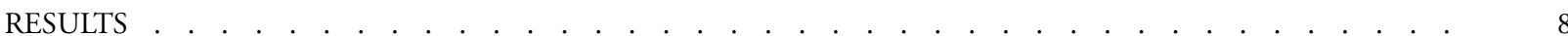

Figure 1. . . . . . . . . . . . . . . . . . . . . . . . . . . . . . . . . . . . . 9

Figure 2. . . . . . . . . . . . . . . . . . . . . . . . . . . . . . . . . . . . . . 12

Figure 3. . . . . . . . . . . . . . . . . . . . . . . . . . . . . . . . . . . . . . 13

Figure $4 . \quad$. . . . . . . . . . . . . . . . . . . . . . . . . . . . . . . . . . . . . 15

ADDITIONAL SUMMARY OF FINDINGS . . . . . . . . . . . . . . . . . . . . . . . . . . . . . 16

DISCUSSION . . . . . . . . . . . . . . . . . . . . . . . . . . . . . . . . . . . . . 19

AUTHORS' CONCLUSIONS . . . . . . . . . . . . . . . . . . . . . . . . . . . . . . . 21

ACKNOWLEDGEMENTS . . . . . . . . . . . . . . . . . . . . . . . . . . . . . . . . . 21

REFERENCES . . . . . . . . . . . . . . . . . . . . . . . . . . . . . . . . . . . . . . 22

CHARACTERISTICS OF STUDIES . . . . . . . . . . . . . . . . . . . . . . . . . . . . . . . 25

DATA AND ANALYSES . . . . . . . . . . . . . . . . . . . . . . . . . . . . . . . . . . . . . . . . . . . . . . . 49

Analysis 1.1. Comparison 1 Trials primarily intended to treat fatigue (intervention versus control), Outcome 1 Continuous outcomes (subgroup analysis)

Analysis 1.2. Comparison 1 Trials primarily intended to treat fatigue (intervention versus control), Outcome 2 Continuous outcomes (sensitivity analysis)

Analysis 1.3. Comparison 1 Trials primarily intended to treat fatigue (intervention versus control), Outcome 3 Dichotomous outcomes.

Analysis 3.1. Comparison 3 Trials not primarily intended at post-stroke fatigue (individual results), Outcome 1 Brown 2011 (CPAP versus sham, continuous outcome).

Analysis 3.2. Comparison 3 Trials not primarily intended at post-stroke fatigue (individual results), Outcome 2 Lorig 2001 (CDSMP versus wait-list, continuous outcome).

Analysis 3.3. Comparison 3 Trials not primarily intended at post-stroke fatigue (individual results), Outcome 3 Ogden 1998 (tirilazad versus vehicle, dichotomous outcome).

Analysis 3.4. Comparison 3 Trials not primarily intended at post-stroke fatigue (individual results), Outcome 4 Karaiskos 2012 (duloxetine versus citalopram, continuous outcome.

Analysis 3.5. Comparison 3 Trials not primarily intended at post-stroke fatigue (individual results), Outcome 5 Karaiskos 2012 (duloxetine versus sertraline, continuous outcome.

Analysis 3.6. Comparison 3 Trials not primarily intended at post-stroke fatigue (individual results), Outcome 6 Karaiskos 2012 (citalopram versus sertraline, continuous outcome). . . . . . . . . . . . . . . . . . . . 56

ADDITIONAL TABLES . . . . . . . . . . . . . . . . . . . . . . . . . . . . . . . . . . 56

APPENDICES . . . . . . . . . . . . . . . . . . . . . . . . . . . . . . . . . . . . . . . . . .

WHAT'S NEW . . . . . . . . . . . . . . . . . . . . . . . . . . . . . . . . . . . . . . . . . . . . . . . . .

HISTORY . . . . . . . . . . . . . . . . . . . . . . . . . . . . . . . . . . . . . . . 68

CONTRIBUTIONS OF AUTHORS . . . . . . . . . . . . . . . . . . . . . . . . . . . . . . . . . . . . . . 68

DECLARATIONS OF INTEREST . . . . . . . . . . . . . . . . . . . . . . . . . . . . . . . . . . . . . 69

SOURCES OF SUPPORT . . . . . . . . . . . . . . . . . . . . . . . . . . . . . . . . . . . . . . . . 69

DIFFERENCES BETWEEN PROTOCOL AND REVIEW . . . . . . . . . . . . . . . . . . . . . . . . . . . . 69

INDEX TERMS . . . . . . . . . . . . . . . . . . . . . . . . . . . . . . . . . . . . . 71

Interventions for post-stroke fatigue (Review)

Copyright () 2015 The Cochrane Collaboration. Published by John Wiley \& Sons, Ltd. 


\title{
[Intervention Review]
}

\section{Interventions for post-stroke fatigue}

\author{
Simiao Wu ${ }^{1,2}$, Mansur A Kutlubaev ${ }^{3}$, Ho-Yan Y Chun ${ }^{1}$, Eileen Cowey ${ }^{4}$, Alex Pollock ${ }^{5}$, Malcolm R Macleod ${ }^{1}$, Martin Dennis ${ }^{1}$, \\ Elizabeth Keane ${ }^{6}$, Michael Sharpe ${ }^{7}$, Gillian E Mead ${ }^{1}$ \\ ${ }^{1}$ Centre for Clinical Brain Sciences, University of Edinburgh, Edinburgh, UK. ${ }^{2}$ Department of Neurology, West China Hospital, \\ Sichuan University, Chengdu, China. ${ }^{3}$ Department of Neurology, Neurosurgery and Medical Genetics, Bashkir State Medical University, \\ Ufa, Russian Federation. ${ }^{4}$ Nursing \& Health Care School, University of Glasgow, Glasgow, UK. ${ }^{5}$ Nursing, Midwifery and Allied \\ Health Professions Research Unit, Glasgow Caledonian University, Glasgow, UK. ${ }^{6}$ Department of Medicine for the Elderly, Western \\ General Hospital, Edinburgh, UK. ${ }^{7}$ Department of Psychiatry, University of Oxford, Oxford, UK \\ Contact address: Gillian E Mead, Centre for Clinical Brain Sciences, University of Edinburgh, Edinburgh, UK. gillian.e.mead@ed.ac.uk. \\ gmead@staffmail.ed.ac.uk.
}

Editorial group: Cochrane Stroke Group.

Publication status and date: New search for studies and content updated (conclusions changed), published in Issue 7, 2015.

Review content assessed as up-to-date: 13 May 2014.

Citation: Wu S, Kutlubaev MA, Chun HYY, Cowey E, Pollock A, Macleod MR, Dennis M, Keane E, Sharpe M, Mead GE. Interventions for post-stroke fatigue. Cochrane Database of Systematic Reviews 2015, Issue 7. Art. No.: CD007030. DOI: 10.1002/14651858.CD007030.pub3.

Copyright (C) 2015 The Cochrane Collaboration. Published by John Wiley \& Sons, Ltd.

\section{A B S T R A C T}

\section{Background}

Post-stroke fatigue (PSF) is a common and distressing problem after stroke. The best ways to prevent or treat PSF are uncertain. Several different interventions can be argued to have a rational basis.

\section{Objectives}

To determine whether, among people with stroke, any intervention reduces the proportion of people with fatigue, fatigue severity, or both; and to determine the effect of intervention on health-related quality of life, disability, dependency and death, and whether such intervention is cost effective.

\section{Search methods}

We searched the Cochrane Stroke Group Trials Register (last searched May 2014), Cochrane Central Register of Controlled Trials (The Cochrane Library, 2014, Issue 4), MEDLINE (1950 to May 2014), EMBASE (1980 to May 2014), CINAHL (1982 to May 2014), AMED (1985 to May 2014), PsycINFO (1967 to May 2014), Digital Dissertations (1861 to May 2014), British Nursing Index (1985 to May 2014), PEDro (searched May 2014) and PsycBITE (searched May 2014). We also searched four ongoing trials registries, scanned reference lists, performed citation tracking of included trials and contacted experts.

\section{Selection criteria}

Two review authors independently scrutinised all titles and abstracts and excluded obviously irrelevant studies. We obtained the full texts for potentially relevant studies and three review authors independently applied the inclusion criteria. We included randomised controlled trials (RCTs) that compared an intervention with a control, or compared different interventions for PSF. 


\section{Data collection and analysis}

Two review authors independently extracted data and assessed risk of bias for each included trial. The primary outcomes were severity of fatigue, or proportion of people with fatigue after treatment. We performed separate analyses for trials investigating efficacy in treating PSF, trials investigating efficacy in preventing PSF and trials not primarily investigating efficacy in PSF but which reported fatigue as an outcome. We pooled results from trials that had a control arm. For trials that compared different potentially active interventions without a control arm, we performed analyses for individual trials without pooling.

We calculated standardised mean difference (SMD) as the effect size for continuous outcomes and risk ratio (RR) for dichotomous outcomes. We pooled the results using a random-effects model and assessed heterogeneity using the $\mathrm{I}^{2}$ statistic. We performed separate subgroup analyses for pharmacological and non-pharmacological interventions. We also performed sensitivity analyses to assess the influence of methodological quality.

\section{Main results}

We retrieved 12,490 citations, obtained full texts for 58 studies and included 12 trials (three from the 2008 search and nine from the 2014 search) with 703 participants. Eight trials primarily investigated the efficacy in treating PSF, of which six trials with seven comparisons provided data suitable for meta-analysis (five pharmacological interventions: fluoxetine, enerion, (-)-OSU6162, citicoline and a combination of Chinese herbs; and two non-pharmacological interventions: a fatigue education programme and a mindfulnessbased stress reduction programme). The fatigue severity was lower in the intervention groups than in the control groups (244 participants, pooled SMD -1.07, 95\% confidence interval (CI) -1.93 to -0.21$)$, with significant heterogeneity between trials $\left(\mathrm{I}^{2}=87 \%\right.$, degrees of freedom $(\mathrm{df})=6$, P value $<0.00001$ ). The beneficial effect was not seen in trials that had used adequate allocation concealment (two trials, 89 participants, SMD $-0.38,95 \%$ CI -0.80 to 0.04 ) or trials that had used adequate blinding of outcome assessors (four trials, 198 participants, SMD -1.10, $95 \%$ CI -2.31 to 0.11 ).

No trial primarily investigated the efficacy in preventing PSF.

Four trials (248 participants) did not primarily investigate the efficacy on fatigue but other symptoms after stroke. None of these interventions showed any benefit on reducing PSF, which included tirilazad mesylate, continuous positive airway pressure for sleep apnoea, antidepressants and a self management programme for recovery from chronic diseases.

\section{Authors' conclusions}

There was insufficient evidence on the efficacy of any intervention to treat or prevent fatigue after stroke. Trials to date have been small and heterogeneous, and some have had a high risk of bias. Some of the interventions described were feasible in people with stroke, but their efficacy should be investigated in RCTs with a more robust study design and adequate sample sizes.

\section{PLAIN LANGUAGE SUMMARY}

\section{Interventions for post-stroke fatigue}

Review question: We reviewed the evidence about the effect of any intervention that had been used to treat or prevent fatigue in people with stroke.

Background: Fatigue is a common and distressing problem after stroke, but no intervention has been recommended to treat or prevent it in people with stroke. Thus, it is important to find out if any intervention could reduce the presence or severity, or both, of fatigue in people with stroke.

Study characteristics: The evidence is current to May 2014. We found 12 randomised controlled trials (clinical studies where people are randomly put into one of two or more treatment groups) with 703 people with stroke. Of these 12 trials, eight trials recruited only people with fatigue and were primarily intended to treat fatigue, no trial was primarily intended to prevent fatigue and the other four trials were not primarily intended to treat or prevent fatigue but reported fatigue as an outcome.

Key results: There was insufficient evidence to support the use of any intervention to treat or prevent fatigue in people with stroke.

Quality of the evidence: The general study quality was low. The available data were limited as each identified intervention was only investigated in a single trial. In addition, some trials were small and used poor study designs. Therefore, further trials of better quality are needed.

Interventions for post-stroke fatigue (Review)

Copyright $\odot 2015$ The Cochrane Collaboration. Published by John Wiley \& Sons, Ltd. 


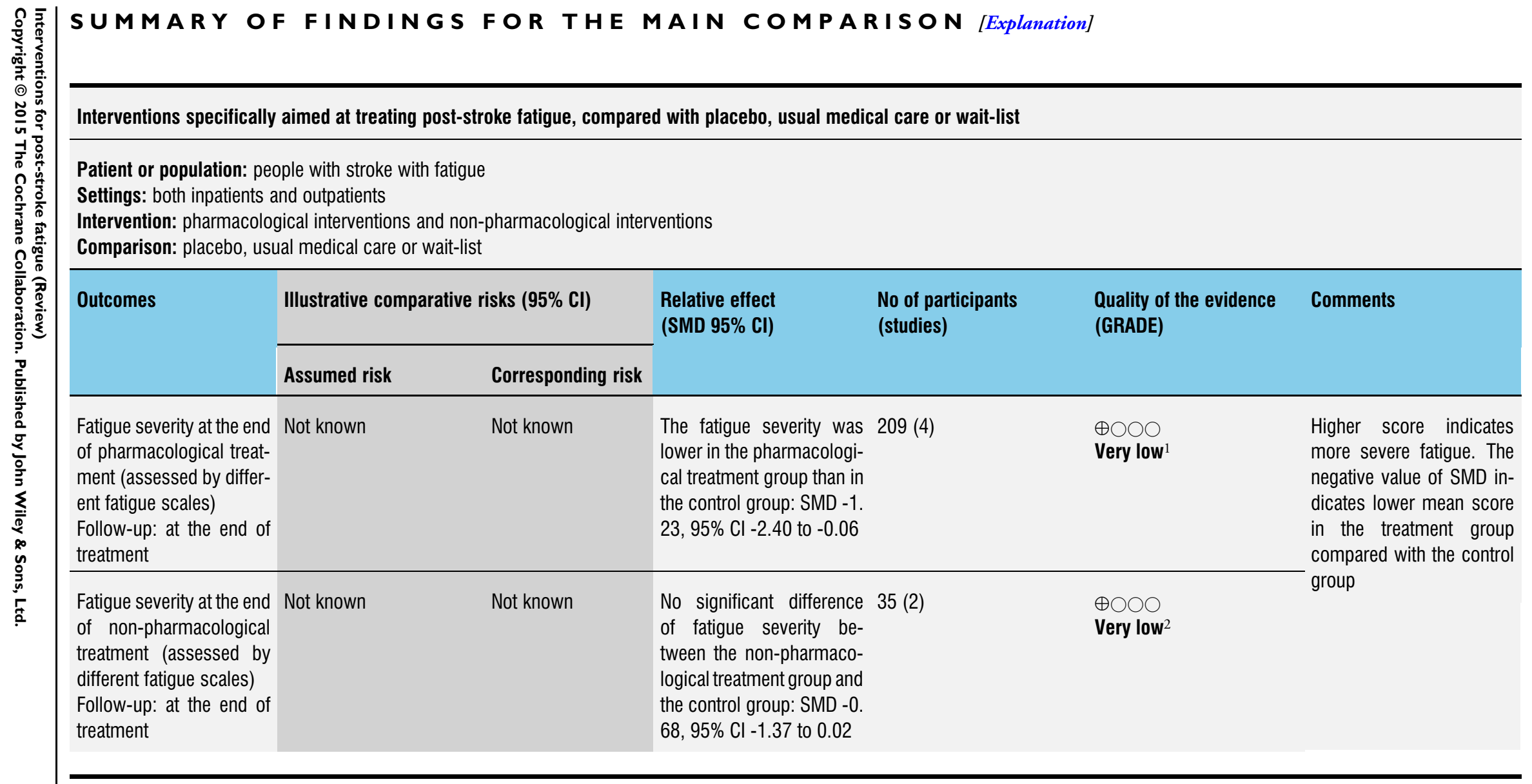

Cl: confidence interval

SMD: standardised mean difference

1. The beneficial effect was not seen in trials using the adequate strategies for allocation concealment or those using adequate-blinding of outcome assessors (risk of bias). In addition, there is substantial heterogeneity between the trials, but the available date were insufficient for us to identify the source of heterogeneity (heterogeneity). Furthermore, this result did not provide information for the efficacy of any specific intervention (indirectness).

2. Only two small trials (each with fewer than 20 participants) were identified, thus it is possible that these trials did not have adequate power to detect clinical difference, rather than these interventions had no effect on fatigue (imprecision). In addition, neither trial used adequate allocation concealment or intention-to-treat analysis (risk of biases). 


\section{B A C K G R O U N D}

\section{Description of the condition}

Fatigue is a common, distressing and long-term problem after stroke. The reported proportion of people with post-stroke fatigue (PSF) ranges from 23\% to $75 \%$ (Choi-Kwon 2011). This variation in proportion between studies reflects the heterogeneity in the recruited participants, time since stroke and assessment methods for fatigue. PSF is common immediately after stroke and it tends to persist in most but not all people. It contributes to a lower quality of life and a higher risk of death (Glader 2002; van de Port 2007). According to a national survey conducted in the UK, the management and prevention of fatigue after stroke was ranked, by people with stroke and health professionals, among the top 10 research priorities relating to life after stroke (Pollock 2012).

The aetiology or mechanism of PSF is unknown. A myriad of biological, psychosocial and behavioural factors might be associated with fatigue (Wu 2015). One systematic review of biological correlates of PSF showed that there was no conclusive evidence on the association between PSF and lesion site (Kutlubaev 2012). One single study found that PSF was associated with reduced excitability of the motor cortex (Kuppuswamy 2015). Some small studies found associations between PSF and inflammatory biomarkers (Syed 2007; Ormstad 2011; Ormstad 2014), and associations between PSF and attention deficits (Passier 2011; Radman 2012). One systematic review of psychological associations of PSF found that PSF was associated with depressive symptoms, and this association existed even in people with stroke who did not meet the clinical criteria of depression (Wu 2014a). In addition, some studies found associations with anxiety, loss of control and passive coping (Wu 2014a). Another interesting hypothesis is that fatigue may be associated with physical deconditioning, which is common after stroke (Saunders 2013). Current evidence for this hypothesis is limited: one study found an association between PSF and lower limb extensor power (Lewis 2011), while another small study found no association between PSF and any fitness indices (Michael 2006). Furthermore, one longitudinal study found that a lower level of physical activity at one month independently predicts a higher level of fatigue at six and 12 months' follow-up (Duncan 2015).

\section{Description of the intervention}

Since PSF may have several causative or maintaining factors (Wu 2015), there are a number of potential interventions, in combination or alone, that may be helpful. Possible interventions include pharmacological interventions (e.g. antidepressants, wakefulness stimulants), psychological interventions (e.g. cognitive behavioural therapy, educational programme) and physical training (e.g. graded physical training, aerobic exercise).

\section{How the intervention might work}

Due to our lack of knowledge of the exact aetiology or mechanism of PSF, it is unclear which approach may be effective in treating or preventing PSF. In clinical practice, physicians may assess for co-existing, treatable conditions such as anaemia, depression, hypothyroidism and infection, but often these conditions are not present in people with PSF. We could hypothesise that drugs, such as antidepressants, which regulate neuroendocrine and neurotransmitter systems, might reduce fatigue; that psychological interventions, which improve mood and behaviours, might reduce fatigue or that exercise, by means of reversing physical deconditioning, might reduce fatigue.

\section{Why it is important to do this review}

Fatigue is a common and distressing problem after stroke but there is uncertainty about how to manage it. Therefore, we performed this systematic review using broad inclusion criteria with an aim to identify any intervention that had been used to treat or prevent PSF.

\section{O B J E C T I V E S}

To determine whether, among people with stroke, any intervention reduces the proportion of people with fatigue, fatigue severity, or both; and to determine the effect of intervention on health-related quality of life, disability, dependency and death, and whether such intervention is cost effective.

\section{METHODS}

\section{Criteria for considering studies for this review}

\section{Types of studies}

We included randomised controlled trials (RCTs) in people with a clinical diagnosis of stroke, where the interventions were used to treat or prevent PSF. This included three groups of trials.

- Trials primarily intended to treat PSF: the aim of the intervention was to treat fatigue (as stated by the trial investigators), which required participants to have fatigue at recruitment.

- Trials primarily intended to prevent PSF: the aim of the intervention was to prevent fatigue (as stated by the trial investigators) in people with stroke who did not have fatigue at recruitment. 
- Trials not primarily intended to treat or prevent PSF but which reported fatigue as an outcome: the aim of the intervention was to improve health status or other symptoms after stroke, and fatigue was pre-specified as an outcome. These trials usually did not specify whether the participants had fatigue at recruitment.

We excluded trials that used fatigue as a measure to assess whether the intervention was tolerable in participants (i.e. whether the intervention had induced intolerable tiredness during treatment) rather than a measure to assess the therapeutic effect.

For trials using a cross-over design, we only included data from the first phase, that is, before crossing over the treatment.

We included trials irrespective of their publication status and publication language.

\section{Types of participants}

We included adults (aged 18 years and over), men and women, with a clinical diagnosis of stroke. We included all pathological subtypes of stroke, including ischaemic stroke, haemorrhagic stroke and subarachnoid haemorrhage (SAH). We included any method of diagnosis or assessment of PSF, but it was not necessary for participants to have fatigue at recruitment.

For trials reporting mixed populations of participants (e.g. a group of people with either stroke or brain injury), we included them only if more than $75 \%$ of the participants had had a stroke, or if separate data for the people with stroke were reported by or obtained from the trial investigators.

\section{Types of interventions}

We included pharmacological interventions and non-pharmacological interventions in combination or alone. We included any trial that attempted to evaluate the following comparisons.

- A comparison between an intervention and a control (where the control was either placebo, usual medical care or wait-list).

- A comparison between two or more different interventions, with or without a control.

- A comparison between different doses or intensity of the same type of intervention, with or without a control.

We anticipated that the types of interventions would include antidepressants, other pharmacological agents, cognitive behavioural therapy, educational programmes, counselling or physical exercise, but we did not limit the review to these types of interventions.

\section{Types of outcome measures}

\section{Primary outcomes}

The primary outcome for this review was fatigue at the end of treatment, measured as either the proportion of people with fatigue or the mean severity of fatigue, or both. Examples of possible assessment measures included, but were not limited to:

- Fatigue Severity Scale (FSS) (Krupp 1989);

- Visual Analogue Scale for fatigue severity (VAS-f);

- self reported fatigue questionnaires;

- energy/fatigue scale from the Medical Outcomes Study (i.e. Short Form-36 vitality subscale).

If a trial had used a number of different tools to assess fatigue, we included the main outcome measure as specified by trial investigators. For instances where trial investigators had not specified the main one, we specified the main outcome measure in order of preference based on the following two criteria.

- A measure of fatigue designed specifically for stroke (e.g. a case definition of PSF) (Lynch 2007); a generic measure for fatigue that has been tested in stroke (e.g. Fatigue Assessment Scale, Profile of Mood States - fatigue subscale, Short Form-36 vitality scale, Multidimensional Fatigue Symptom Inventory, FSS, Functional Assessment of Chronic Illness Fatigue, Neurological Fatigue Index) (Mead 2007; Tyson 2014); a generic measure for fatigue that has not been previously tested in stroke.

- If the scales were in the same category according to the above criterion, we specified the main outcome measure from most commonly used scales (e.g. FSS) to less commonly used scales in the publications identified in this review.

\section{Secondary outcomes}

- Health-related quality of life (e.g. Short Form-36).

- Disability (e.g. Barthel Index score).

- Dependence (e.g. modified Rankin scale; mRS).

- Death.

- Cost effectiveness.

\section{Search methods for identification of studies}

See the 'Specialized register' section in the Cochrane Stroke Group module. We searched for trials in all languages and arranged translation of relevant papers published in languages other than English.

\section{Electronic searches}

We performed updated searches of the following electronic databases and trials registers from the previous searches in 2008 to May 2014.

- Cochrane Stroke Trial Register (searched May 2014).

- Cochrane Central Register of Controlled Trials

(CENTRAL) (The Cochrane Library, 2014 Issue 4) (Appendix 1).

- MEDLINE (1950 to May 2014) (Appendix 2).

- EMBASE (1980 to May 2014) (Appendix 3).

- CINAHL (1982 to May 2014) (Appendix 4).

- AMED (1985 to May 2014) (Appendix 5). 
- PsycINFO (1967 to May 2014) (Appendix 6).

- ProQuest Dissertations and Theses Database (1861 to May

2014) (Appendix 7).

- British Nursing Index (1985 to May 2014) (Appendix 8).

- PEDro (www.pedro.fhs.usyd.edu.au/) (May 2014).

- PsycBITE (www.psycbite.com) (May 2014).

- ISRCTN (www.isrctn.com/) (May 2014).

- Trials Central (www.trialscentral.org/) (May 2014).

- Stroke Trials Registry (www.strokecenter.org/trials/) (May 2014).

- Health Service Research Projects in Progress (

wwwcf.nlm.nih.gov/hsr_project/home_proj.cfm) (May 2014).

We developed the search strategies for the major databases with the help of the Cochrane Stroke Group Trials Search Co-ordinator and adapted the MEDLINE search strategy for the other databases.

\section{Searching other resources}

In order to identify further published, unpublished and ongoing trials, we checked reference lists, used the Web of Science Cited Reference Search for forward tracking of included trials and contacted experts.

\section{Data collection and analysis}

\section{Selection of studies}

For the 2008 review, all titles and abstracts from each search were scrutinised for relevance by one of the four previous review authors (GM, EK, LS, AP) who performed the search and excluded obviously irrelevant studies. Full texts were obtained for potentially relevant studies and a secondary review author scrutinised these full texts and determined whether they fulfilled the inclusion criteria (GM scrutinised studies identified by EK, EK scrutinised studies identified by GM, AP scrutinised studies identified by LS and LS scrutinised studies identified by AP).

For the current review, one review author (SW) scrutinised all titles and abstracts from the electronic search (published since February 2008) for relevance. Four other review authors (HYC, EC, MK, GM) scrutinised all these titles and abstracts independently from SW: HYC screened studies from MEDLINE, EMBASE, PsycINFO, AMED, CINAHL, CENTRAL, ProQuest Dissertations and Theses Database, PEDro and British Nursing Index; EC screened studies from PsycBITE, ISRCTN, Stroke Trials Registry and Health Service Research Projects in Progress; MK screened studies from Trials Central; and GM screened studies from the Cochrane Stroke Trial Register. We excluded obviously irrelevant citations and obtained full references for potentially relevant studies. Three review authors (SW, HYC, MK) each independently read all full texts and determined whether the study fulfilled the inclusion criteria (for studies published in Chinese, SW and HYC independently applied the inclusion criteria; for studies published in Russian, MK applied the inclusion criteria and discussed with SW). We resolved any discrepancies about whether or not a study fulfilled the inclusion criteria through discussion.

\section{Data extraction and management}

Two review authors (SW, HYC) independently extracted data from the included trials and recorded the information on a data extraction form. Another review author (MK) extracted the data for one trial published in Russian. We collected information about the study setting, the methodological design (randomisation; allocation concealment; blinding of participants, researchers and outcome assessors; and intention-to-treat analysis), the numbers of participants at recruitment and at the end of the study, the characteristics of participants (age, sex, time since stroke onset, pathological subtypes and severity of stroke), the treatment and control interventions (type of intervention, dose/intensity, frequency and duration), the primary and secondary outcome measures (methods and time of assessment), the criteria and assessment methods of fatigue at baseline and follow-up, and the results of each assessment. We contacted trial investigators to request additional information that we thought relevant but which had not been reported in the publication.

\section{Assessment of risk of bias in included studies}

Two review authors (SW, HYC) independently documented the methodological quality of the included trials for the following quality criteria: allocation concealment, blinding of outcome assessors and intention-to-treat analysis. This was done by one review author (MK) for the trial published in Russian. We used the Cochrane criteria and 'Risk of bias' tool to assess the methodological quality (Higgins 2011).

For allocation concealment, we distinguished between trials that were adequately concealed (e.g. central randomisation at a site remote from the study, computerised allocation in which records are in a locked readable file that can be assessed only after entering participant details, or the drawing of opaque envelopes), inadequately concealed (e.g. open list or table of random numbers, open computer systems or drawing of non-opaque envelopes), and where concealment was unclear (e.g. no information in the report and trial investigators did not respond to our request or were unable to provide it).

For blinding of outcome assessors, we distinguished between trials in which the main outcome was measured by an assessor who was blind to treatment allocation, and trials in which it was measured by a non-blinded assessor. For trials where the main outcome was measured by the participants themselves, we distinguished whether or not the participants were aware of their allocation.

We defined 'intention-to-treat' as present if two criteria were fulfilled: 
- all participants were analysed in the groups to which they were randomised regardless of which (or how much) treatment they actually received, and regardless of other protocol irregularities, such as ineligibility; and

- all participants were included regardless of whether their outcomes were actually collected.

For trials that did not fulfil these two criteria, we determined whether an 'available-case analysis' or a 'treatment-received analysis' had been performed. If, in a trial, outcome data of some participants were not available (e.g. due to drop-out or death) and the investigators only reported available data, we defined it as 'available-case analysis'. If, in a trial, some participants randomised to one group ended up in another group and the investigators reported outcome data based on the grouping at the end of study, we defined it as 'treatment-received analysis'.

\section{Measures of treatment effect}

We calculated standardised mean differences (SMDs) and relevant 95\% confidence intervals (CIs) for continuous outcomes (i.e. fatigue scores after treatment) and risk ratios (RRs) and relevant 95\% CI for dichotomous outcomes (i.e. presence or absence of fatigue). If there were fatigue scales where the score decreases as fatigue increases, we multiplied outcomes of these scales by -1 . For trials reporting both dichotomous and continuous outcomes of fatigue, we collected data for both types of measures.

\section{Assessment of heterogeneity}

We assessed heterogeneity between trials and between pre-specified subgroups. We determined statistical significance of heterogeneity based on the statistic with $\mathrm{Chi}^{2}$ distribution with $\mathrm{k}$ - 1 degrees of freedom (df; where $\mathrm{k}$ was the number of trials or number of subgroups). We quantified heterogeneity using the $\mathrm{I}^{2}$ statistic, which describes the proportion of total variance across trials that is attributed to heterogeneity.

\section{Assessment of reporting biases}

We had intended to explore publication bias using a funnel plot. However, this was not done because, according to the Cochrane Handbook for Systematic Reviews of Interventions (Higgins 2011), "tests for funnel plot asymmetry should be used only when there are at least 10 studies included in the meta-analysis". In our review, there were only six trials in the meta-analysis.

\section{Data synthesis}

We performed separate analyses for trials primarily intended to treat PSF, for trials primarily intended to prevent PSF, and for trials not primarily targeting PSF, because the key characteristic of their participants (i.e. whether they had fatigue at recruitment) was different.

\section{Trials primarily intended to treat post-stroke fatigue}

We performed separate analyses for trials that compared the intervention(s) with a control (where placebo, usual medical care or wait-list was used as control) and for trials that compared different interventions without a control.

\section{Trials with a control arm}

We performed separate analyses for continuous outcomes and for dichotomous outcomes of fatigue. For either type of outcome, where data were suitable, we performed meta-analyses using a random-effects model in Review Manager 5 (RevMan 2014).

- If a trial compared interventions of different doses versus control (e.g. high-intensity exercise versus low-intensity exercise versus control), we combined the results of the various active treatment arms using a random-effects model, or where that was not possible, we divided the numbers of participants in the control group into several parts, one to go with each active arm, so that participants were not double counted.

- If a trial compared two or more different interventions versus control, we divided the numbers of participants in the control group into several parts, one to go with each active arm.

- If a trial assessed outcomes at multiple time points (e.g. immediately after treatment and at six-month follow-up), we performed separate analyses for outcomes assessed at each time point.

\section{Trials without a control arm}

For trials without a control arm, we had intended to perform the same analyses as we did for trials with a control arm. However, we did not perform a meta-analysis because no two trials compared a same pair of interventions; instead, we calculated individual mean difference (MD) or RR for each trial, which would indicate the comparative efficacy of one intervention over the other. Here we used MD rather than SMD for continuous outcomes because SMD was used for the pooling of results from trials using different scales for the same outcome, but for individual trials MD was preferable because it was more interpretable.

\section{Trials primarily intended to prevent post-stroke fatigue}

We had intended to perform the same analyses for this group of trials as we did for the trials primarily intended to treat PSF, but we identified no trials for inclusion in this group.

\section{Trials not primarily intended to treat or prevent post-stroke} fatigue

We had intended to perform the same analyses for this group of trials as we did for the trials primarily intended to treat PSF. However, the data were too diverse across trials to be pooled, as they were 
different in all four aspects of PICO (studied populations, treatment and control interventions and outcome measures). Therefore, we calculated the MD or RR for each trial and reported them individually.

\section{Subgroup analysis and investigation of heterogeneity}

We had intended to explore clinical heterogeneity by subgroup analyses for the primary outcome, that is, severity or proportion of fatigue (Deeks 2001). These were:

- type of interventions;

- source of participants (i.e. inpatients versus community patients);

- time of recruitment since stroke onset;

- amount of treatment (i.e. dose/intensity and duration).

We had intended to perform the subgroup analysis for different types of interventions. However, trials in the meta-analysis each had used a different intervention. Thus, we broadly categorised these interventions into 'pharmacological interventions' and 'nonpharmacological interventions' and performed a subgroup analysis to investigate whether one group of interventions was superior to the other.

We did not perform other subgroup analyses (i.e. for source of participants, time since stroke and amount of treatment). This is because these subgroups were pre-specified to investigate the contribution of these clinical characteristics to heterogeneity under the same type of intervention (e.g. antidepressant, cognitive behavioural therapy or physical exercise), but trials included in the meta-analysis had each used a different intervention, thus, we could not perform further subgroup analyses under the individual type of interventions.

\section{Sensitivity analysis}

We explored methodological heterogeneity by sensitivity analyses.

- Allocation concealment: with analysis limited to trials with adequate allocation concealment.

- Blinding of outcome assessors: with analysis limited to trials with blinding of outcome assessors.

- Intention-to-treat analysis: with analysis limited to trials with intention-to-treat analyses.

- We performed one post-hoc sensitivity analysis by excluding one trial in which the baseline fatigue scores were not comparable between groups.

- We performed one post-hoc sensitivity analysis by excluding one comparison that was a visual outlier in the forest plot.

For each sensitivity analysis, we compared the pooled effect size with the summary effect size of all included trials, using a Z-test (Borenstein 2009).

\section{R E S U L T S}

\section{Description of studies}

See: Characteristics of included studies; Characteristics of excluded studies; Characteristics of ongoing studies.

\section{Results of the search}

Figure 1 summarises the process for electronic searches and study selection. 
Figure I. Diagram of electronic search and study selection.

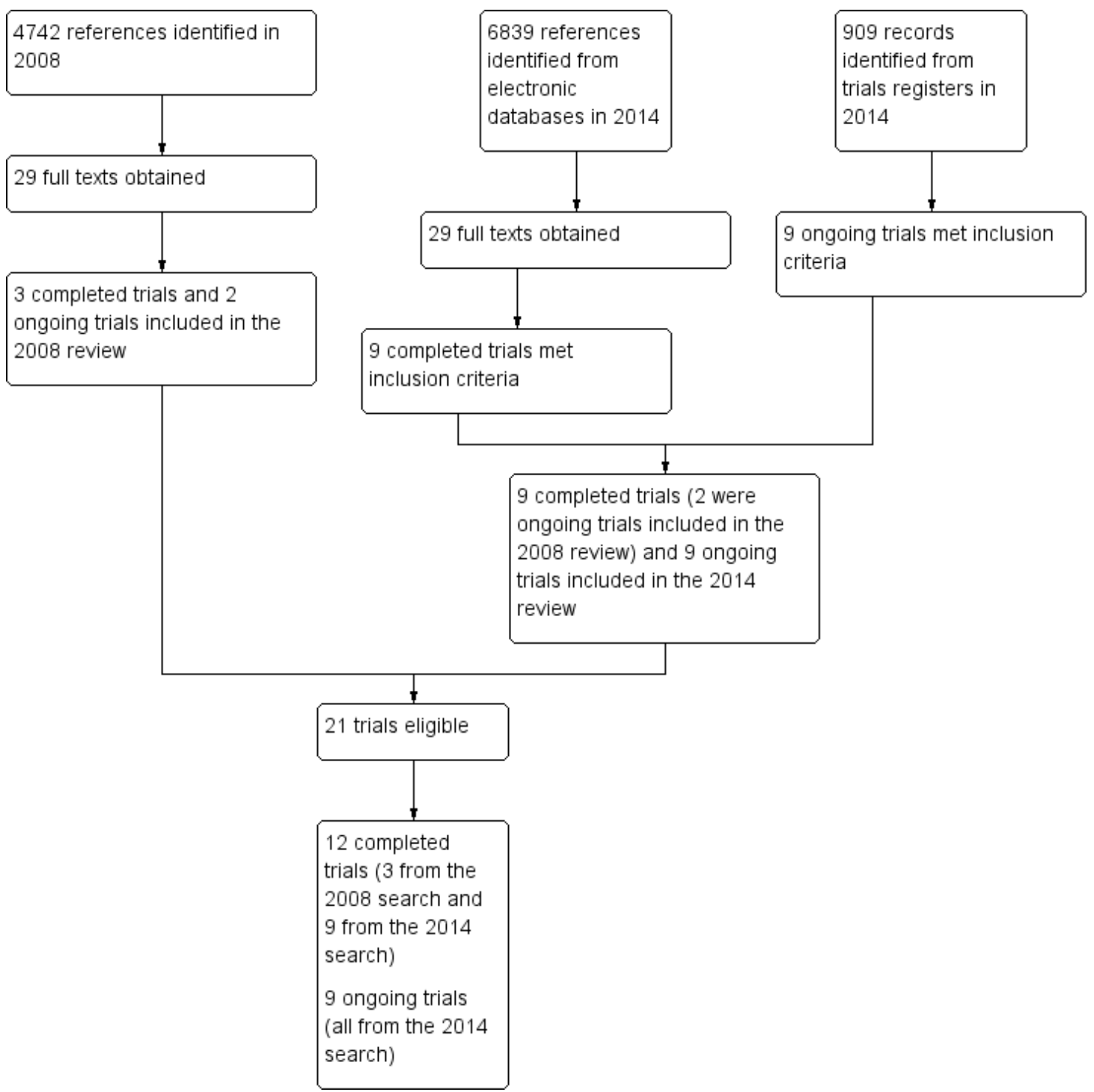

For the 2008 review, we identified 4742 citations and obtained full texts for 29 potentially eligible studies, of which three trials were eligible (Choi-Kwon 2007; Lorig 2001; Ogden 1998). We also identified two ongoing trials, both of which were published by the time of the current review (Brown 2013; Zedlitz 2012). We identified these two trials in the 2014 search and included them in the current review.

For the current review, we searched trials published after 2008 and identified 6839 unique citations from electronic databases and 909 records from ongoing trials registers. We obtained full texts for 29 published studies and relevant information for nine ongoing trials in the 2008 review) and nine new ongoing trials that met the inclusion criteria. Together with the three trials identified in the 2008 review, we included 12 published trials (Brown 2013; Choi-Kwon 2007; Clarke 2012; Guo 2012; Gurak 2005; Johansson 2012a; Johansson 2012b; Karaiskos 2012; Lorig 2001; Ogden 1998; Zedlitz 2012; Zhou 2010), and nine ongoing trials (AFFINITY 2013; Chuang 2013; EFFECTS 2014; FOCUS 2012; Liu 2012; MacKay-Lyons 2012; Michael 2008; Overgaard 2012; Vanroy 2010). ongoing trials. We included nine new trials (of which two were 


\section{Included studies}

\section{Completed trials}

Among the 12 included trials (703 participants), eight trials (455 participants) were primarily intended to treat PSF (i.e. where the presence of fatigue was an inclusion criterion for recruitment) (Choi-Kwon 2007; Clarke 2012; Guo 2012; Gurak 2005; Johansson 2012a; Johansson 2012b; Zedlitz 2012; Zhou 2010), no trial was primarily intended to prevent fatigue after stroke and the other four trials (248 participants) did not primarily target PSF but reported fatigue as an outcome (Brown 2013; Karaiskos 2012; Ogden 1998; Lorig 2001).

Trials primarily intended to treat post-stroke fatigue

\section{Participant characteristics}

- Sex and age: All eight trials (455 participants) recruited adults of both sexes with the male proportion ranging from 33\% (Gurak 2005) to 80\% (Choi-Kwon 2007) and the mean age ranging from 50 years (Johansson 2012a) to 72 years (Clarke 2012), except for one trial, which recruited mixed populations of people with stroke (16 participants) or traumatic brain injury (10 participants) but did not report these demographics for the subgroup of people with stroke separately (Johansson 2012b).

- Subtype of stroke: Five trials recruited people with ischaemic stroke and haemorrhagic stroke (Choi-Kwon 2007; Clarke 2012; Johansson 2012a; Johansson 2012b; Zedlitz 2012), and three trials recruited only people with ischaemic stroke (Guo 2012; Gurak 2005; Zhou 2010).

- Source of participants: Six trials recruited communitydwelling people with stroke (Choi-Kwon 2007; Clarke 2012; Gurak 2005; Johansson 2012a; Johansson 2012b; Zedlitz 2012), one trial recruited inpatients (Guo 2012), and one trial recruited both inpatients and outpatients (Zhou 2010).

- Recruitment time window: Three trials recruited people who were at least three months after stroke onset (Choi-Kwon 2007; Clarke 2012; Gurak 2005), one trial more than four months after stroke (Zedlitz 2012), two trials more than one year after stroke (Johansson 2012a; Johansson 2012b), one trial within six months of stroke (Guo 2012), and one trial with people at a mean of six months and no more than three years after stroke (Zhou 2010).

- Measures for baseline fatigue: Different diagnostic criteria of fatigue were used at recruitment, which included the self reported experience of fatigue by participants (Choi-Kwon 2007), a mean score of the FSS of 4 or more (Clarke 2012), the Traditional Chinese Medicine (TCM) diagnostic criteria for Qideficiency (i.e. fatigue in Chinese culture) (Guo 2012), a score of the Multidimensional Fatigue Inventory-20 (MFI-20, cut-off score not reported) (Gurak 2005), a total score of the Mental Fatigue Scale (MFS) of 10 or more (Johansson 2012a; Johansson 2012b), a total score of the Checklist Individual Strength-fatigue subscale (CIS-f) of 40 or more (Zedlitz 2012), and a total score of the energy subscale of the Stroke Specific Quality of Life (SSQOL-energy) of 12 or less (Zhou 2010).

\section{Treatment and control interventions}

Four trials investigated pharmacological interventions and the other four trials investigated non-pharmacological interventions. Table 1 summarises details of treatment and control interventions for each individual trials.

\section{Outcome measures}

Table 1 summarises outcome measures and time of assessment for each individual trial.

- Methods of outcome assessment: All eight trials reported fatigue scores in each group after treatment (continuous outcome of fatigue): three trials used the FSS (Choi-Kwon 2007; Clarke 2012; Guo 2012), two trials used the MFS (Johansson 2012a; Johansson 2012b), one trial used the MFI-20 (Gurak 2005), one trial used the CIS-f (Zedlitz 2012), and one trial used the SSQOL-energy (Zhou 2010). All these scales, except for the SSQOL-energy, increase as fatigue severity increases. Two trials reported the numbers/proportions of people with stroke with PSF after treatment (dichotomous outcome of fatigue): one trial used the self report of subjective experience of fatigue by participants (Choi-Kwon 2007), and the other trial used a cutoff score of 12 on the SSQOL-energy as the criterion for the presence of fatigue (Zhou 2010).

- Time of outcome assessment: All eight trials assessed fatigue outcomes immediately after the end of treatment. In addition, four trials assessed the presence or severity of fatigue at a later follow-up point: one trial at two months after the end of treatment (Zhou 2010), two trials at three months after the end of treatment (Choi-Kwon 2007; Clarke 2012), and the other study at six months after the end of treatment (Zedlitz 2012).

\section{Trials primarily intended to prevent post-stroke fatigue}

We identified no trials primarily intended to prevent PSF.

\section{Trials not primarily intended to treat or prevent post-stroke} fatigue

Four trials (248 participants) did not primarily target PSF but primarily intended to investigate the efficacy of interventions on 
the recovery of other symptoms after stroke. These trials reported fatigue as a secondary outcome.

\section{Intervention compared with control}

Three trials compared intervention with control.

- Brown 2013 assessed the feasibility of continuous positive airway pressure (CPAP) therapy for sleep apnoea in people with ischaemic stroke. Thirty-two people with stroke who had a positive result on the test for sleep apnoea were randomised to either the active CPAP group or the sham CPAP group. Participants were given a device of active or sham CPAP for home use. Nineteen participants completed the three-month treatment. The primary outcome was the self reported usage of CPAP by participants. Fatigue was measured using the FSS as a secondary outcome by the end of the three-month treatment. We calculated the MD for post-treatment fatigue scores between the active CPAP group and the sham CPAP group.

- Lorig 2001 evaluated a Chronic Disease Self-Management Programme (CDSMP) on health status, healthcare utilisation and self efficacy outcomes in people with stroke, heart disease, lung disease or arthritis. In total, 1140 community-dwelling people were recruited, of which 125 had stroke. Of these 125 people with stroke, 67 were allocated to the CDSMP group and 58 to the wait-list control group. Participants in the CDSMP group were immediately offered a manual of programme content and received seven consecutive weekly sessions (peer-taught sessions, 2.5 hours for each session). Participants in the wait-list group were offered the manual and CDSMP six months after randomisation. Primary outcomes were health behaviours, health status and health service utilisation. Fatigue was measured using the energy/fatigue scale from the long-form Medical Outcomes Study as a secondary outcome. Outcomes were collected at baseline, six months, one year and two years after randomisation. The trial investigators did not report results separately for the different diseases, but they provided unpublished data for the subgroup of 125 people with stroke at the six-month follow-up. However, the investigators did not provide data of posttreatment scores but only the changes of scores from baseline to after treatment. We calculated the MD for the changes of scores between the CDSMP group and the wait-list group.

- Ogden 1998 assessed the efficacy of tirilazad mesylate (a hypothesised neuroprotective agent) on recovery from SAH. Thirty-one women were randomised to receive either tirilazad mesylate $(150 \mathrm{mg} / 100 \mathrm{~mL})$ or placebo $(100 \mathrm{~mL})$ for 10 consecutive days after SAH. Eighteen women were interviewed three months later and were asked whether they had experienced fatigue that was much worse than before their SAH. If they answered 'yes' then the interviewer explored this with further questioning and participants were asked to provide specific examples. Participants' responses to questioning were analysed as a 'yes or no' to debilitating fatigue based on the subjective opinion of the interviewer. We calculated the RR for the risk of participants having fatigue after treatment between the tirilazad group and the placebo group.

\section{Different interventions compared without a control}

One trial compared different interventions without a control.

- Karaiskos 2012 investigated the efficacy of three antidepressants for treating depression in people with ischaemic or haemorrhagic stroke. Sixty people with a clinical diagnosis of depression after stroke were randomised to one of three groups for antidepressive treatment: duloxetine (60 to $120 \mathrm{mg} /$ day, for three months), citalopram (20 to $40 \mathrm{mg} /$ day, for three months) or sertraline (50 to $200 \mathrm{mg} / \mathrm{day}$, for three months). The primary aim of this trial was to investigate the effects of these antidepressants on depression and anxiety. Fatigue was measured using the FSS as a secondary outcome at one month, two months and three months after the start of treatment. We calculated the MDs for FSS at the end of three-month treatment between the duloxetine group and the citalopram group, between the duloxetine group and the sertraline group, and between the citalopram group and the sertraline group.

\section{Ongoing trials}

The two ongoing trials identified in the previous review, Brown 2013 and Zedlitz 2012, were completed and published by the time of our search in 2014 and are discussed in the Included studies section in this review. We identified a further nine ongoing trials in the 2014 search.

Three trials were primarily intended to treat PSF.

- Chuang 2013 (estimated enrolment: 160 participants) investigates the efficacy of a combined therapy of functional electrical stimulation and graded treadmill training (one hour daily, three days per week for four weeks) versus conventional rehabilitation on fatigue and shoulder pain after stroke. The inclusion criteria require participants to be at least six months after stroke and have hemiplegic shoulder pain and PSF within the past seven days before assessment. The primary outcome is a vertical numerical rating scale with face rating scale for fatigue and pain at the end of treatment.

- Liu 2012 (90 participants) investigates the efficacy of Astragalus membranaceus (a Chinese herb, $2.8 \mathrm{~g}$ three times per day, treatment duration unknown) versus placebo ( $2.8 \mathrm{~g}$ three times per day, treatment duration unknown) on PSF. The inclusion criteria require participants to be at least three months after stroke and have fatigue based on a screening scale (methods unknown). The primary outcome is the Brief Fatigue Inventory at two years after treatment.

- Overgaard 2012 (128 participants) investigates the efficacy of modafinil (a wakefulness promoting agent, $400 \mathrm{mg}$ once daily for three months) versus placebo (400 mg once daily for three 
months) on PSF. The inclusion criteria require participants to be within 14 days of stroke onset and have fatigue according to the MFI-20. The primary outcome is the total score of MFI-20 at the end of the three-month treatment period.

Three trials are investigating the efficacy of physical training on functional outcomes of stroke, where fatigue is measured as a secondary outcome.

- MacKay-Lyons 2012 (20 participants) investigates the efficacy of aerobic exercise or cognitive training, or both, on cognition after stroke. People who are at least six months after stroke are randomised to one of the four arms for a six-week treatment: aerobic training group, cognitive training group, aerobic plus cognitive training group and control group. Fatigue is assessed using the FSS at 10-week follow-up.

- Michael 2008 (54 participants) investigates the efficacy of adaptive physical activity (APA) on physical fitness and quality of life of people with stroke. People who are at least six months after an ischaemic stroke or who are one year after a haemorrhagic stroke and with residual hemiparetic gait deficits are randomised to one of the three arms for a six-month treatment: APA group, APA plus progressive treadmill walking group and home exercise group. Fatigue is assessed by psychosocial questionnaires as a secondary outcome at baseline, three months, six months and nine months after the beginning of the treatment.

- Vanroy 2010 (50 participants) investigates the efficacy of aerobic exercise on aerobic capacity and daily functioning in people with stroke. People who are within six weeks after stroke onset are randomised to either an aerobic exercise group or a passive mobilisation group for a 12-week treatment. Fatigue is assessed at baseline, after 12 weeks' treatment, six months, one year and two years after baseline (assessment methods unknown). This trial has been completed but is not yet published.

Three parallel trials investigate the efficacy of fluoxetine on recovery of stroke and assess fatigue as a secondary outcome.

- FOCUS 2012 (3000 participants).

- AFFINITY 2013 (1600 participants).

- EFFECTS 2014 (1500 participants).
These three trials share the same core protocol, which recruits people who are between two and 15 days after stroke onset and randomise them to either the fluoxetine group (20 mg daily orally for six months) or the placebo group (20 mg daily orally for six months). The primary outcome is the mRS at six months after recruitment. Fatigue is a secondary outcome assessed by the vitality subscale of Short Form-36 at six months and 12 months after recruitment.

\section{Excluded studies}

In the 2008 review, we excluded two trials because one had no fatigue-related outcomes (Allison 2007), and in one fatigue was not a measure for therapeutic effect (Underwood 2006). We identified a further nine trials from the 2014 search but we excluded them after full-text screening: in two trials, fatigue was measured to assess whether participants were too tired after using the intervention rather than to test the therapeutic effect on fatigue (Cruz 2013; Lin 2013); three ongoing trials were specifically targeting PSF but were excluded because they had only a single treatment group without a control arm (Feys 2013; Kirkevold 2012; Wu 2014b); two trials did not use randomisation (Kim 2012; Sianni 2008); one trial compared people with multiple sclerosis with people with stroke but did not have a control group for people with stroke (Brioschi 2009); and one trial recruited mixed populations of participants but did not report data for the subgroup of people with stroke and we could not obtain these data from trial investigators (Robinson 2003).

\section{Risk of bias in included studies}

Figure 2 and Figure 3 summarise the risk of bias in all included trials, irrespective of whether they were primarily intended to treat or prevent PSF. Reasons or support information for the judgement are provided in a 'Risk of bias' table for each trial in Characteristics of included studies. In this section, we separately summarise the risk of bias of the eight trials primarily intended to treat PSF and that of the four trials not primarily intended for PSF.

Figure 2. Risk of bias graph: review authors' judgements about each risk of bias item presented as percentages across all included studies.

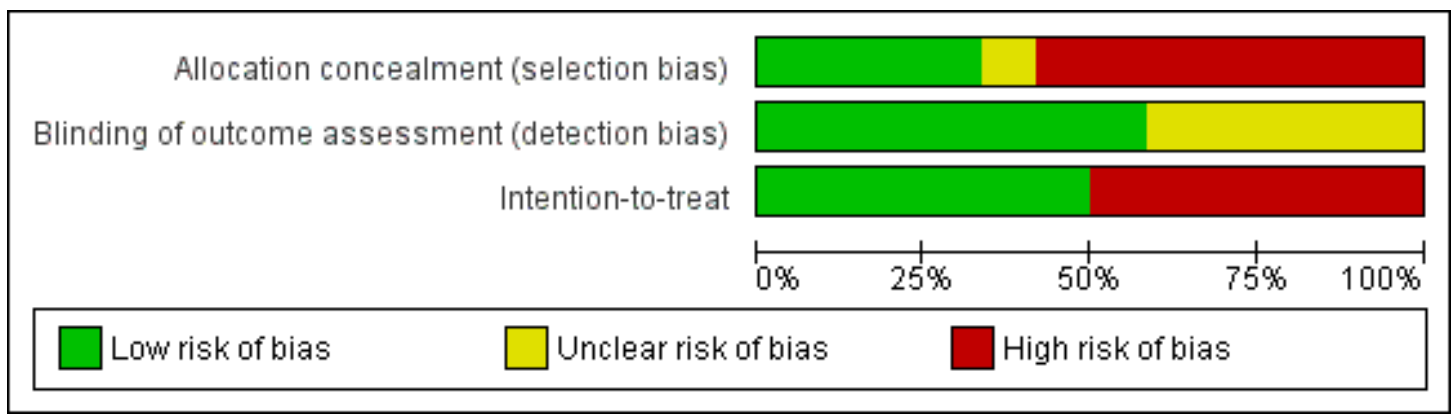

Interventions for post-stroke fatigue (Review) 
Figure 3. Risk of bias summary: review authors' judgements about each risk of bias item for each included study.

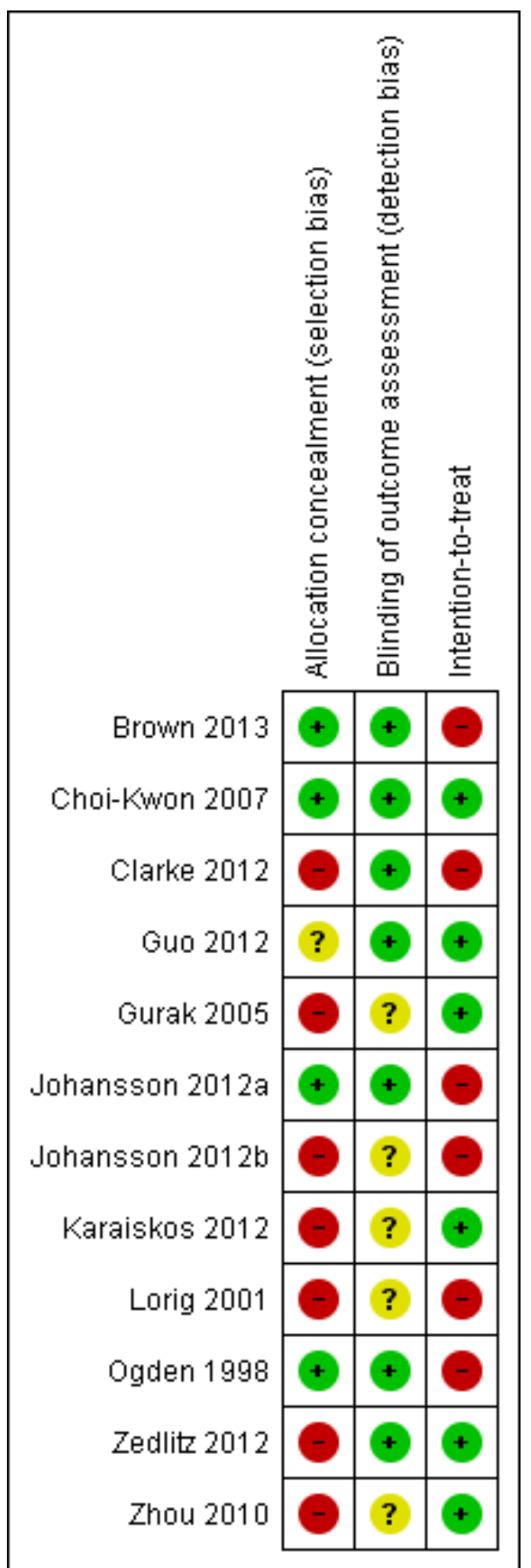




\section{Allocation concealment (selection bias)}

Of the eight trials primarily intended to treat PSF, two trials had a low risk of bias (Choi-Kwon 2007; Johansson 2012a), one trial reported the use of 'placebo' but did not report details of allocation concealment thus its risk of bias was unclear (Guo 2012), and the other five trials had a high risk of bias because they did not use adequate allocation concealment (Clarke 2012; Gurak 2005; Johansson 2012b; Zedlitz 2012; Zhou 2010).

Of the four trials not primarily intended for PSF, two trials had a low risk of bias (Brown 2013; Ogden 1998), and the other two trials had a high risk of bias (Karaiskos 2012; Lorig 2001).

\section{Blinding of outcome assessors (detection bias)}

Of the eight trials primarily intended to treat PSF, five trials used adequate strategies for outcome assessor blinding and thus had a low risk of bias (Choi-Kwon 2007; Clarke 2012; Guo 2012; Johansson 2012a; Zedlitz 2012), and the other three trials did not report sufficient information to permit this judgement thus the risk was unclear (Gurak 2005; Johansson 2012b; Zhou 2010).

Of the four trials not primarily intended for PSF, two trials had a low risk of bias (Brown 2013; Ogden 1998), and the risk in other two trials was unclear (Karaiskos 2012; Lorig 2001).

\section{Intention-to-treat analysis (attrition bias)}

Of the eight trials primarily intended to treat PSF, two trials performed intention-to-treat analysis (low risk) (Choi-Kwon 2007; Zedlitz 2012), three trials had the same numbers of participants at the end of trial as at randomisation (low risk) (Guo 2012; Gurak 2005; Zhou 2010), and the other three trials had drop-outs and used the available-case analysis (high risk) (Clarke 2012; Johansson 2012a; Johansson 2012b).

Of the four trials not primarily intended for PSF, one study had the same number of participants at the end of trial as that at randomisation (low risk) (Karaiskos 2012), and the other three trials had drop-outs and used the available-case analysis (high risk) (Brown 2013; Lorig 2001; Ogden 1998).

\section{Effects of interventions}

See: Summary of findings for the main comparison Interventions specifically targeting the treatment of post-stroke fatigue; Summary of findings 2 Interventions not specifically targeting post-stroke fatigue

\section{Trials primarily intended to treat post-stroke fatigue}

Eight trials (455 participants) were primarily intended to treat PSF, of which six trials compared the intervention(s) with control (where the control was placebo, usual medical care or waitlist) (Choi-Kwon 2007; Clarke 2012; Guo 2012; Gurak 2005; Johansson 2012a; Johansson 2012b), and the other two trials compared different potentially active interventions without a control arm (Zedlitz 2012; Zhou 2010) (Table 1).

\section{Trials with a control arm (intervention versus control)}

Of the six trials (244 participants) that had a control arm (ChoiKwon 2007; Clarke 2012; Guo 2012; Gurak 2005; Johansson 2012a; Johansson 2012b), one trial compared two potentially active interventions with a control (Guo 2012). For this trial, we divided the number of participants in the control group to two equal-size groups so that there were two comparisons each with a treatment group and a control group. Thus, there were seven comparisons with 244 participants.

\section{Continuous outcomes}

\section{Summary meta-analysis}

All of these six trials (seven comparisons with 244 participants) reported continuous measures of fatigue after treatment. Fatigue severity was lower in the intervention group compared with the control group (pooled SMD -1.07, 95\% CI -1.93 to -0.21), with significant heterogeneity between trials $\left(\mathrm{I}^{2}=87 \%, \mathrm{df}=6, \mathrm{P}\right.$ value $<0.00001$ for heterogeneity) (Analysis 1.1)

\section{Subgroup analysis}

We had intended to perform the subgroup analysis for different types of interventions (e.g. antidepressants, psychological therapy and physical training), but this was not achieved because each of the seven comparisons used a different treatment intervention. Thus, we could only broadly categorise these interventions to two groups: 'pharmacological interventions' and 'non-pharmacological interventions'. Although there was no significant heterogeneity between these two subgroups $\left(\mathrm{I}^{2}=0 \%, \mathrm{df}=1, \mathrm{P}\right.$ value $=0.42$, indicating no statistically significant difference of effect sizes between two subgroups), only pharmacological interventions showed a marginally significant effect on reducing PSF (five comparisons, 209 participants, pooled SMD $-1.23,95 \%$ CI -2.40 to 
-0.06; with significant heterogeneity: $\mathrm{I}^{2}=91 \%$, df $=4$, P value $<0.00001$ ) while non-pharmacological interventions showed no statistically significant effect (two comparisons, 35 participants, pooled SMD $-0.68,95 \%$ CI -1.37 to 0.02 ; with no significant heterogeneity: $\mathrm{I}^{2}=0 \%, \mathrm{df}=1, \mathrm{P}$ value $\left.=0.42\right)($ Analysis 1.1$)$.

\section{Sensitivity analysis}

- Trials using adequate allocation concealment

- Two trials (two comparisons, 89 participants) reported adequate strategies for allocation concealment (Choi-Kwon 2007; Johansson 2012a), of which interventions showed no significant effect on PSF (pooled SMD - $0.38,95 \%$ CI -0.80 to 0.04 ; with no significant heterogeneity: $\mathrm{I}^{2}=0 \%$, $\mathrm{df}=1$, $\mathrm{P}$ value $=0.90$ ) (Analysis 1.2).

- Trials using adequate blinding of outcome assessors - Four trials (five comparisons, 198 participants) reported adequate strategies for blinding of outcome assessors (Choi-Kwon 2007; Clarke 2012; Guo 2012; Johansson 2012a), of which interventions showed no significant effect on PSF (pooled SMD -1.10, 95\% CI -2.31 to 0.11; with significant heterogeneity: $\mathrm{I}^{2}=91 \%, \mathrm{df}=4, \mathrm{P}$ value $<0.00001$ ) (Analysis 1.2).

- Trials using intention-to-treat analysis

○ Three trials (four comparisons, 203 participants) used intention-to-treat analysis or had no participant lost to follow-up (Choi-Kwon 2007; Guo 2012; Gurak 2005), of which the intervention showed a beneficial effect over the control (pooled SMD - 1.41, 95\% CI -2.73 to -0.09; with significant heterogeneity: $\mathrm{I}^{2}=93 \%, \mathrm{df}=3$, P value < 0.00001) (Analysis 1.2). This pooled SMD was not significantly different $(\mathrm{P}$ value $=$
0.67 ) from the summary SMD of all seven comparisons (pooled SMD - $1.07,95 \%$ CI -1.93 to -0.21 ).

- Trials with no significant difference in baseline fatigue scores between groups

- Fatigue scores at baseline in one trial were significantly higher in the control group than the treatment group (Choi-Kwon 2007), so we performed a post-hoc sensitivity analysis by excluding this trial. The pooled SMD of the remaining five trials (six comparisons, 161 participants) was 1.22 (95\% CI -2.34 to -0.09; with significant heterogeneity: $\mathrm{I}^{2}=$ $88 \%$, df $=5$, P value $<0.00001$ ) (Analysis 1.2), which was not significantly different $(\mathrm{P}$ value $=0.84)$ from the summary SMD of all seven comparisons (pooled SMD -1.07, 95\% CI -1.93 to $0.21)$.

- Excluding the visual outlier in the forest plot

- One comparison in Guo 2012, a combination of oral and intravenous Chinese herbs versus placebo Chinese herbs (SMD -4.35, 95\% CI -5.48 to -3.22), appeared as an outlier in the forest plot (Analysis 1.1). After excluding this comparison (45 participants), the pooled SMD of the remaining six comparisons (199 participants) was -0.49 (95\% CI -0.78 to 0.20 ; with no significant heterogeneity: $\mathrm{I}^{2}=0 \%, \mathrm{df}=5, \mathrm{P}$ value $=0.52$ ) (Analysis 1.2), which was not significantly different $(\mathrm{P}$ value $=0.21$ ) from the summary SMD of all seven comparisons (pooled SMD -1.07, 95\% CI -1.93 to -0.21).

\section{Analysis of individual trials}

For the seven comparisons in the meta-analysis, Figure 4 presents the treatment interventions of each individual trial and a visual comparison of their effect sizes.

Figure 4. Effects of interventions on fatigue severity at the end of treatment and at three-month follow-up.

$\begin{array}{lll}\text { Trials } & \text { Participants } & \text { Treatment interventions } \\ \text { Outcomes at the end of treatment } & \\ \text { Guo 2012a } & n=45 & \text { Citicoline } \\ \text { Johansson 2012a } & n=6 & (-) \text {-OSU6162 } \\ \text { Choi-Kwon 2007 } & n=83 & \text { Fluoxetine } \\ \text { Clarke 2012 } & n=19 & \text { Fatigue Group Education Therapy } \\ \text { Johansson 2012b } & n=16 & \text { Mindfulness-based Stress Reduction } \\ \text { Gurak 2005 } & n=30 & \text { Enerion } \\ \text { Guo 2012b } & n=45 & \text { A combination of Chinese herbs } \\ \text { Outcomes at three } & \text { months after the end of treatment } \\ \text { Clarke 2012 } & n=19 & \text { Fatigue Group Education Therapy } \\ \text { Choi-Kwon 2007 } & n=83 & \text { Fluoxetine }\end{array}$

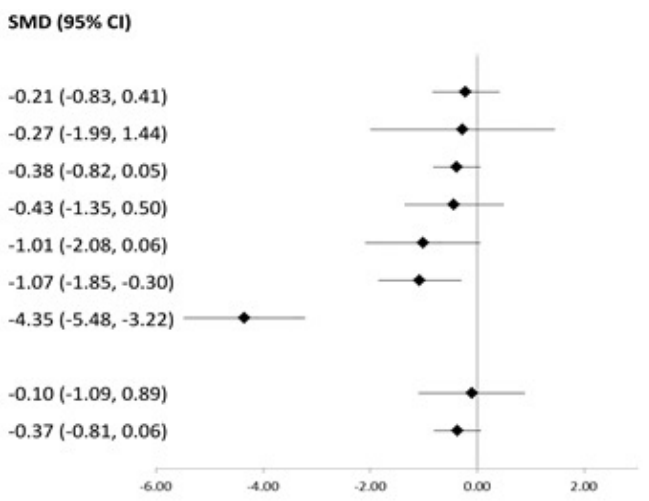

Interventions for post-stroke fatigue (Review) 
For the two trials that assessed fatigue at three months after the end of treatment, we also calculated the SMDs for these followup outcomes. Figure 4 presents the results.

\section{Dichotomous outcomes}

Of the six trials (seven comparisons) that compared the intervention with control, only one trial (83 participants) reported the number/proportion of participants with PSF after treatment (dichotomous outcomes of fatigue) (Choi-Kwon 2007). There was no significant difference in proportions of participants with PSF between the fluoxetine group and the placebo group at baseline ( $100 \%$ versus $100 \%)$, at the end of treatment ( $82 \%$ versus $93 \%$, RR $0.89,95 \%$ CI 0.75 to 1.05 , Analysis 1.3 ), or at three months after the end of treatment ( $85 \%$ versus $93 \%$, RR $0.91,95 \%$ CI 0.78 to 1.07$)$

\section{Trials without a control arm (comparison between different interventions)}

Two trials compared different potentially active interventions without a control arm. Because these two pairs of comparisons were different (also because they reported different types of outcomes), we did not perform a meta-analysis, but calculated individual MD or RR for each trial.

Zedlitz 2012 (83 participants) reported the continuous outcomes of fatigue after treatment. Fatigue scores were not significantly different between the COgnitive and GRaded Activity Training (COGRAT) group and the cognitive therapy group either at the end of treatment (for CIS-f: MD 0.80, 95\% CI -3.63 to 5.23; for Self-Observation List-fatigue subscale (SOL-f): MD -0.30, 95\% CI -1.35 to 0.75 ) or at six months after the end of treatment (for CIS-f: MD $-2.00,95 \%$ CI -6.74 to 2.74; for SOL-f: MD -0.50, 95\% CI -1.64 to 0.64$)$.

Zhou 2010 (128 participants) reported both continuous outcomes and dichotomous outcomes of fatigue after treatment. Trial investigators reported that scores of SSQOL-energy after treatment were significantly higher (indicating better outcome) in the electroacupuncture plus cupping group than the medication group ( $\mathrm{P}$ value $<0.05)$. These scores were presented graphically but raw data were not reported and we could not obtain these data from trial investigators, thus we did not calculate an MD for this trial. Twenty-two participants in the electroacupuncture plus cupping group and 41 participants in the medication group had PSF at the end of treatment (34\% versus $64 \%$, RR $0.54,95 \%$ CI 0.37 to 0.79 ), and 30 participants in the electroacupuncture plus cupping group and 52 participants in the medication group had PSF at two months after the end of treatment (47\% versus $81 \%$, RR 0.58 , $95 \%$ CI 0.43 to 0.77 ).

\section{Secondary outcomes}

Three trials assessed health-related quality of life (Clarke 2012; Guo 2012; Zedlitz 2012), and one trial assessed disability and dependence (Clarke 2012). No trial reported death or cost-effectiveness. Here we present the results of these outcomes reported by the trial investigators.

Clarke 2012 reported a significant improvement in Short Form36 social functioning for both groups $(\mathrm{P}$ value $=0.03)$ but there was no difference between groups ( $P$ value $=0.20$ ). There was no significant change from baseline to post-treatment assessment in the other subscales of Short Form-36, the Barthel Index or the $\mathrm{mRS}$, and none of the changes were significantly different between groups.

Guo 2012 reported that the total score of Stroke Specific Quality of Life after treatment was significantly higher in the TCM (a combination of Chinese herbs) group than that in the citicoline group ( $\mathrm{P}$ value $<0.01$ ) and the placebo group ( $\mathrm{P}$ value $<0.01$ ). Zedlitz 2012 reported a significant reduction of scores of Strokeadapted Sickness Impact Profile-30 from baseline to post-treatment assessment $(\mathrm{P}$ value $=0.002)$, but this change was not significant between groups ( $\mathrm{P}$ value $>0.1$ )

\section{Trials primarily intended to prevent post-stroke fatigue}

We identified no trials that were primarily intended to prevent PSF.

\section{Trials not primarily intended to treat or prevent post- stroke fatigue}

We identified four trials that were not primarily intended to treat or prevent PSF. Three trials reported continuous outcomes and one reported dichotomous outcomes of fatigue after treatment. We did not pool results from these trials because they had substantial differences in the studied populations, treatment and control interventions, and outcome measures. Instead, we calculated effect sizes for each of these trials and present the individual result in Table 2. None of these interventions showed any benefit on reducing fatigue in people with stroke. 
Interventions not specifically targeting post-stroke fatigue, compared with compared with placebo, usual medical care or wait-list

Patient or population: people with stroke not necessarily having fatigue

Settings: outpatients

Intervention: interventions not specifically targeting fatigue but other symptoms in people with stroke

Comparison: placebo, usual medical care, or wait-list

\begin{tabular}{|c|c|c|c|c|c|c|}
\hline \multirow[t]{2}{*}{ Outcomes } & \multicolumn{2}{|c|}{ Illustrative comparative risks (95\% Cl) } & \multirow{2}{*}{$\begin{array}{l}\text { Relative effect } \\
\text { (MD or RR and } 95 \% \mathrm{Cl} \text { ) }\end{array}$} & \multirow{2}{*}{$\begin{array}{l}\text { No of participants } \\
\text { (studies) }\end{array}$} & \multirow{2}{*}{$\begin{array}{l}\text { Quality of the evidence } \\
\text { (GRADE) }\end{array}$} & \multirow[t]{2}{*}{ Comments } \\
\hline & Assumed risk & Corresponding risk & & & & \\
\hline $\begin{array}{l}\text { Fatigue severity at the end } \\
\text { of treatment (assessed by } \\
\text { Fatigue Severity Scale) } \\
\text { Follow-up: at the end of } \\
\text { treatment }\end{array}$ & $\begin{array}{l}\text { Sham CPAP group: the } \\
\text { mean fatigue score was } \\
2.66 \text { (-0.65 to } 5.97)\end{array}$ & $\begin{array}{l}\text { Active CPAP group: the } \\
\text { mean fatigue score was } \\
3.11 \text { ( } 0.57 \text { to } 5.65)\end{array}$ & $\begin{array}{l}\text { Fatigue severity in the ac- } \\
\text { tive CPAP group was } 0 \text {. } \\
45 \text { points higher (- }-0.59 \text { to } \\
1.49 \text { higher) on Fatigue } \\
\text { Severity Scale, but this } \\
\text { difference was of no sta- } \\
\text { tistical significance }\end{array}$ & $32(1)$ & $\begin{array}{l}\oplus \circ \bigcirc \bigcirc \\
\text { Very low }\end{array}$ & $\begin{array}{l}\text { Higher score indicates } \\
\text { more severe fatigue }\end{array}$ \\
\hline
\end{tabular}

Changes of fatigue scores Placebo group: the mean CDSMP group: the mean The increase of fatigue 125 (1)

$\oplus \circ \bigcirc \bigcirc$

from baseline to after energy score after treat- energy score after treat- severity in the CDSMP

treatment (assessed by ment was 0.246 points ment was 0.087 points group was 0.16 points

energy/fatigue scale from lower (-0.924 to 1.416$)$ lower $(-1.849$ to 2.023$)$ less $(-0.44$ to 0.12 less)

the Medical Outcomes than baseline (i.e. fatigue than baseline (i.e. fatigue on the energy/fatigue

Study) severity increased by 0 . severity increased by 0 .

Follow-up: at the end of 246 points)

087 points)

treatment scale, but this difference

was of no statistical sig-

Very low ${ }^{2}$

nificance
Higher energy score indicates lower fatigue severity; decrease of energy score indicates increase of fatigue severity; the greater decrease of energy score indicates the greater increase of fatigue severity

Proportion of participants Placebo group: the pro- Tirilazad mesylate group: The risk participants with 31 (1)

with fatigue after treat- portion of participants the proportion of partic- fatigue in tirilazad group

ment (assessed by the with fatigue was $60 \%$ (9/ ipants with fatigue was was $47 \%$ of that in the

self report by partici- 15$) \quad 25 \%(4 / 16)$

pants)

control group (RR 0.42

$95 \% \mathrm{Cl} 0.16$ to 1.07$)$, but 
CDSMP: Chronic Disease Self-Management Programme

Cl: confidence interval

CPAP: continuous positive airway pressure

MD: mean difference

RR: risk ratio

1. This was a small trial (imprecision) with a significant attrition bias (risk of bias), as 13 out of 32 participants dropped out and the investigators only reported data for the remaining 19 participants. The intervention (CPAP) was primarily aimed to treat sleep apnoea, which showed no effect on either scores of sleep apnoea or scores of fatigue. Together with the significant attrition bias, we have no confidence in concluding whether the intervention was effective or ineffective in treating sleep apnoea, or fatigue, or both (indirectness). 2. This trial had several sources of risks of bias: a) attrition bias (21 out of 125 participants dropped out, 16\%); b) performance bias (the interventions were visibly different to participants); and c) detection bias (no sufficient information to permit judgement on this risk). The intervention was not specifically designed for people with stroke or to manage fatigue (indirectness).

3. This was a small trial (imprecision) with a significant attrition bias (risk of bias), as 13 out of 31 participants dropped out and the investigators only reported data for the remaining 18 participants. Fatigue was not measured at baseline, so we do not know specifically whether this intervention was effective in preventing fatigue in non-fatigued people with stroke or if it was effective in treating fatigue in fatigued people with stroke (indirectness). 


\section{DISCUSSION}

\section{Summary of main results}

We included 12 trials (703 participants) in this review: three trials identified in the 2008 version and nine additional trials published since 2008 (two of which were ongoing trials in the 2008 review). We also identified nine ongoing trials meeting our inclusion criteria. Of the 12 published trials, eight trials primarily intended to treat PSF, none primarily intended to prevent PSF and the other four trials did not primarily target PSF. Summary of findings for the main comparison and Summary of findings 2 present the key findings from these trials.

Of the eight trials primarily intended to treat PSF, four trials investigated pharmacological interventions and the other four investigated non-pharmacological interventions. Meta-analysis indicated a statistically significant benefit of these interventions on treating PSF. However, the benefit was not seen in trials with a low risk of bias. Subgroup analysis further demonstrated a marginally statistically significant benefit of pharmacological interventions and no statistically significant benefit of non-pharmacological interventions. The identified trials were small and heterogeneous, and some had a high risk of bias. Of the four trials not primarily intended to treat or prevent PSF, none showed an effect on reducing fatigue in people with stroke. In summary, there are insufficient data to draw any firm conclusions about whether or not these interventions were effective, either to treat or prevent PSF.

\section{Antidepressants and other psychostimulants}

One previous systematic review found that PSF was associated with depressive symptoms and this association existed even in people with stroke who did not meet clinical criteria for depression (Wu 2014a). Thus, it is plausible that treatment for depression may reduce PSF. In addition, small trials found that PSF was associated with serotonin synthesis (Ormstad 2014). Potential efficacy of psychostimulants in the management of PSF was shown in non-randomised trials (Brioschi 2009; Kalinskī 2008). However, RCTs identified in the current review found no beneficial effects of any antidepressants (Choi-Kwon 2007; Karaiskos 2012), or other psychostimulants (Johansson 2012a), on PSF. It is important to note that these trials were small, thus may lack the power to detect the effect. A number of larger trials are ongoing, which may provide further evidence on the efficacy of psychostimulants on PSF (AFFINITY 2013; EFFECTS 2014; FOCUS 2012; Overgaard 2012).

\section{Psychological interventions}

Although PSF is associated with depressive symptoms and neuroendocrine changes, RCTs to date provided no evidence on the efficacy of psychostimulants. One possible explanation is that PSF is a complex symptom influenced by a mixture of biological, physical, psychological and behavioural factors and there are interac- tions between these factors (Wu 2015). Psychological interventions (e.g. cognitive behavioural therapy) targeting these psychobehavioural factors are effective in treating fatigue in other conditions (such as cancer (Armes 2007), and chronic fatigue syndrome (White 2011)), thus might be promising for PSF. However, RCTs investigating psychological interventions in people with PSF did not demonstrate whether or not these interventions were effective due to the limitations in the study design (Clarke 2012; Johansson 2012b; Lorig 2001; Zedlitz 2012). Thus, future studies are expected to investigate the efficacy of psychological interventions specially designed for PSF in RCTs with adequate sample sizes and controlled with usual medical care.

\section{Physical training}

Small studies found that PSF was associated with reduced physical fitness (Lewis 2011), and lower levels of physical activity (Duncan 2015). Furthermore, one study found that PSF was related to the reduced excitability of the motor cortex (Kuppuswamy 2015). Physical training after stroke may improve physical fitness and stimulate cortical excitability, which may help to reduce fatigue. In this review, we found one trial that reported that cognitive behavioural therapy plus graded activity training was more effective in reducing PSF than cognitive behavioural therapy alone (Zedlitz 2012). However, from this trial we do not know whether the reduction of fatigue was a result of the physical training alone or a combination effect of physical training and cognitive behavioural therapy. This question may be answered by some ongoing trials that compare physical training, cognitive training, or both, with a sham or usual medical care control (Chuang 2013; MacKay-Lyons 2012; Michael 2008; Vanroy 2010).

\section{Traditional Chinese therapies}

In this review, we identified two trials which investigated traditional Chinese therapies for PSF (Guo 2012; Zhou 2010). In general, the quality of these trials was low and the components of these Chinese traditional therapies were complicated. Efficacy of these interventions should be investigated in future RCTs with more robust study designs and using adequate controls. Furthermore, since these are complex interventions that have different components, a pre-specified protocol or regimen of interventions are needed before starting the trial, and where possible, which component(s) plays the leading role in therapeutic effect should be investigated. For example, a randomised, placebo-controlled, double-blind trial is ongoing to investigate the efficacy of Astragalus membranaceus (a Chinese herb) on PSF (Liu 2012).

\section{Other interventions}

Vitamin supplementation is potentially effective in some cases of PSF. One observational study found that fatigue after lacunar strokes was associated with vitamin B12 deficiency (Huijts 2012). 
There is also a case report of the efficacy of high-dose vitamin B1 in treating fatigue in three people with stroke (Costantini 2014). One non-randomised trial reported that the antioxidant idebenon (a synthetic analogous of coenzyme Q10) was effective in the management of PSF (Вог ko 2013). In this review, we identified one small trial that found that enerion (a synthetic derivative of vitamin B1) was effective in reducing PSF (Gurak 2005). However, this trial was limited by its small sample size of 15 participants in each group and the high risk of selection bias, thus future trials are needed. Another two interventions, tirilazad mesylate (Ogden 1998), and CPAP (Brown 2013), had no effect on PSF. However, neither of these interventions was specifically designed for PSF. In addition, these two trials were small and both had a high risk of attrition bias. Thus, the effect of these interventions on PSF is unknown.

\section{Overall completeness and applicability of evidence}

The inclusion criteria of this review were deliberately broad with an aim to inform future research. We sought to include trials in which fatigue was a secondary as well as a primary outcome and the participants in the included trials did not necessarily have fatigue at baseline to be eligible for inclusion, because identifying strategies to prevent (as well as treat) fatigue are important.

We identified five broad categories of interventions particularly targeting the treatment of PSF, that is, antidepressants and other psychostimulants, psychological interventions, physical training, traditional Chinese therapies and other interventions. Generally, the existing trials provided no evidence on the efficacy of antidepressants on PSF, irrespective of whether the participants met the criteria of post-stroke depression or not. However, these trials were small and may, therefore, lack the power to detect significant effects. Psychological interventions targeting patients' cognition and behaviours are feasible in people with stroke but their efficacy should be investigated in future RCTs that compare these interventions with the usual medical care control. Traditional Chinese therapies (including medicine and physical therapy) showed promising effects on PSF, but the components of each therapy were complicated and the study quality was poor. Some other interventions showed efficacy on PSF in single small trials, for example enerion (a compound of vitamin B1) and tirilazad mesylate (a hypothesised neuroprotective agent). In addition, (-)-OSU6162 (a monoaminergic stabiliser) was tolerable in six people with stroke patients but had no efficacy on fatigue. These were small trials and the efficacy of these drugs should be investigated in future RCTs with an adequate sample size and a robust study design. CPAP, which was designed for sleep apnoea after stroke, was of no benefit on reducing either fatigue or sleep apnoea after stroke. This trial was very small and had significant drop-outs. In addition, we do not know if other interventions, if effective for sleep disorders, are helpful to reduce PSF.

There was considerable heterogeneity in the study design of the included trials. First, the heterogeneity might be attributed to the different interventions used in different trials. Although we stratified heterogeneity by grouping trials into pharmacological interventions and non-pharmacological interventions, significant heterogeneity remained within the subgroup of pharmacological interventions, where no two trials used a same type of drug. This means each type of intervention has only been evaluated in one trial, which limits the generalisability of the findings. Second, heterogeneity might also be attributed to the differences in participant characteristics, with many different criteria used for diagnosis of fatigue and also the time window from stroke onset to randomisation ranging from within first few months to several years after stroke. Given different factors may contribute to fatigue at different stages of its natural history (Wu 2015), the efficacy of a specific intervention may be different for people with different characteristics.

Another important aspect of study design is the sample size required to detect a clinically significant therapeutic effect. Of the 12 included trials, only six trials $(50 \%)$ had a sample size of over 50 participants (Choi-Kwon 2007; Guo 2012; Karaiskos 2012; Lorig 2001; Zedlitz 2012; Zhou 2010), and the largest sample was 128 participants (Zhou 2010). The other six trials each had no more than 30 participants who completed the trial and were primarily aimed to test the feasibility of the interventions rather than to investigate efficacy (Brown 2013; Clarke 2012; Gurak 2005; Johansson 2012a; Johansson 2012b; Ogden 1998). In addition, none of these 12 trials reported how the sample size was determined. The small sample sizes might have limited the power to detect the clinically significant effect.

Adverse effects were not a pre-specified outcome of this review. Only one included trial specifically investigated adverse effects (Karaiskos 2012), where nausea, somnolence, insomnia, dizziness, dry mouth, headache and diarrhoea were reported. There was no difference between the duloxetine group, the citalopram group and the sertraline group and no participants withdrew from this trial. In another trial, one participant in the fluoxetine group (a selective serotonin reuptake inhibitor) and another in the placebo group withdrew due to the 'side effect' (Choi-Kwon 2007). Another trial reported several drop-outs due to the intolerance of the CPAP device (Brown 2013). Two trials reported medical issues as the reason for drop-out (Clarke 2012; Ogden 1998), but it is unclear whether it was related to adverse effects of the intervention. The other four trials reported drop-outs but did not give the reason (Johansson 2012a; Johansson 2012b; Lorig 2001; Zedlitz 2012). In general, no severe adverse effects were reported for the included interventions.

\section{Quality of the evidence}

The included trials were small and heterogeneous, and some of 
them had a high risk of bias. It is difficult to interpret the significance of outcomes when there is inadequate concealment of allocation, non-blind assessment or significant drop-outs in several of the included trials. Although the interventions showed an overall significant effect on treating PSF, the sensitivity analyses indicated that, in trials with a low risk of bias, this effect was no longer significant. In summary, there was no robust evidence to inform the prevention or treatment of PSF. The efficacy of interventions should be investigated in future RCTs with a more robust design.

\section{Potential biases in the review process}

The identification of all relevant trials might have been confounded by a number of factors. We did not search any non-English databases, thus we only had access to trials that published their abstracts in English. In addition, for trials measuring fatigue as a secondary outcome, trial investigators might not have reported the results of fatigue in the abstract or coded it as a keyword identifiable for electronic searches. Furthermore, some trials had used scales of which part of the scale is the valid tool for assessing PSF (e.g. the vitality subscale of the Short Form-36); for these trials, if fatigue was not a specific target of the intervention, 'fatigue' or its synonyms might not appear in the report, thus we could not identify such trials through electronic searches. To minimise the risk of missing relevant studies, we used extensive search strategies and contacted experts in the field for relevant studies. We would appreciate if other researchers who have noticed any relevant studies missing from this review could inform us, so that we can update our review.

Although two review authors independently extracted the trial data, for one trial that was published in Russian, only one author (a native speaker of Russian) extracted the data and assessed the study quality. To minimise the risk of biased assessment, another review author reviewed the extracted data and clarified the eligibility with the Russian-speaking review author.

\section{Agreements and disagreements with other studies or reviews}

As far as we know, there are no other systematic reviews of interventions for PSF. Our review identified a mixture of pharmacological and non-pharmacological interventions. Non-pharmacological interventions identified in our review were similar to those identified in a Cochrane Overview of reviews of interventions for fatigue in adults with advanced progressive illness (e.g. cancer, motor neuron diseases and chronic pulmonary diseases), which include aerobic exercise, physical training, education programmes and psychological interventions (Payne 2012). However, in the Cochrane Overview, the pharmacological interventions (e.g. amantadine and carnitine) were different from the pharmacological interventions identified in our review (e.g. antidepressants and neuroendocrine regulators). A possible explanation is that the choice of drugs might be relevant or specific to fundamental dis- eases. Furthermore, we found that psychological interventions or physical training, or both, for fatigue were feasible in people with stroke, although their efficacy on PSF should be further investigated. This is consistent with a systematic review of interventions for chronic fatigue syndrome, where the review authors concluded that cognitive behavioural therapy and graded exercise therapy were promising treatment strategies for fatigue (Whiting 2001).

\section{AUTHORS' CONCLUSIONS}

\section{Implications for practice}

There was insufficient evidence on the efficacy of any intervention for the treatment or prevention of post-stroke fatigue (PSF). Trials to date have been small and heterogeneous, and some have had a high risk of bias. Some of the interventions described were feasible in people with stroke, but their efficacy should be investigated in randomised controlled trials (RCTs) with more robust study designs and adequate sample sizes.

\section{Implications for research}

Given the high prevalence and distressing consequences of fatigue following stroke, more research is urgently needed to identify effective interventions for PSF. The wide range of different interventions identified in this review reflect the uncertainty and complexity of the aetiology and mechanism of PSF. Some pharmacological interventions have shown benefit on PSF in small single trials, but their efficacy should be further investigated in RCTs. Furthermore, given that some studies have found an association between fatigue and mood disorders and physical fitness, psychological interventions and physical training are promising strategies for the management of PSF. These interventions have shown feasibility in people with stroke and their efficacy should be investigated in future RCTs.

\section{ACKNOWLEDGEMENTS}

For the 2008 review, we are very grateful to Mrs Brenda Thomas (Cochrane Stroke Group Trials Search Co-ordinator) and Mrs Hazel Fraser (Cochrane Stroke Group Managing Editor) who helped develop the search strategies, searched the Cochrane Stroke Group Trials Register and the Cochrane Central Register of Controlled Trials. We are grateful to the editors and peer reviewers for their helpful comments on the 2008 review (Professor Peter Langhorne, Professor Anne Forster, Dr Valery Feigin, Dr Steff Lewis, Mrs Brenda Thomas). Ms Maureen Harding, Geriatric Medicine, University of Edinburgh, helped obtain articles for the review. Professor Kate Lorig and Dr Phil Ritter, Stanford University, accessed and provided data from the subgroup of people with 
stroke from the Lorig 2001 trial. Dr Gunnel Carllson responded to our queries about ongoing trials. Professor Fasotti and Dr Zedlitz provided information about the COGRAT study, and Dr Brown provided information about the SATS study. The Scottish Branch of the British Geriatrics Society provided a small project grant to Dr Elizabeth Keane to support this work for the review.

For the current review, we are grateful to Mrs Hazel Fraser who helped search the Cochrane Stroke Trial Register and Mrs Brenda Thomas who helped search the Cochrane Central Register of Controlled Trials, MEDLINE, EMBASE, PsycINFO, AMED and CINAHL. We are grateful to the editors, peer reviewers and the consumer reviewer for their helpful comments on this update re- view (Professor Peter Langhorne, Dr Maree Hackett, Dr Valentina Assi, Mrs Brenda Thomas, Ms Julie Gildie). We are grateful to Dr Devin Brown who provided unpublished fatigue scores from the SATS study (Brown 2013), and Dr Birgitta Johansson who provided unpublished data for the subgroup of people with stroke from their two trials (Johansson 2012a; Johansson 2012b). Dr Christel Vanroy responded to our queries about their ongoing trial (Vanroy 2010). Dr Simiao Wu was supported by the China Scholarship Council/University of Edinburgh joint Scholarship to complete this review.

The work presented here represents the views of the review authors and not necessarily those of the funding bodies.

\section{REF E R E NCES}

\section{References to studies included in this review}

Brown 2013 \{published data only\}

Brown DL, Chervin RD, Kalbfleisch JD, Zupancic MJ, Migda EM, Svatikova A, et al. Sleep Apnea Treatment after Stroke (SATS) trial: is it feasible?. Journal of Stroke and Cerebrovascular Diseases 2013;22:1216-24.

Choi-Kwon 2007 \{published data only\} Choi-Kwon S, Choi J, Kang D-W, Kim JS. Fluoxetine is not effective in the treatment of post-stroke fatigue: a doubleblind, placebo-controlled study. Cerebrovascular Diseases 2007;23:102-8.

Clarke 2012 \{published data only\}

Clarke A, Barker-Collo S, Feigin V. Poststroke fatigue: does group education make a difference? A randomized pilot trial. Topics in Stroke Rehabilitation 2012;19:32-9.

Guo 2012 \{published data only\} Guo YH, Chen HX, Xie RM. Effects of qi-supplementing dominated Chinese materia medica combined with rehabilitation training on the quality of life of ischemic post-stroke fatigue patients of qi deficiency syndrome [Chinese]. Zhongguo Zhong xi yi jie he za zhi [Chinese Journal of Integrated Traditional and Western Medicine] 2012;32:160-3.

Gurak 2005 \{published data only\}

Gurak SV, Parfenov VA. Asthenia after stroke and myocardial infarction and its treatment with Enerion. Klinicheskaya Gerontologia 2005;8:9-12.

Johansson 2012a \{published data only\} Johansson B, Carlsson A, Carlsson ML, Karlsson M, Nilsson MKL, Nordquist-Brandt E. Placebo-controlled cross-over study of the monoaminergic stabiliser (-)-OSU6162 in mental fatigue following stroke or traumatic brain injury. Acta Neuropsychiatrica 2012;24:266-74.

Johansson 2012b \{published data only\} Johansson B, Bjuhr H, Rönnbäck L. Mindfulness-based stress reduction (MBSR) improves long-term mental fatigue after stroke or traumatic brain injury. Brain Injury 2012;26: $1621-8$.

Karaiskos 2012 \{published data only\}

Karaiskos D, Tzavellas E, Spengos K, Vassilopoulou S, Paparrigopolous T. Duloxetine versus citalopram and sertraline in the treatment of poststroke depression, anxiety, and fatigue. Journal of Neuropsychiatry and Clinical Neurosciences 2012;24:349-53.

Lorig 2001 \{published data only\} Lorig KR, Ritter P, Stewart AL, Sobel DS, Brown BW, Bandura A, et al. Chronic disease self-management program: 2-year health status and health care utilization outcomes. Medical Care 2001;39:1217-23.

Ogden 1998 \{published data only\}

Ogden JA, Mee EW, Utley T. Too little, too late: does tirilazad mesylate reduce fatigue after subarachnoid haemorrhage?. Neurosurgery 1998;4:782-7.

Zedlitz 2012 \{published data only\} Zedlitz AMEE, Rietveld TCM, Geurts AC, Fasotti L. Cognitive and graded activity training can alleviate persistent fatigue after stroke: a randomized, controlled trial. Stroke 2012;43:1046-51.

Zhou 2010 \{published data only\} Zhou Y, Zhou GY, Li SK, Jin JH. Clinical observation on the therapeutic effect of electroacupuncture combined with cupping on post-stroke fatigue [Chinese]. Zhen Ci Yan Jiu 2010;35:380-3

\section{References to studies excluded from this review}

Allison 2007 \{published data only\}

Allison R, Dennett R. Pilot randomized controlled trial to assess the impact of additional supported standing practice on functional ability post stroke. Clinical Rehabilitation 2007;21:614-9.

Brioschi 2009 \{published data only\}

Brioschi A, Gramigna S, Werth E, Staub F, Ruffieux C, Bassetti C, et al. Effect of modafinil on subjective fatigue in 
multiple sclerosis and stroke patients. European Neurology 2009;62:243-9.

\section{Cruz 2013 \{published data only\}}

Cruz TV. Stroke wearable operative rehabilitation device impact trial (SWORD-IT). clinicaltrials.gov/show/ NCT01967290 (accessed 21 June 2015).

Feys 2013 \{published data only\} Feys P. Effect of I-TRAVLE training on arm function in MS and chronic stroke patients. clinicaltrials.gov/show/ NCT01918748 (accessed 21 June 2015).

Kim 2012 \{published data only\}

Kim I. Effects of an enjoyable nurse-led intervention to promote movement in poststroke inpatients. Clinical Nursing Research 2012;21:390-405.

Kirkevold 2012 \{published data only\}

Kirkevold M. Poststroke fatigue - developing and testing a program to reduce cope with fatigue. clinicaltrials.gov/ show/NCT01629654 (accessed 21 June 2015).

Lin 2013 \{published data only\}

Lin KC. Comparative efficacy research of robotassisted therapy with and without constraint-induced therapy in stroke rehabilitation. clinicaltrials.gov/show/ NCT01907139 (accessed 21 June 2015).

Robinson 2003 \{published data only\} Robinson S, Vollmer C, Hermes B. A program to reduce fatigue in convalescing elderly adults. Journal of Gerontological Nursing 2003;29:47-53.

Sianni 2008 \{published data only\}

Sianni A. The benefiting effect of exercise after an acute cerebrovascular stroke (ACVS). International Journal of Stroke 2008;3 Suppl 1:468.

Underwood 2006 \{published data only\} Underwood J, Clark PC, Blanton S, Aycock DM, Wolf SL. Pain, fatigue, and intensity of practice in people with stroke who are receiving constraint-induced movement therapy. Physical Therapy 2006;86:1241-50.

Wu 2014b \{published data only\}

Wu S. A rehabilitation therapy for post-stroke fatigue. clinicaltrials.gov/show/NCT02131532 (accessed 21 June 2015).

\section{References to ongoing studies}

AFFINITY 2013 \{published data only\}

Hackett M, Hankey G. Assessment of fluoxetine in stroke recovery (AFFINITY) trial. www.affinitytrial.org/download/study 'outline/ Protocol\%20Summary\%20V3.pdf (accessed 21 June 2015).

Chuang 2013 \{published data only\} Chuang L-L. A study of post-stroke pain and fatigue: clinical evaluation and treatment effect. clinicaltrials.gov/ show/NCT01913509 (accessed 21 June 2015).

EFFECTS 2014 \{published data only\}

Laska AC, Lundström E, Berthold E, Markaki I, Löfmark U, Wiberg B, et al. Efficacy oF Fluoxetine - a randomisEd
Controlled Trials in Stroke. Determination of the efficacy and safety of fluoxetine treatment for stroke - a randomized placebo-controlled study of 1500 patients. www.effects.se/? page id $=114$ (accessed 21 June 2015).

FOCUS 2012 \{published data only\}

Mead GE. Fluoxetine Or Control Under Supervision (FOCUS) trial. www.focustrial.org.uk/default.html (accessed 21 June 2015).

Liu 2012 \{published data only\}

Liu C-H. Randomized, double blind, placebo control trial to evaluate the efficacy of Astragalus membranaceus in the patients after stroke with fatigue. clinicaltrials.gov/ct2/ show/NCT01554787 (accessed 21 June 2015).

MacKay-Lyons 2012 \{published data only\} MacKay-Lyons M. Combined effects of aerobic exercise and cognitive training on cognition after stroke. clinicaltrials.gov/ct2/show/NCT01674790 (accessed 21 June 2015)

Michael 2008 \{published data only\} Michael KM. Testing Adaptive Physical Activity in Stroke (TAPAS). clinicaltrials.gov/ct2/show/NCT01042990 (accessed 21 June 2015).

Overgaard 2012 \{published data only\}

Overgaard K. Poulsen M. Treatment of post stroke fatigue with a wakefulness promoting agent. clinicaltrials.gov/ct2/ show/NCT01800097 (accessed 21 June 2015).

Vanroy 2010 \{published data only\}

Vanroy C, Cras P, Vanlandewijck Y. The effect of an aerobic exercise programme in stroke patients. clinicaltrials.gov/ ct2/show/NCT01070459 (accessed 21 June 2015).

\section{Additional references}

Armes 2007

Armes J, Chalder T, Addington-Hall J, Richardson A, Hotopf M. A randomized controlled trial to evaluate the effectiveness of a brief, behaviorally oriented intervention for cancer-related fatigue. Cancer 2007;110:1385-95.

\section{Borenstein 2009}

Borenstein M, Hedges LV, Higgins JPT, Rothstein HR. Subgroup analyses. Introduction to Meta-Analysis. 1st Edition. Chichester, West Sussex, UK: John Wiley \& Sons, 2009:149-86.

Bỡ ko 2013

Boĭ ko AN, Lebedeva AV, Shchukin IA, Soldatov MA, Petrov SV, Khozova AA, et al. Emotional disorders and quality of life in patients with post stroke asthenia. Zhurnal Nevrologii i Psikhiatrii Imeni S.S. Korsakova 2013;113(11): 27-33.

Choi-Kwon 2011

Choi-Kwon S, Kim JS. Poststroke fatigue: an emerging, critical issue in stroke medicine. International Journal of Stroke 2011;6:328-36.

Costantini 2014

Costantini A, Pala MI, Catalano ML, Notarangelo C, Careddu P. High-dose thiamine improves fatigue after 
stroke: a report of three cases. Journal of Alternative and Complementary Medicine 2014;20:683-5.

\section{Deeks 2001}

Deeks JJ, Altman DG, Bradburn MJ. Statistical methods for examining heterogeneity and combining results from several studies in meta-analysis. In: Egger M, Davey-Smith G, Altman DG editor(s). Systematic Reviews in Healthcare: Meta-analysis in Context. 2nd Edition. London: BMJ Publishing Group, 2001.

Duncan 2015

Duncan F, Lewis SJ, Greig CA, Dennis MS, Sharpe M, MacLullich AM, et al. Exploratory longitudinal cohort study of associations of fatigue after stroke. Stroke 2015;46: $1052-8$.

\section{Glader 2002}

Glader E-L, Stegmayr B, Asplund K. Post-stroke fatigue. A 2-year follow-up study of stroke patients in Sweden. Stroke 2002;33:1327-33.

\section{Higgins 2011}

Higgins JPT, Green S (editors). Cochrane Handbook for Systematic Reviews of Interventions Version 5.1.0 [updated March 2011]. The Cochrane Collaboration 2011. Available from www.cochrane-handbook.org.

\section{Huijts 2012}

Huijts M, Duits A, Staals J, van Oostenbrugge RJ. Association of vitamin B12 deficiency with fatigue and depression after lacunar stroke. PLoS One 2012;7:e30519.

\section{Kalinskiı̄ 2008}

Kalinskī̌ PP, Nazarov VV, Samarets NA, Ulitina MN. Peculiarities of treatment of asthenic syndrome in the acute period of ischemic stroke. Zhurnal Nevrologii i Psikhiatrii Imeni S.S. Korsakova 2008;108:72-4.

\section{Krupp 1989}

Krupp LB, LaRocca NG, Muir-Nash J, Steinberg AD. The Fatigue Severity Scale. Archives of Neurology 1989;46: $1121-3$.

\section{Kuppuswamy 2015}

Kuppuswamy A, Clark EV, Turner IF, Rothwell JC, Ward NS. Post-stroke fatigue: a deficit in corticomotor excitability?. Brain 2015;138:136-48. [DOI: 10.1093/ brain/awu306

\section{Kutlubaev 2012}

Kutlubaev MA, Duncan FH, Mead GE. Biological correlates of post-stroke fatigue: a systematic review. Acta Neurologica Scandinavica 2012;125:219-27.

\section{Lewis 2011}

Lewis SJ, Barugh AJ, Greig CA, Saunders DH, Fitzsimons $\mathrm{C}$, Dinan-Young $\mathrm{S}$, et al. Is fatigue after stroke associated with physical deconditioning? A cross-sectional study in ambulatory stroke survivors. Archives of Physical Medicine and Rehabilitation 2011;92:295-8.

\section{Lynch 2007}

Lynch J, Mead G, Greig C, Young A, Lewis S, Sharpe M. Fatigue after stroke: the development and evaluation of a case definition. Journal of Psychosomatic Research 2007;63: 539-44.

\section{Mead 2007}

Mead G, Lynch J, Greig C, Young A, Lewis S, Sharpe M. Evaluation of fatigue scales in stroke patients. Stroke 2007; 38:2090-5.

\section{Michael 2006}

Michael KM, Allen JK, Macko RF. Fatigue after stroke: relationship to mobility, fitness, ambulatory activity, social support and falls efficacy. Rehabilitation Nursing 2006;5: $210-7$.

\section{Ormstad 2011}

Ormstad H, Aass HC, Amthor KF, Lund-Sorensen N, Sandvik L. Serum cytokine and glucose levels as predictors of poststroke fatigue in acute ischemic stroke patients. Journal of Neurology 2011;258:670-6.

\section{Ormstad 2014}

Ormstad H, Verkerk R, Amthor K-F, Sandvik L. Activation of the kynurenine pathway in the acute phase of stroke and its role in fatigue and depression following stroke. Journal of Molecular Neuroscience 2014;54:1-7.

\section{Passier 2011}

Passier PE, Post MW, van Zandvoort MJ, Rinkel GJ, Lindeman E, Visser-Meily JM. Predicting fatigue 1 year after aneurysmal subarachnoid hemorrhage. Journal of Neurology 2011;258:1091-7.

Payne 2012

Payne C, Wiffen PJ, Martin S. Interventions for fatigue and weight loss in adults with advanced progressive illness. Cochrane Database of Systematic Reviews 2012, Issue 1. [DOI: 10.1002/14651858.CD008427.pub2]

Pollock 2012

Pollock A, St George B, Fenton M, Firkins L. Top ten research priorities relating to life after stroke. Lancet Neurology 2012;11:209.

\section{Radman 2012}

Radman N, Staub F, Aboulafia-Brakha T, Berney A, Bogousslavsky J, Annoni JM. Poststroke fatigue following minor infarcts: a prospective study. Neurology 2012;79: $1422-7$.

\section{RevMan 2014 [Computer program]}

The Nordic Cochrane Centre. The Cochrane Collaboration. Review Manager (RevMan). Version 5.3. Copenhagen: The Nordic Cochrane Centre. The Cochrane Collaboration, 2014.

\section{Saunders 2013}

Saunders DH, Sanderson M, Brazzelli M, Greig CA, Mead GE. Physical fitness training for stroke patients. Cochrane Database of Systematic Reviews 2013, Issue 10. [DOI: 10.1002/14651858.CD003316.pub5]

\section{Syed 2007}

Syed AB, Castell LM, Ng A, Winward C, Rothwell PM. Plasma glutamate levels predict fatigue after TIA and minor stroke. Cerebrovascular Diseases 2007;23 Suppl 2:117. 


\section{Tyson 2014}

Tyson SF, Brown P. How to measure fatigue in neurological conditions? A systematic review of psychometric properties and clinical utility of measures used so far. Clinical Rehabilitation 2014;28:804-16.

van de Port 2007

van de Port IG, Kwakkel G, Schepers VP, Heinemans CT, Lindeman $\mathrm{E}$. Is fatigue an independent factor associated with activities of daily living, instrumental activities of daily living and health-related quality of life in chronic stroke?. Cerebrovascular Diseases 2007;23:40-5.

\section{White 2011}

White P, Goldsmith K, Johnson A, Potts L, Walwyn R, DeCesare J, et al. Comparison of adaptive pacing therapy, cognitive behaviour therapy, graded exercise therapy, and specialist medical care for chronic fatigue syndrome (PACE): a randomised trial. Lancet 2011;377:823-36.

Whiting 2001

Whiting P, Bagnall A, Sowden AJ, Cornell JE, Mulrow
CD, Ramírez G. Interventions for the treatment and management of chronic fatigue syndrome: a systematic review. JAMA 2001;286:1360-8. [DOI: 10.1001/ jama.286.11.1360]

\section{Wu 2014 a}

Wu S, Barugh A, Macleod M, Mead G. Psychological associations of poststroke fatigue: a systematic review and meta-analysis. Stroke 2014;45:1778-3.

\section{Wu 2015}

Wu S, Mead G, Macleod M, Chalder T. A model of understanding fatigue after stroke. Stroke 2015;46:893-8.

\section{References to other published versions of this review}

\section{McGeough 2009}

McGeough E, Pollock A, Smith LN, Dennis M, Sharpe $\mathrm{M}$, Lewis $\mathrm{S}$, et al. Interventions for post-stroke fatigue. Cochrane Database of Systematic Reviews 2009, Issue 3. [DOI: 10.1002/14651858.CD007030.pub2]

* Indicates the major publication for the study 


\section{CHARACTERISTICS OF STUDIES}

\section{Characteristics of included studies [ordered by study ID]}

\section{Brown 2013}

\begin{tabular}{|c|c|}
\hline Methods & $\begin{array}{l}\text { Parallel randomised trial } \\
\text { Method of randomisation: randomised stated, method unclear } \\
\text { Method of concealment: used sham control with device of identical appearance of that } \\
\text { for active CPAP } \\
\text { Blinding: double-blind } \\
\text { Analysis: only reported data of participants who had completed the 3-month follow-up } \\
\text { (available-case analysis) }\end{array}$ \\
\hline Participants & $\begin{array}{l}\text { Location: USA } \\
\text { Setting: enrolled from a single centre of inpatient neurology service, the treatment was } \\
\text { conducted in the community } \\
\text { Number of participants: } 32 \text { at randomisation ( } 59 \% \text { male, median unknown), } 19 \text { com- } \\
\text { pleted study, case-available analysis for } 19 \text { participants } \\
\text { Treatment group: } 15 \text { ( } 33 \% \text { male, median age } 61 \text { years, IQR } 46 \text { to } 76) \\
\text { Control group: } 17 \text { ( } 76 \% \text { male, median age } 74 \text { years, IQR } 55 \text { to } 81) \\
\text { Stroke criteria: ischaemic stroke based on accepted clinical criteria } \\
\text { Time since stroke onset at randomisation: median time from stroke onset to CPAP } \\
\text { titration was } 4 \text { days } \\
\text { Fatigue criteria: participants did not have to have fatigue to be recruited } \\
\text { Other entry criteria: had sleep apnoea; modified Rankin Scale } \geq 2 \\
\text { Comparability of groups: unclear }\end{array}$ \\
\hline Interventions & $\begin{array}{l}\text { Treatment intervention: active CPAP } \\
\text { Control intervention: sham CPAP } \\
\text { Treatment duration: } 3 \text { months } \\
\text { Delivered by: voluntary use by participants }\end{array}$ \\
\hline
\end{tabular}

Outcomes

Time for fatigue assessment: by the end of 3-month use of CPAP

Primary outcome: objective usage data of CPAP

Secondary outcome: FSS score

Notes

Only people with sleep apnoea were recruited

This study was primarily aimed at testing the feasibility of CPAP to treat sleep apnoea in people with stroke. Fatigue was measured as 1 of the symptoms of sleep apnoea for the efficacy of CPAP

The investigators reported median scores and IQR of FSS and we requested mean scores and SD from the investigators

Funding: National Institutes of Health Grant K23 NS051202 and National Center for

Research Resources Grant M01-RR000042

Risk of bias

Bias

Authors' judgement

Support for judgement

Interventions for post-stroke fatigue (Review)

Copyright () 2015 The Cochrane Collaboration. Published by John Wiley \& Sons, Ltd. 
Brown 2013 (Continued)

\begin{tabular}{|c|c|c|}
\hline Allocation concealment (selection bias) & Low risk & $\begin{array}{l}\text { Quote: "The active and sham CPAP units } \\
\text { were identical in appearance, with the } \\
\text { exception of the barely discernible aug- } \\
\text { mented leak port on the latter, and made } \\
\text { similar sounds while on"; "blinding to sub- } \\
\text { ject condition was successfully maintained" }\end{array}$ \\
\hline $\begin{array}{l}\text { Blinding of outcome assessment (detection } \\
\text { bias) } \\
\text { All outcomes }\end{array}$ & Low risk & $\begin{array}{l}\text { Quote: "Outcome assessors were masked to } \\
\text { intervention allocation" }\end{array}$ \\
\hline Intention-to-treat & High risk & $\begin{array}{l}\text { Available-case analysis: only reported data } \\
\text { of participants who had completed the 3- } \\
\text { month follow-up }\end{array}$ \\
\hline
\end{tabular}

Choi-Kwon 2007

\begin{tabular}{ll}
\hline Methods & Parallel randomised trial \\
Method of randomisation: computer-generated list of treatment numbers \\
Method of concealment: control group used a placebo of identical appearance with \\
fluoxetine \\
Blinding: double-blind \\
Analysis: ITT
\end{tabular}

Interventions

Treatment intervention: fluoxetine $20 \mathrm{mg} /$ day, single morning dose, orally

Control intervention: placebo $20 \mathrm{mg} /$ day, single morning dose, orally

Treatment duration: 3 months

Delivered by: taken by participants at home

Outcomes

Time for fatigue assessment: baseline, by the end of 3-month treatment, at 6-month follow-up from baseline

Primary outcome: mean scores of FSS and VAS-f

Secondary outcome: percent changes in FSS and VAS scores between baseline and follow- 
Choi-Kwon 2007 (Continued)

up

\begin{tabular}{ll}
\hline Notes & Only people reporting subjective experiences of PSF were recruited \\
& Funding: a research fund from the Korean Ministry of Health and Welfare (03-PJI- \\
PGI-CH06-0001), and a grant from the Brain Research Center of the 21st Century \\
Frontier Research Program funded by the Ministry of Science and Technology of Korea \\
(M103KV010010 06K220101010)
\end{tabular}

Risk of bias

\begin{tabular}{|c|c|c|}
\hline Bias & Authors' judgement & Support for judgement \\
\hline Allocation concealment (selection bias) & Low risk & $\begin{array}{l}\text { Treatment allocation was based on a com- } \\
\text { puter-generated list of treatment numbers. } \\
\text { The control group used a placebo of iden- } \\
\text { tical appearance with fluoxetine }\end{array}$ \\
\hline $\begin{array}{l}\text { Blinding of outcome assessment (detection } \\
\text { bias) } \\
\text { All outcomes }\end{array}$ & Low risk & $\begin{array}{l}\text { Outcomes were self reported by partici- } \\
\text { pants who were not aware of allocation }\end{array}$ \\
\hline Intention-to-treat & Low risk & $\begin{array}{l}\text { The primary efficacy analysis was done us- } \\
\text { ing ITT analysis. In addition, on-treatment } \\
\text { analysis was performed to see the consis- } \\
\text { tency of the primary results } \\
5 \text { participants ( } 2 \text { placebo, } 3 \text { treatment) } \\
\text { dropped out before completing the } 3 \text { - } \\
\text { month treatment protocol, leaving } 78 \text { par- } \\
\text { ticipants. The reasons for the drop-out were } \\
\text { protocol violation in } 3 \text { participants and ad- } \\
\text { verse effects in } 2 \text {. The drop-out rate and } \\
\text { reasons for drop-out were not different be- } \\
\text { tween the } 2 \text { groups }\end{array}$ \\
\hline
\end{tabular}

Clarke 2012

\begin{tabular}{|c|c|}
\hline Methods & $\begin{array}{l}\text { Parallel randomised trial } \\
\text { Method of randomisation: block randomisation } \\
\text { Method of concealment: unclear } \\
\text { Blinding: single-blind (participants) } \\
\text { Analysis: available-case analysis }\end{array}$ \\
\hline Participants & $\begin{array}{l}\text { Location: New Zealand } \\
\text { Setting: stroke clinic or local community } \\
\text { Number of participants: } 19 \text { at randomisation, } 16 \text { completed study, case-available analysis } \\
\text { for } 16 \text { participants ( } 62 \% \text { male, mean age } 72 \text { years) } \\
\text { Treatment group: } 9 \text { ( } 67 \% \text { male, mean age } 69 \text { years) } \\
\text { Control group: } 7 \text { ( } 57 \% \text { male, mean age } 76 \text { years) }\end{array}$ \\
\hline
\end{tabular}

Interventions for post-stroke fatigue (Review)

Copyright @ 2015 The Cochrane Collaboration. Published by John Wiley \& Sons, Ltd. 
Clarke 2012 (Continued)

Stroke criteria: ischaemic or haemorrhagic stroke, criteria unclear

Time since stroke onset at randomisation: 3 to 18 months after stroke (mean 8 months for treatment group, 10 months for control group)

Fatigue criteria: FSS $\geq 4$

Other entry criteria: medically stable and no significant impairments

Comparability of groups: the treatment group was younger and had stroke more recently than control group. No significant difference of mean FSS scores between groups at base-

line. No significant difference at baseline in other demographics or stroke characteristics

Interventions

Treatment intervention: 6 group psychoeducation sessions (targeting alleviating fatigue) , 60 minutes weekly

Control intervention: 6 group psychoeducation sessions (general education without targeting fatigue), 60 minutes weekly

Treatment duration: 6 weeks

Delivered by: a clinical psychologist

Outcomes

Time for fatigue assessment: baseline, during the final treatment session, at 3-month follow-up

Primary outcome: change on scores of FSS

Secondary outcome: VAS-f, CIS-f

Notes

Only people with scores of FSS $\geq$ were recruited

Funding: no information available

Risk of bias

Bias

Allocation concealment (selection bias)
Authors' judgement

High risk
Support for judgement

Quote: "This was a single-blind study, the researcher knew which condition the patient had been allocated to, but the patients were not aware. As the patient is not aware of whether they are receiving the experimental condition or the control condition, there should be no placebo effect. However, the researchers could unconsciously treat the patients differently depending on the condition and thus influence the outcome of the study"

Blinding of outcome assessment (detection Low risk bias)

All outcomes

Interventions for post-stroke fatigue (Review)
Quote: "This was a single-blind study, the researcher know which condition the patient had been allocated to, but the patients were not aware."; "Any possible experimenter effects were minimised by ensuring all measures were self-report rather than researcher rated" 
Clarke 2012 (Continued)

\begin{tabular}{|c|c|c|}
\hline Intention-to-treat & High risk & $\begin{array}{l}\text { Available-case analysis: } 3 \text { participants ( } 2 \text { in } \\
\text { treatment group and } 1 \text { in control group) } \\
\text { withdrew without attending any group ses- } \\
\text { sions. They were excluded from all further } \\
\text { analyses }\end{array}$ \\
\hline
\end{tabular}

Guo 2012

Methods

Parallel randomised trial

Method of randomisation: random number table

Method of concealment: placebo-controlled, unclear whether the appearance was identical to the tested drug

Blinding: unclear

Analysis: no loss to follow-up

Participants

Location: China

Setting: inpatients

Number of participants: 90 at randomisation and all completed the study (56\% male, mean age 66 years)

Treatment group 1: 30 (63\% male, mean age 66 years)

Treatment group 2: 30 ( $50 \%$ male, mean age 66 years)

Control group: 30 (50\% male, mean age 65 years)

Stroke criteria: ischaemic, criteria unclear

Time since stroke onset at randomisation: within 6 months after stroke onset (mean 1 month for each group)

Fatigue criteria: diagnosis of fatigue according to Traditional Chinese Medicine Diagnostic Criteria

Other entry criteria: 40 to 85 years, medically stable

Comparability of groups: no significant difference in mean scores of either FSS or SSQOL

between groups at baseline

Interventions

Treatment 1 intervention: oral traditional Chinese medicine (Qi-supplementing dominated decoction (Astragalus membranaceus $60 \mathrm{~g}$, Ligusticum wallichii $15 \mathrm{~g}$, Radix paeoniae rubrathe $15 \mathrm{~g}$, Andachyranthes bidentata $15 \mathrm{~g}$ ), $100 \mathrm{~mL}$, twice per day, 4 weeks) plus intravenous traditional Chinese medicine (Radix ginseng rubra plus Radix ophiopogonis, $250 \mathrm{~mL}$, daily, 14 days), and rehabilitation therapy (60 minutes, twice a day, 4 weeks) Treatment 2 intervention: placebo oral traditional Chinese medicine (poria cocos $15 \mathrm{~g}$, rice sprout $20 \mathrm{~g}$, malt $20 \mathrm{~g}$ and liquorice $10 \mathrm{~g}, 100 \mathrm{~mL}$, twice per day, 4 weeks) plus intravenous citicoline $(500 \mathrm{mg} / 250 \mathrm{~mL}$, daily, 14 days $)$, and rehabilitation therapy (60 minutes, twice a day, 4 weeks)

Control intervention: placebo oral traditional Chinese medicine $(100 \mathrm{~mL}$, twice per day, 4 weeks) plus intravenous saline $(250 \mathrm{~mL}$, daily, 14 days), and rehabilitation therapy (60 minutes, twice a day, 4 weeks)

Treatment duration: 4 weeks

Delivered by: unclear

Interventions for post-stroke fatigue (Review) 
Guo 2012 (Continued)

\begin{tabular}{ll}
\hline Outcomes & $\begin{array}{l}\text { Time for fatigue assessment: baseline and at the end of 4-week treatment } \\
\text { Primary outcome: mean FSS score after treatment } \\
\text { Secondary outcome: mean SSQOL score after treatment } \\
\text { Measured immediately at the end of 4-week treatment }\end{array}$ \\
\hline Notes & $\begin{array}{l}\text { Only people with PSF were recruited } \\
\text { Funding: supported by the Natural Science Foundation of Guangdong Province, China } \\
\text { (Grant No. 2007B31400008) }\end{array}$ \\
\hline
\end{tabular}

Risk of bias

\begin{tabular}{l|l|l}
\hline Bias & Authors judgement & Support for judgement \\
\hline Allocation concealment (selection bias) & Unclear risk & $\begin{array}{l}\text { Unclear whether the appearance of the } \\
\text { tested drug and placebo were identical }\end{array}$ \\
\hline $\begin{array}{l}\text { Blinding of outcome assessment (detection } \\
\text { bias) } \\
\text { All outcomes }\end{array}$ & Low risk & $\begin{array}{l}\text { Outcomes were assessed by a rehabilitation } \\
\text { physician and a resident who were not in- } \\
\text { volved in the intervention }\end{array}$ \\
\hline \begin{tabular}{l} 
Intention-to-treat \\
\hline
\end{tabular} & Low risk & No loss to follow-up reported \\
\hline
\end{tabular}

Gurak 2005

\begin{tabular}{|c|c|}
\hline Methods & $\begin{array}{l}\text { Parallel randomised trial } \\
\text { Method of randomisation: simple randomisation } \\
\text { Method of concealment: unclear } \\
\text { Blinding: unclear } \\
\text { Analysis: unclear }\end{array}$ \\
\hline Participants & $\begin{array}{l}\text { Location: Russia } \\
\text { Setting: outpatient clinic } \\
\text { Number of participants: } 30 \text { at randomisation and all completed the study ( } 33 \% \text { male, } \\
\text { mean age } 51 \text { years) } \\
\text { Treatment group: } 15 \\
\text { Control group: } 15 \\
\text { Stroke criteria: ischaemic, criteria unclear } \\
\text { Time since stroke onset at randomisation: }>3 \text { months after stroke } \\
\text { Fatigue criteria: MFI- } 20 \\
\text { Other entry criteria: unclear } \\
\text { Comparability of groups: unclear }\end{array}$ \\
\hline Interventions & $\begin{array}{l}\text { Treatment intervention: enerion (a synthetic derivative of vitamin } \mathrm{B} 1,200 \mathrm{mg} \text {, twice } \\
\text { per day, } 30 \text { days) plus standard rehabilitation } \\
\text { Control intervention: standard rehabilitation } \\
\text { Treatment duration: } 30 \text { days } \\
\text { Delivered by: unclear }\end{array}$ \\
\hline
\end{tabular}




\section{Gurak 2005 (Continued)}

$\begin{array}{ll}\text { Outcomes } & \text { Time for fatigue assessment: baseline and at the end of } 30 \text {-day treatment } \\ \text { Primary outcome: MFI-20 (general fatigue, physical fatigue, low activity, low motivation } \\ \text { and mental fatigue) }\end{array}$

Notes Only people with PSF (MFI-20) were recruited

Funding: no information available

Risk of bias

\begin{tabular}{l|l|l}
\hline Bias & Authors' judgement & Support for judgement \\
\hline $\begin{array}{l}\text { Allocation concealment (selection bias) } \\
\text { High risk }\end{array}$ & $\begin{array}{l}\text { Interventions used in the 2 groups were vis- } \\
\text { ibly different, so participants and medical } \\
\text { staff would be aware of what was being used }\end{array}$ \\
\hline $\begin{array}{l}\text { Blinding of outcome assessment (detection } \\
\text { All outcomes }\end{array}$ & Unclear risk & Not enough information reported \\
\hline Intention-to-treat & Low risk & No loss to follow-up reported \\
\hline
\end{tabular}

Johansson 2012a

Methods
Cross-over design

Method of randomisation: "randomisation was done externally"

Method of concealment: "randomisation was done externally. Measures were taken to guarantee blinding." "Both the patients and all the study staff members were blinded."

"The code was broken only after all patients had terminated the study"

Blinding: double-blind

Analysis: available-case analysis
Location: Sweden

Setting: community

Number of participants: 6 at randomisation, 1 participant dropped out and 1 new participant was recruited to take his place ( $67 \%$ male, mean age 50 years)

Treatment group: 4

Control group: 2

Stroke criteria: ischaemic and haemorrhagic, criteria unclear

Time since stroke onset at randomisation: 1 to 10 years ( $m e a n=7$ years)

Fatigue criteria: MFS $\geq 10$

Other entry criteria: 1 to 10 years after stroke, 30 to 65 years old

Comparability of groups: unclear
Treatment intervention: oral monoaminergic stabiliser (-)-OSU6162 (week 1: $15 \mathrm{mg}$, twice per day; week 2: $30 \mathrm{mg}$, twice per day; weeks 3 and 4: $45 \mathrm{mg}$, twice per day. The dose was individually flexible for 4 weeks

Control intervention: oral placebo (week 1: $15 \mathrm{mg}$, twice per day; week 2: $30 \mathrm{mg}$, twice 
Johansson 2012a (Continued)

per day; weeks 3 and 4: $45 \mathrm{mg}$, twice per day. The dose was individually flexible for 4 weeks

Treatment duration: 4 weeks

Delivered by: unclear

Outcomes

Notes
Time for fatigue assessment: baseline and at the end of 4-week treatment Primary outcome: MFS

Only people with PSF (MFS $\geq 10$ ) were recruited

Only the results of the first cohort of this cross-over study were used in the current systematic review

Funding: supported by the Arvid Carlsson Foundation and the Foundation for Neuropharmacological Research and Education

\section{Risk of bias}

\begin{tabular}{lll} 
Bias & Authors' judgement & Support for judgement \\
\hline Allocation concealment (selection bias) & Low risk & $\begin{array}{l}\text { Quote: "Randomisation was done exter- } \\
\text { nally. Measures were taken to guarantee } \\
\text { blinding." "Both the patients and all the } \\
\text { study staff members were blinded." "The } \\
\text { code was broken only after all patients had } \\
\text { terminated the study" }\end{array}$
\end{tabular}

Blinding of outcome assessment (detection Low risk bias)

All outcomes
Quote: "Randomisation was done externally. Measures were taken to guarantee blinding." "Both the patients and all the study staff members were blinded." "The code was broken only after all patients had terminated the study"

Intention-to-treat High risk

Quote: "In case of dropouts, new patients were included in order to obtain six stroke subjects"

Comments: the investigators only reported the results of 6 people with stroke, which consisted of 5 recruited at baseline and 1 recruited during the study, while data for 1 participant who dropped out were not reported 
Johansson 2012b

$\begin{array}{ll}\text { Methods } & \text { Cross-over design } \\ \text { Method of randomisation: randomised stated, method unclear } \\ \text { Method of concealment: wait-list controlled, thus no concealment } \\ \text { Blinding: wait-list controlled, thus no blinding } \\ \text { Analysis: no loss to follow-up }\end{array}$

Interventions

Treatment intervention: mindfulness-based stress reduction (8 weekly group sessions, 2 . 5 hours for each session, 1 silent led retreat between session 6 and session 7, and 45 minutes home practice for 6 days a week for 8 weeks

Control intervention: wait-list

Treatment duration: 8 weeks

Delivered by: unclear

Outcomes

Time for fatigue assessment: baseline and by the end of 8 -week treatment

Primary outcome: MFS

Notes

Only people with PSF (MFS $\geq 10$ ) were recruited

Only the results of the first cohort of this cross-over study were used in the current systematic review

Funding: supported by grants from AFA Insurance and The Health \& Medical Care Committee of the Region Vastra Gotaland

\section{Risk of bias}

Bias

Allocation concealment (selection bias)

High risk

\section{Support for judgement}

Wait-list controlled, so participants and medical staff would be aware of what was being used

Not enough information reported

Blinding of outcome assessment (detection Unclear risk bias)

All outcomes 
Johansson 2012b (Continued)

\begin{tabular}{|c|c|c|}
\hline Intention-to-treat & High risk & $\begin{array}{l}\text { Available-case analysis: only reported data } \\
\text { for participants who had completed the } \\
\text { study }\end{array}$ \\
\hline
\end{tabular}

Karaiskos 2012

Methods

Method of randomisation: randomised stated, method unclear
Method of concealment: open-label
Blinding: open-label
Analysis: no loss to follow-up

Location: Greece

Setting: outpatients

Number of participants: 60 participants at randomisation and all completed the study (mean age 53 years, sex unclear)

Treatment group 1: 20 (mean age 51 years, sex unclear)

Treatment group 2: 20 (mean age 54 years, sex unclear)

Control group: 20 (mean age 52 years, sex unclear)

Stroke criteria: ischaemic and haemorrhagic, based on clinical history, physical examination and brain MRI

Time since stroke onset at randomisation: within 1 year after stroke

Fatigue criteria: participants did not have to have fatigue at recruitment

Other entry criteria: clinical diagnosis of depression, within 1 year after stroke

Comparability of groups: no significant differences between groups at baseline in demographics, stroke characteristics and fatigue scores
Interventions

Outcomes
Treatment 1 intervention: oral duloxetine, 60 to $120 \mathrm{mg} /$ day

Treatment 2 intervention: oral citalopram, 20 to $40 \mathrm{mg} /$ day

Treatment 3 intervention: oral sertraline, 50 to $200 \mathrm{mg} / \mathrm{day}$

Treatment duration: 3 months

Delivered by: unclear

Time for fatigue assessment: baseline, 1 month, 2 months and 3 months after the start of treatment

Primary outcome: Hamilton Rating Scale for Depression, Hamilton Rating Scale for Anxiety

Secondary outcome: FSS

Notes

Only people with post-stroke depression were recruited

Fatigue was measured as one of the symptoms of depression

Funding: no information available

\section{Risk of bias}

Bias

Authors' judgement

\section{Support for judgement}


Karaiskos 2012 (Continued)

\begin{tabular}{l|ll}
\hline Allocation concealment (selection bias) & High risk & $\begin{array}{l}\text { "Open-label” trial, so participants and } \\
\text { medical staff would be aware of what was } \\
\text { being used }\end{array}$ \\
\hline $\begin{array}{l}\text { Blinding of outcome assessment (detection } \\
\text { bias) } \\
\text { All outcomes }\end{array}$ & Unclear risk & Not enough information reported \\
\hline \begin{tabular}{l} 
Intention-to-treat \\
\hline
\end{tabular} & Low risk & No loss to follow-up reported \\
\hline
\end{tabular}

\section{Lorig 2001}

Methods

Parallel randomised trial

Method of randomisation: randomisation stated, methods unclear

Method of concealment: control

Blinding: control

Analysis: available-case analysis

Participants

Location: USA

Setting: community

Number of participants: 1140 participants who were over 40 years old and with heart disease, lung disease, stroke or arthritis were randomised, of whom 125 were people with stroke. 104 participants completed 6-month assessment

Treatment group: 58 (age and sex unclear)

Control group: 46 (age and sex unclear)

Stroke criteria: "completed cerebrovascular accident with neurologic handicap and normal mentation"

Time since stroke onset at randomisation: unclear

Fatigue criteria: participants did not have to have fatigue at recruitment

Other entry criteria: > 40 years old

Comparability of groups: unclear

Interventions

Treatment intervention: 7 weekly group sessions each lasting 2.5 hours in community centres where participants were taught CDSMP by peer leaders. This included teaching about exercise programmes; the use of cognitive symptom management techniques; nutritional change; fatigue and sleep management; use of community resources; use of medications; dealing with emotions of fear, anger and depression; communication with others; problem solving and decision making

Control intervention: a wait-list control, i.e. participants continued with usual care for 6 months and were then offered the CDSMP

Treatment duration: 7 weeks

Delivered by: 2 peer leaders who had received 20 hours of training taught the CDSMP, using a detailed teaching manual

Outcomes

Time for fatigue assessment: baseline and 6 months after randomisation

Primary outcome: 'health behaviours, health status, and health service utilisation', where the energy/fatigue scale from the Medical Outcomes Study was used to measure fatigue

Interventions for post-stroke fatigue (Review) 


This study was primarily aimed to improve health status, where fatigue was measured
by an energy subscale of a scale for health-related quality of life
Data for the 125 participants with stroke were provided by the investigators of the trial
Funding: the University of California Tobacco-related Disease Research Program (Grant
No. TR156) and AHCPR (Grant No. 5 RO1 HS06680)

\section{Risk of bias}

\begin{tabular}{l|l|l}
\hline Bias & Authors' judgement & Support for judgement \\
\hline Allocation concealment (selection bias) & High risk & $\begin{array}{l}\text { 'wait-list-controlled', so participants and } \\
\text { medical staff would be aware of what was } \\
\text { being used }\end{array}$ \\
\hline $\begin{array}{l}\text { Blinding of outcome assessment (detection } \\
\text { bias) } \\
\text { All outcomes }\end{array}$ & Unclear risk & Not enough information reported \\
\hline \begin{tabular}{l} 
Intention-to-treat \\
\hline
\end{tabular} & High risk & Available-case analysis \\
\hline
\end{tabular}

\section{Ogden 1998}

Methods

\begin{tabular}{ll} 
& $\begin{array}{l}\text { Method of randomisation: randomisation stated, methods unclear } \\
\text { Method of concealment: double-blind, the code was broken after the outcome assessment } \\
\text { Blinding: double-blind, the code was broken after the outcome assessment } \\
\text { Analysis: available-case analysis }\end{array}$ \\
\hline Participants & $\begin{array}{l}\text { Location: New Zealand } \\
\text { Setting: inpatients }\end{array}$ \\
Number of participants: 31 women with SAH were randomised, 21 were eligible for 3- \\
month follow-up assessment of whom 18 completed this assessment (mean age 47 years) \\
Treatment group: 9 (mean age 45 years) \\
Control group: 9 (mean age 50 years) \\
Stroke criteria: SAH \\
Time since stroke onset at randomisation: at admission for SAH \\
Fatigue criteria: participants did not have to have fatigue at recruitment \\
Other entry criteria: unclear \\
Comparability of groups: unclear
\end{tabular}

Treatment intervention: tirilazad mesylate $100 \mathrm{~mL}(1.5 \mathrm{mg} / \mathrm{mL})$ for 10 consecutive days after onset of SAH, unknown delivery route

Control intervention: vehicle (sterile solution) $100 \mathrm{~mL}$ for 10 consecutive days after onset of SAH, unknown delivery route

Treatment duration: 10 days

Delivered by: unclear 


\section{Ogden 1998 (Continued)}

\begin{tabular}{|c|c|c|}
\hline Outcomes & \multicolumn{2}{|c|}{$\begin{array}{l}\text { Time for fatigue assessment: } 3 \text { months after randomisation } \\
\text { Primary outcome: Glasgow Outcome Scale } \\
\text { Secondary outcome: self-reported experience of debilitating fatigue by participants }\end{array}$} \\
\hline Notes & \multicolumn{2}{|c|}{$\begin{array}{l}\text { People did not have to have fatigue to be recruited } \\
\text { Fatigue was assessed as one of the neuropsychological symptoms in a subgroup of } 18 \\
\text { participants from the } 31 \text { participants recruited } \\
\text { Funding: the Health Research Council of New Zealand (Grant 95/291) }\end{array}$} \\
\hline \multicolumn{3}{|l|}{ Risk of bias } \\
\hline Bias & Authors' judgement & Support for judgement \\
\hline Allocation concealment (selection bias) & Low risk & $\begin{array}{l}\text { Quote: "double blind protocol." "The drug } \\
\text { code was broken after all assessments had } \\
\text { been scored" }\end{array}$ \\
\hline $\begin{array}{l}\text { Blinding of outcome assessment (detection } \\
\text { bias) } \\
\text { All outcomes }\end{array}$ & Low risk & $\begin{array}{l}\text { Quote: "double blind protocol." "The drug } \\
\text { code was broken after all assessments had } \\
\text { been scored" }\end{array}$ \\
\hline Intention-to-treat & High risk & Available-case analysis \\
\hline
\end{tabular}

\section{Zedlitz 2012}

Methods

Parallel randomised trial

Method of randomisation: block randomisation per treatment centre

Method of concealment: interventions used in the 2 groups were visibly different, so participants and medical staff would be aware of what was being used

Blinding: 'assessor-blind'

Analysis: ITT

Lacation: Netherlands
Setting: community-dwelling, recruited from rehabilitation centres
Number of participants: 83 participants at randomisation, 73 completed treatment, 68
completed follow-up. ITT analysis for 83 participants $(52 \%$ male, mean age 55 years)
Treatment 1 group: 38 (55\% male, mean age 55 years)
Treatment 2 group: 45 (49\% male, mean age 55 years)
Stroke criteria: ischaemic stroke, haemorrhagic stroke or SAH, criteria unclear
Time since stroke onset at randomisation: $>4$ months after stroke, mean 3.9 years
Fatigue criteria: CIS-fatigue $\geq 40$
Other entry criteria: more than 4 months after stroke, 18 to 70 years old, no cardiopul-
monary complications or psychiatric disorders
Comparability of groups: unclear

Interventions

Treatment 1 intervention (CO): group cognitive therapy (emphasising pacing and relaxation), 2 hours each session, once a week, for 12 weeks

Treatment 2 intervention (COGRAT): CO plus physical training (walking on treadmill, 
strength training and homework assignment, 2 hours each session, twice a week, for 12 weeks)

Treatment duration: 12 weeks

Delivered by: CO was delivered by neuro-psychologists and GRAT was delivered by physiotherapists

Outcomes

Time for fatigue assessment: baseline, by the end of 12 -week treatment, and at 3-month follow-up

Primary outcome: CIS-f

Secondary outcomes: self observation list (for fatigue, pain and sleep), Hamilton Anxiety and Depression Scale (for depression and anxiety), Stroke-adapted Sickness Impact Profile-30, 6-minute walk test

Notes

Only people with severe fatigue (CIS- $\mathrm{f} \geq 40$ ) and $>4$ months after stroke were recruited Mainly focused on the change of scores before and after treatment within a group rather than comparing between groups

Funding: a grant from the Dutch Health Research and Development (ZonMw) (Grant No. 14350053)

\section{Risk of bias}

\begin{tabular}{|c|c|c|}
\hline Bias & Authors' judgement & Support for judgement \\
\hline Allocation concealment (selection bias) & High risk & $\begin{array}{l}\text { Interventions used in the } 2 \text { groups were vis- } \\
\text { ibly different, so participants and medical } \\
\text { staff would be aware of what was being used }\end{array}$ \\
\hline $\begin{array}{l}\text { Blinding of outcome assessment (detection } \\
\text { bias) } \\
\text { All outcomes }\end{array}$ & Low risk & Quote: “assessor-blind” \\
\hline Intention-to-treat & Low risk & $\begin{array}{l}\text { Quote: "All further analyses were per- } \\
\text { formed on an intention-to-treat basis. Any } \\
\text { missing values after treatment were im- } \\
\text { puted by carrying the last observation for- } \\
\text { ward, adhering a conservative assumption } \\
\text { with respect to treatment effects" }\end{array}$ \\
\hline
\end{tabular}

Zhou 2010

Methods

Parallel design

Method of randomisation: randomisation stated, methods unclear

Method of concealment: interventions used in the 2 groups were visibly different, so participants and medical staff would be aware of what was being used

Blinding: unclear

Analysis: no loss to follow-up 
Zhou 2010 (Continued)

\begin{tabular}{|c|c|c|}
\hline Participants & \multicolumn{2}{|c|}{$\begin{array}{l}\text { Location: China } \\
\text { Setting: both inpatients and outpatients } \\
\text { Number of participants: } 128 \text { participants at randomisation and all completed the study } \\
\text { ( } 59 \% \text { male, mean age } 57 \text { years) } \\
\text { Treatment } 1 \text { group (electroacupuncture plus cupping): } 64 \text { ( } 56 \% \text { male, mean age } 58 \\
\text { years) } \\
\text { Treatment } 2 \text { group (medication): } 64 \text { ( } 62 \% \text { male. mean age } 56 \text { years) } \\
\text { Stroke criteria: ischaemic stroke, criteria unclear } \\
\text { Time since stroke onset at randomisation: within } 3 \text { years after stroke, mean } 6 \text { months } \\
\text { Fatigue criteria: SSQOL-energy < } 12 \\
\text { Other entry criteria: within } 3 \text { years after stroke, }<70 \text { years old } \\
\text { Comparability of groups: unclear }\end{array}$} \\
\hline Interventions & \multicolumn{2}{|c|}{$\begin{array}{l}\text { Treatment } 1 \text { intervention (electroacupuncture plus cupping): electroacupuncture for } 30 \\
\text { minutes daily, } 10 \text { days as } 1 \text { cycle, for } 3 \text { cycles with 2-day intervals between cycles, plus } \\
\text { cupping at back for } 10 \text { minutes, once every } 2 \text { days, for } 5 \text { weeks } \\
\text { Treatment } 2 \text { intervention (medication): oral sertraline ( } 50 \mathrm{mg} \text {, daily, for } 5 \text { weeks), plus } \\
\text { oral compound aminobutyric acid and vitamin E capsules ( } 2 \text { capsules, } 3 \text { times per day, } \\
\text { for } 5 \text { weeks) and oral magnesium gluconate solution ( } 1000 \mathrm{mg} / 10 \mathrm{~mL} \text {, containing } \\
\text { magnesium } 58.6 \mathrm{mg}, 3 \text { times per day, for } 5 \text { weeks) } \\
\text { Treatment duration: } 5 \text { weeks } \\
\text { Delivered by: rehabilitation therapists or physicians }\end{array}$} \\
\hline Outcomes & \multicolumn{2}{|c|}{$\begin{array}{l}\text { Time for fatigue assessment: baseline, at the end of 5-week treatment, at 2-month follow- } \\
\text { up } \\
\text { Primary outcome: SSQOL-energy at the end of treatment } \\
\text { Secondary outcome: SSQOL-energy at 2-month follow-up }\end{array}$} \\
\hline Notes & \multicolumn{2}{|c|}{$\begin{array}{l}\text { Only people with severe fatigue (SSQOL-energy subscale }<12 \text { ) were recruited } \\
\text { Funding: no information available }\end{array}$} \\
\hline \multicolumn{3}{|l|}{ Risk of bias } \\
\hline Bias & Authors' judgement & Support for judgement \\
\hline Allocation concealment (selection bias) & High risk & $\begin{array}{l}\text { Interventions used in the } 2 \text { groups were vis- } \\
\text { ibly different, so participants and medical } \\
\text { staff would be aware of what was being used }\end{array}$ \\
\hline $\begin{array}{l}\text { Blinding of outcome assessment (detection } \\
\text { bias) } \\
\text { All outcomes }\end{array}$ & Unclear risk & Not enough information reported \\
\hline Intention-to-treat & Low risk & No loss to follow-up reported \\
\hline
\end{tabular}

CDSMP: Chronic Disease Self-Management Programme

CIS-f: Checklist Individual Strength-fatigue subscale

Interventions for post-stroke fatigue (Review)

Copyright $\odot 2015$ The Cochrane Collaboration. Published by John Wiley \& Sons, Ltd. 
CPAP: continuous positive airway pressure

FSS: Fatigue Severity Scale

ITT: intention-to-treat

IQR: interquartile range

MFI-20: Multidimensional Fatigue Inventory-20

MFS: Mental Fatigue Scale

MRI: magnetic resonance imaging

PSF: post stroke fatigue

SAH: subarachnoid haemorrhage

SD: standard deviation

SF-36-vitality: Short Form-36 vitality subscale

SSQOL-energy: Stroke-specific Quality of Life-energy subscale

TIA: transient ischaemic attack

VAS-f: Visual Analogue Scale-fatigue

Characteristics of excluded studies [ordered by study ID]

\begin{tabular}{|c|c|}
\hline Study & Reason for exclusion \\
\hline Allison 2007 & Fatigue was not an outcome of the study \\
\hline Brioschi 2009 & $\begin{array}{l}\text { Compared the effects of modafinil on subjective fatigue between participants with multiple sclerosis and partic- } \\
\text { ipants with stroke. No control group for people with stroke }\end{array}$ \\
\hline Cruz 2013 & $\begin{array}{l}\text { Not specifically targeted fatigue: fatigue was assessed at the end of each hand-to-mouth task as a measure for the } \\
\text { tolerance of this intervention }\end{array}$ \\
\hline Feys 2013 & The study was a single-arm trial and did not specifically target fatigue \\
\hline Kim 2012 & $\begin{array}{l}\text { Not a controlled trial: compared the results of participants from treatment group with those from a group of } \\
\text { non-synchronised, non-equivalent inpatients in the ward }\end{array}$ \\
\hline Kirkevold 2012 & The study was a single-arm trial that tested an intervention for post-stroke fatigue \\
\hline Lin 2013 & $\begin{array}{l}\text { The study did not specifically target at fatigue: post-intervention exertional fatigue was assessed as a measure for } \\
\text { the tolerance of the intervention }\end{array}$ \\
\hline Robinson 2003 & Reported a mixed population of participants and the data for people with stroke could not be obtained \\
\hline Sianni 2008 & The study did not use randomised allocation \\
\hline Underwood 2006 & $\begin{array}{l}\text { The study did not specifically target at fatigue: fatigue was assessed during the intervention as a measure for the } \\
\text { tolerance of the intervention }\end{array}$ \\
\hline Wu 2014b & The study is a single-arm trial that tested an intervention for post-stroke fatigue \\
\hline
\end{tabular}




\section{Characteristics of ongoing studies [ordered by study ID]}

\section{AFFINITY 2013}

Trial name or title An Australian-led, investigator-initiated, multi-centre, prospective, randomised, parallel group, double-blind, placebo-controlled trial to establish the effect(s) of routine administration of fluoxetine (20 $\mathrm{mg}$ once daily) in patients with recent stroke

\begin{tabular}{|c|c|}
\hline Methods & RCT \\
\hline Participants & Target number of participants: 1600 people with stroke who are 2 to 15 days after stroke onset \\
\hline Interventions & Fluoxetine $20 \mathrm{mg}$, daily, or matching placebo capsule, for 6 months \\
\hline Outcomes & $\begin{array}{l}\text { Primary outcome } \\
\text { Functional ability } 180 \text { days after randomisation measured by the modified Rankin Scale (mRS) using the } \\
\text { simplified modified Rankin Scale questionnaire (smRSq). Secondary outcomes at 180- and 365-day assess- } \\
\text { ments: } \\
\text { - improves participants': survival, mood (Patient Health Questionnaire-9 item (PHQ-9)), cognitive } \\
\text { function (Telephone Interview of Cognitive Status (TICSm)), communication (Stroke Impact Scale (SIS)); } \\
\text { motor function (SIS); overall health status (SIS); Health-Related Quality of Life (HRQoL) (EuroQoL (EQ- } \\
\text { 5D-5L)) and functional ability (smRSq) at the } 365 \text { day assessment } \\
\text { - reduces: new diagnosis of depression requiring treatment with antidepressants; fatigue (vitality domain } \\
\text { of the Short Form } 36 \text { item, SF-36) } \\
\text { - has risks of serious adverse events that offset its benefits } \\
\text { - reduces the cost of health care over the first year and } \\
\text { - is cost-effective }\end{array}$ \\
\hline Starting date & 2013 \\
\hline
\end{tabular}

Contact information Associate Professor Maree Hackett, The George Institute for Global Health, The University of Sydney. Tel. +61 299934593 Email: mhackett@georgeinstitute.org.au

Professor Graeme Hankey, Royal Perth Hospital and The University of Western Australia

\section{Chuang 2013}

\begin{tabular}{ll} 
Trial name or title & A study of post-stroke pain and fatigue: clinical evaluation and treatment effect (NCT01913509) \\
\hline Methods & Randomised, parallel-controlled, single-blind (participants) trial \\
\hline Participants & $\begin{array}{l}\text { Target number of participants: } 160 \text { participants who are }>6 \text { months after a first-ever stroke, with self reported } \\
\text { hemiplegic shoulder pain and post-stroke fatigue in the past } 7 \text { days }\end{array}$ \\
\hline Interventions & $\begin{array}{l}\text { For people with ambulatory ability: } \\
\text { Experimental intervention } 1: \text { combined therapy of functional electrical stimulation (FES) and graded treadmill } \\
\text { training (GTT), } 1 \text { daily, } 3 \text { days per week, for } 4 \text { weeks } \\
\text { Control } 1: \text { conventional rehabilitation }(\mathrm{CR}) 1,1 \text { hour daily, } 3 \text { days per week, for } 4 \text { weeks } \\
\text { For people with non-ambulatory ability: }\end{array}$
\end{tabular}


Experimental intervention 2: combined therapy of FES and body weight supported treadmill training (BWSTT), 1 hour daily, 3 days per week, for 4 weeks

Control 2: conventional rehabilitation 2, 1 hour daily, 3 days per week, for 4 weeks

Outcomes Numerical Rating Scale with Face Rating Scale (NRS-FRS) for pain and fatigue

Brief Pain Inventory and Brief Fatigue Inventory

\begin{tabular}{l|l}
\hline Starting date & August 2013 \\
\hline Contact information & $\begin{array}{l}\text { Li-Ling Chuang, Chang Gung Memorial Hospital, Tao-Yuan, Taiwan } \\
\text { Tel. 886-3-2118800 ext 3177 } \\
\text { Email: lchuang@mail.cgu.edu.tw }\end{array}$ \\
\hline Notes & $\begin{array}{l}\text { This 3-year project will recruit } 160 \text { participants with chronic stroke and will be implemented in } 4 \text { stages: } \\
\text { - 1st stage: a test-retest study to investigate the reliability and validity of outcome measures of post- } \\
\text { stroke pain and fatigue in } 80 \text { participants } \\
\text { ambulatory participants } \\
\text { - 3rd stage: an RCT to investigate the effects of FES-BWSTT versus CR on pain and fatigue in } 40 \\
\text { ambulatory participants } \\
\text { - 4th stage: a study to determine psychometric properties of the outcome measures } \\
\text { The study is expected to end in July } 2016\end{array}$
\end{tabular}

\section{EFFECTS 2014}

Trial name or title Efficacy oF Fluoxetine - a randomisEd Controlled Trials in Stroke

\begin{tabular}{l|l}
\hline Methods & RCT \\
\hline Participants & Target number of participants: 1500 people with stroke who are 2 to 15 days after stroke onset \\
\hline Interventions & Fluoxetine 20 mg, daily, or matching placebo capsule, for 6 months \\
\hline Outcomes & $\begin{array}{l}\text { The primary outcome measure is the proportion of independent survivors defined as modified Rankin Scale } \\
\text { (mRS) } 0 \text { to } 2 \text { at } 6 \text { months } \\
\text { Secondary outcomes } \\
\text { - Survival at } 6 \text { and } 12 \text { months } \\
\text { - Effect of daily life as measured by the Stroke Impact Scale } \\
\text { - Quality of life as measured by the scale EQ-5D-5L } \\
\text { - Influence of fatigue measured with the vitality subscale of 36-item Short Form } \\
\text { - The presence of the depression measured by Montgomery-Åsberg Depression Rating Scale (MADRS) } \\
\text { - Cognition, effects on memory and concentration measured by Montreal Cognitive Assessment } \\
\text { (MoCA) } \\
\text { - Neurological status including the presence of the effect on muscle strength or power of speech as } \\
\text { measured by the NIH Stroke Scale (NIHSS) }\end{array}$ \\
\hline $\begin{array}{l}\text { 2014 } \\
\text { Starting date }\end{array}$
\end{tabular}


EFFECTS 2014 (Continued)

Contact information Dr. Erik Lundström, Department of Neurology, Karolinska University Hospital, Solna, 17175 Stockholm E-mail: erik.lundstrom@ki.se

Notes

FOCUS 2012

\begin{tabular}{|c|c|}
\hline Trial name or title & Fluoxetine or control under supervision (FOCUS) trial (ISRCTN83290762) \\
\hline Methods & RCT \\
\hline Participants & Target number of participants: 3000 people with stroke who are 2 and 15 days after stroke onset \\
\hline Interventions & Fluoxetine $20 \mathrm{mg}$, daily, or matching placebo capsule, for 6 months \\
\hline Outcomes & $\begin{array}{l}\text { Measured at } 6 \text { and } 12 \text { months after the start of treatment } \\
\text { Primary outcome: modified Rankin Scale at } 6 \text { months } \\
\text { Secondary outcomes: } \\
\text { - death from all causes at } 6 \text { and } 12 \text { months } \\
\text { - modified Rankin Scale at } 12 \text { months } \\
\text { - Stroke Impact Scale } \\
\text { - EuroQoL (EQ-5D-5L) } \\
\text { - Mental Health Inventory } 5 \\
\text { - Vitality subscale of } 36 \text {-item Short Form (as an assessment of fatigue) } \\
\text { - diagnosis of depression } \\
\text { - other adverse events } \\
\text { - adherence to the trial medication } \\
\text { - health and social care resources used during follow-up }\end{array}$ \\
\hline Starting date & July 2012 \\
\hline Contact information & $\begin{array}{l}\text { Gillian Mead, Department of Geriatric Medicine, Royal Infirmary of Edinburgh, } 51 \text { Little France Crescent, } \\
\text { EH16 4SA } \\
\text { Email: gillian.e.mead@ed.ac.uk }\end{array}$ \\
\hline Notes & $\begin{array}{l}\text { Fatigue is one the secondary outcomes } \\
\text { The study is expected to end in October } 2017\end{array}$ \\
\hline
\end{tabular}

Liu 2012

Trial name or title Randomised, double blind, placebo control trial to evaluate the efficacy of Astragalus membranaceus in the patients after stroke with fatigue (NCT01554787)

Methods Randomised, double-blind, placebo-controlled trial

Participants Target number of participants: 90 participants who are 3 months after stroke and with a fatigue score $\geq 4$ (fatigue scale not specified), aged 40 to 80 years old 
Liu 2012 (Continued)

\begin{tabular}{ll}
\hline Interventions & Astragalus membranaceus (Chinese herb) versus placebo \\
\hline Outcomes & $\begin{array}{l}\text { Measured at 2-year follow-up } \\
\text { Primary outcomes: EORTC QLQ-C30 and BFI-T } \\
\text { Secondary outcome: 36-item Short Form }\end{array}$ \\
\hline Starting date & January 2012 \\
\hline Contact information & $\begin{array}{l}\text { Chung-Hsiang Liu, China Medical University Hospital, Taichung, Taiwan. Tel. 886-4-22052121 ext 7635 } \\
\text { Email: greengen@gmail.com }\end{array}$ \\
\hline Notes & $\begin{array}{l}\text { The estimated completion date of the study is December 2013. However, by November 2014, we identified no } \\
\text { relevant publication for this study. We contacted the investigator via email to request for further information } \\
\text { in November 2014 but received no reply prior to publication of this review }\end{array}$ \\
\hline
\end{tabular}

\section{MacKay-Lyons 2012}

Trial name or title Combined effects of aerobic exercise and cognitive training on cognition after stroke (NCT01674790)

\begin{tabular}{|c|c|}
\hline Methods & RCT \\
\hline Participants & Target number of participants: 20 participants who are $>6$ months after stroke \\
\hline Interventions & $\begin{array}{l}\text { Aerobic group: aerobic training (body weight support treadmill training at moderate to high intensity, i.e. } 60 \\
\text { to } 70 \% \text { heart rate reserve, } 20 \text { minutes/day, } 5 \text { days/week, for } 6 \text { weeks) + motion exercise (non-aerobic passive } \\
\text { and active movement of upper and lower extremity, } 20 \text { minutes/day, } 5 \text { days/week, for } 6 \text { weeks) } \\
\text { Cognitive group: cognitive training (computerised dual N-back training programme, } 20 \text { minutes/day, } 5 \\
\text { days/week, for } 6 \text { weeks) plus motion exercise (non-aerobic passive and active movement of upper and lower } \\
\text { extremity, } 20 \text { minutes/day, } 5 \text { days/week, for } 6 \text { weeks) } \\
\text { Aerobic plus cognitive group: aerobic training (body weight support treadmill training at moderate to high } \\
\text { intensity, i.e. } 60 \text { to } 70 \% \text { heart rate reserve, } 20 \text { minutes/day, } 5 \text { days/week, for } 6 \text { weeks) plus cognitive training } \\
\text { (computerised dual N-back training programme that involves a working memory task, } 20 \text { minutes/day, } 5 \\
\text { days/week, for } 6 \text { weeks) } \\
\text { Control group: motion exercise (non-aerobic passive and active movement of upper and lower extremity, } 20 \\
\text { minutes/day, } 5 \text { days/week, for } 6 \text { weeks) plus unstructured mental activity (e.g. listening to light novels on } \\
\text { tape, } 20 \text { minutes/day, } 5 \text { days/week, for } 6 \text { weeks) }\end{array}$ \\
\hline
\end{tabular}

Outcomes

Measured at 10 weeks after the start of treatment

Primary outcomes: tests for cognition (Flanker test, Raven's matrices test and Sternberg digit memory task)

Secondary outcomes

- peak oxygen consumption

- Fatigue Severity Scale-9

- Cognitive Failures Questionnaire

- Montreal Cognitive Assessment

- Expression of brain-derived neurotrophic factor and insulin-like growth factor-1 in peripheral blood samples 
MacKay-Lyons 2012 (Continued)

\begin{tabular}{ll}
\hline Starting date & September 2012 \\
\hline Contact information & $\begin{array}{l}\text { Marilyn MacKay-Lyons, Affiliated Scientist, Capital District Health Authority, Canada } \\
\text { Contact: Megan J Freeman } \\
\text { Email: mfreema7@gmail.com }\end{array}$ \\
\hline Notes & The study is expected to end in June 2015 \\
\hline
\end{tabular}

\section{Michael 2008}

Trial name or title Testing adaptive physical activity in stroke (TAPAS) (NCT01042990)

\begin{tabular}{ll}
\hline Methods & RCT \\
\hline Participants & $\begin{array}{l}\text { Target number of participants: } 54 \text { participants who are }>6 \text { months after an ischaemic stroke or who were }> \\
1 \text { year after a haemorrhagic stroke }\end{array}$
\end{tabular}

Interventions $\quad$ Adaptive physical activity: a structured gait, balance and progressive walking programme in a group gym setting, 3 times/week, for 6 months

Adaptive physical activity plus treadmill: a structured gait and balance programme in a group gym setting plus progressive treadmill walking, 3 times/week, for 6 months

Control: education and instruction on a home exercise programme that participants do on their own

Outcomes $\quad$ Measured at 3 and 6 months after the start of treatment and at 3 months post-treatment

Primary outcomes (for physical fitness): $\mathrm{VO}_{2}$ peak, Berg Balance Scale, Dynamic Gait Index, Step Activity

Monitoring, 6-minute walks

Secondary outcomes: psychosocial questionnaires that includes fatigue as a self reported outcome measure

Starting date September 2008

Contact information Kathleen Michael, Baltimore VA Medical Center, University of Maryland, Baltimore, USA, 21201

Email:kmichael@grecc.umaryland.edu

Notes

The estimated completion date of the study is September 2011. However, by November 2014, we identified no relevant publication for this study. We contacted the investigator via email to request for further information in November 2014 but received no reply prior to publication of this review

\section{Overgaard 2012}

Trial name or title Treatment of post stroke fatigue with a wakefulness promoting agent (NCT01800097)

\begin{tabular}{ll}
\hline Methods & Randomised, placebo-controlled, double-blind trial for an intervention for post-stroke fatigue \\
\hline Participants & $\begin{array}{l}\text { Target number of participants: } 128 \text { participants who have stroke within } 14 \text { days and had a score of Multidi- } \\
\text { mensional Fatigue Inventory-20 (MFI-20) of } \geq 12\end{array}$
\end{tabular}




\section{Overgaard 2012 (Continued)}

\begin{tabular}{ll}
\hline Interventions & $\begin{array}{l}\text { Modafinil: tablet } 400 \mathrm{mg} \text { (200 mg if } \geq 65 \text { years), daily (morning dose), for } 3 \text { months } \\
\text { Placebo: tablet } 400 \mathrm{mg}(200 \mathrm{mg} \text { if } \geq 65 \text { years), daily (morning dose), for } 3 \text { months }\end{array}$ \\
\hline Outcomes & $\begin{array}{l}\text { Primary outcome: MFI-20 at } 3 \text { months } \\
\text { Secondary outcomes: MFI-20 at } 1 \text { and } 6 \text { months, Fatigue Severity Scale at } 1,3 \text { and } 6 \text { months }\end{array}$ \\
\hline Starting date & October 2012 \\
\hline Contact information & $\begin{array}{l}\text { Karsten Overgaard, Herlev Hospital, Herlev, Denmark, 2730 } \\
\text { Email: karsten.overgaard@regionh.dk }\end{array}$ \\
\hline Notes & The study is expected to end in August 2015 \\
\hline
\end{tabular}

Vanroy 2010

Trial name or title The effect of an aerobic exercise programme in stroke patients (NCT01070459)

\begin{tabular}{ll}
\hline Methods & Randomised, controlled, double-blind trial \\
\hline Participants & $\begin{array}{l}\text { Target number of participants: } 50 \text { participants with first-ever stroke (ischaemic or haemorrhagic) and within } \\
6 \text { weeks after onset }\end{array}$ \\
\hline Interventions & $\begin{array}{l}\text { Aerobic exercise group: aerobic training using a leg cycle bike, } 30 \text { minutes/session, } 3 \text { sessions/week, for } 12 \\
\text { weeks; within the } 12 \text { weeks, } 4 \text { information sessions will be offered about risk factors of stroke, usefulness of } \\
\text { an active lifestyle and healthy eating. After the } 12 \text { weeks, half of the participants will be assigned to a group } \\
\text { that will get feedback on how to train their aerobic capacity within the following } 9 \text { months, while the other } \\
\text { half of the participants will not receive this feedback } \\
\text { Control group: passive mobilisation of the hemiplegic knee using a continuous passive motion device, } 30 \\
\text { minutes/session, } 3 \text { sessions/week, for } 12 \text { weeks. After the } 12 \text { weeks, the participants will not receive any other } \\
\text { intervention }\end{array}$ \\
\hline
\end{tabular}

Outcomes $\quad$ Primary outcomes (for physical fitness): $\mathrm{VO}_{2}$ peak, strength, walking, activities of daily living (at baseline, after 12 weeks' training, 6 months, 1 year and 2 years after baseline) Secondary outcomes

- post-stroke fatigue (by Checklist Individual Strength-20)

- depression

- lifestyle

- cardiovascular risk factors

Starting date $\quad$ February 2010

Contact information Christel Vanroy, Revalidatiewetenschappen en Kinesitherapie, Campus Drie Eiken - Lokaal S.022, Universiteitsplein 1- 2610 Wilrijk, Belgium

Email: christel.vanroy@uantwerpen.be

Notes

We contacted the investigator via email in November 2014. The investigator replied stating that "Study will be finished in December 2014. I am currently working on those papers. Output will be expected in 2015 and following" 
RCT: randomised controlled trial

Copyright $\odot 2015$ The Cochrane Collaboration. Published by John Wiley \& Sons, Ltd. 
DATA ANDANALYSES

Comparison 1. Trials primarily intended to treat fatigue (intervention versus control)

\begin{tabular}{|c|c|c|c|c|}
\hline Outcome or subgroup title & $\begin{array}{l}\text { No. of } \\
\text { studies }\end{array}$ & $\begin{array}{c}\text { No. of } \\
\text { participants }\end{array}$ & Statistical method & Effect size \\
\hline $\begin{array}{l}1 \text { Continuous outcomes (subgroup } \\
\text { analysis) }\end{array}$ & 6 & 244 & Std. Mean Difference (IV, Random, 95\% CI) & $-1.07[-1.93,-0.21]$ \\
\hline $\begin{array}{l}1.1 \text { Pharmacological } \\
\text { interventions }\end{array}$ & 4 & 209 & Std. Mean Difference (IV, Random, 95\% CI) & $-1.23[-2.40,-0.06]$ \\
\hline $\begin{array}{l}1.2 \text { Non-pharmacological } \\
\text { interventions }\end{array}$ & 2 & 35 & Std. Mean Difference (IV, Random, 95\% CI) & $-0.68[-1.37,0.02]$ \\
\hline $\begin{array}{l}2 \text { Continuous outcomes } \\
\text { (sensitivity analysis) }\end{array}$ & 6 & & Std. Mean Difference (IV, Random, 95\% CI) & Subtotals only \\
\hline $\begin{array}{l}2.1 \text { Trials with adequate } \\
\text { allocation concealment }\end{array}$ & 2 & 89 & Std. Mean Difference (IV, Random, 95\% CI) & $-0.38[-0.80,0.04]$ \\
\hline $\begin{array}{l}2.2 \text { Trials with adequate } \\
\text { blinding of outcome assessors }\end{array}$ & 4 & 198 & Std. Mean Difference (IV, Random, 95\% CI) & $-1.10[-2.31,0.11]$ \\
\hline $\begin{array}{l}2.3 \text { Trials using } \\
\text { intention-to-treat analysis }\end{array}$ & 3 & 203 & Std. Mean Difference (IV, Random, 95\% CI) & $-1.41[-2.73,-0.09]$ \\
\hline $\begin{array}{l}2.4 \text { Trials with no difference of } \\
\text { baseline fatigue scores between } \\
\text { groups }\end{array}$ & 5 & 161 & Std. Mean Difference (IV, Random, 95\% CI) & $-1.22[-2.34,-0.09]$ \\
\hline 2.5 Excluding the outlier & 6 & 199 & Std. Mean Difference (IV, Random, 95\% CI) & $-0.49[-0.78,-0.20]$ \\
\hline 3 Dichotomous outcomes & 1 & 83 & Risk Ratio (IV, Random, 95\% CI) & $0.89[0.75,1.05]$ \\
\hline
\end{tabular}

\section{Comparison 3. Trials not primarily intended at post-stroke fatigue (individual results)}

\begin{tabular}{|c|c|c|c|c|}
\hline Outcome or subgroup title & $\begin{array}{l}\text { No. of } \\
\text { studies }\end{array}$ & $\begin{array}{c}\text { No. of } \\
\text { participants }\end{array}$ & Statistical method & Effect size \\
\hline $\begin{array}{l}1 \text { Brown } 2011 \text { (CPAP versus } \\
\text { sham, continuous outcome) }\end{array}$ & 1 & 32 & Mean Difference (IV, Random, 95\% CI) & $0.45[-0.59,1.49]$ \\
\hline $\begin{array}{l}2 \text { Lorig } 2001 \text { (CDSMP versus } \\
\text { wait-list, continuous outcome) }\end{array}$ & 1 & 125 & Mean Difference (IV, Random, 95\% CI) & $-0.16[-0.44,0.12]$ \\
\hline $\begin{array}{l}3 \text { Ogden } 1998 \text { (tirilazad versus } \\
\text { vehicle, dichotomous outcome) }\end{array}$ & 1 & 31 & Risk Ratio (IV, Random, 95\% CI) & $0.42[0.16,1.07]$ \\
\hline $\begin{array}{l}4 \text { Karaiskos } 2012 \text { (duloxetine } \\
\text { versus citalopram, continuous } \\
\text { outcome }\end{array}$ & 1 & 40 & Mean Difference (IV, Random, 95\% CI) & $-0.20[-0.95,0.55]$ \\
\hline $\begin{array}{l}5 \text { Karaiskos } 2012 \text { (duloxetine } \\
\text { versus sertraline, continuous } \\
\text { outcome }\end{array}$ & 1 & 40 & Mean Difference (IV, Random, 95\% CI) & $-0.30[-1.08,0.48]$ \\
\hline
\end{tabular}

Interventions for post-stroke fatigue (Review)

Copyright $\odot 2015$ The Cochrane Collaboration. Published by John Wiley \& Sons, Ltd. 


\section{Analysis I.I. Comparison I Trials primarily intended to treat fatigue (intervention versus control), Outcome I Continuous outcomes (subgroup analysis).}

Review: Interventions for post-stroke fatigue

Comparison: I Trials primarily intended to treat fatigue (intervention versus control)

Outcome: I Continuous outcomes (subgroup analysis)

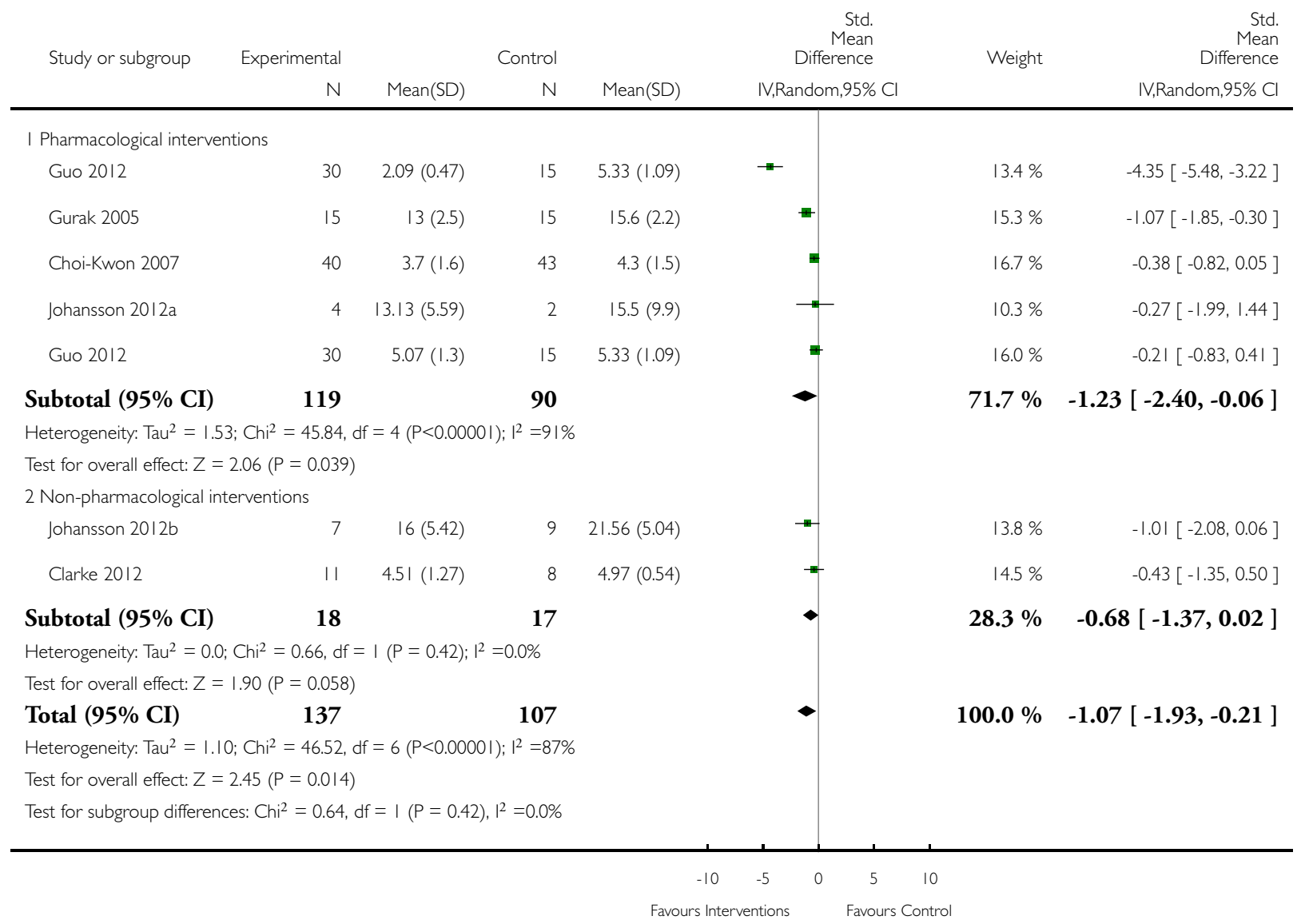




\section{Analysis I.2. Comparison I Trials primarily intended to treat fatigue (intervention versus control), Outcome 2 Continuous outcomes (sensitivity analysis).}

Review: Interventions for post-stroke fatigue

Comparison: I Trials primarily intended to treat fatigue (intervention versus control)

Outcome: 2 Continuous outcomes (sensitivity analysis)

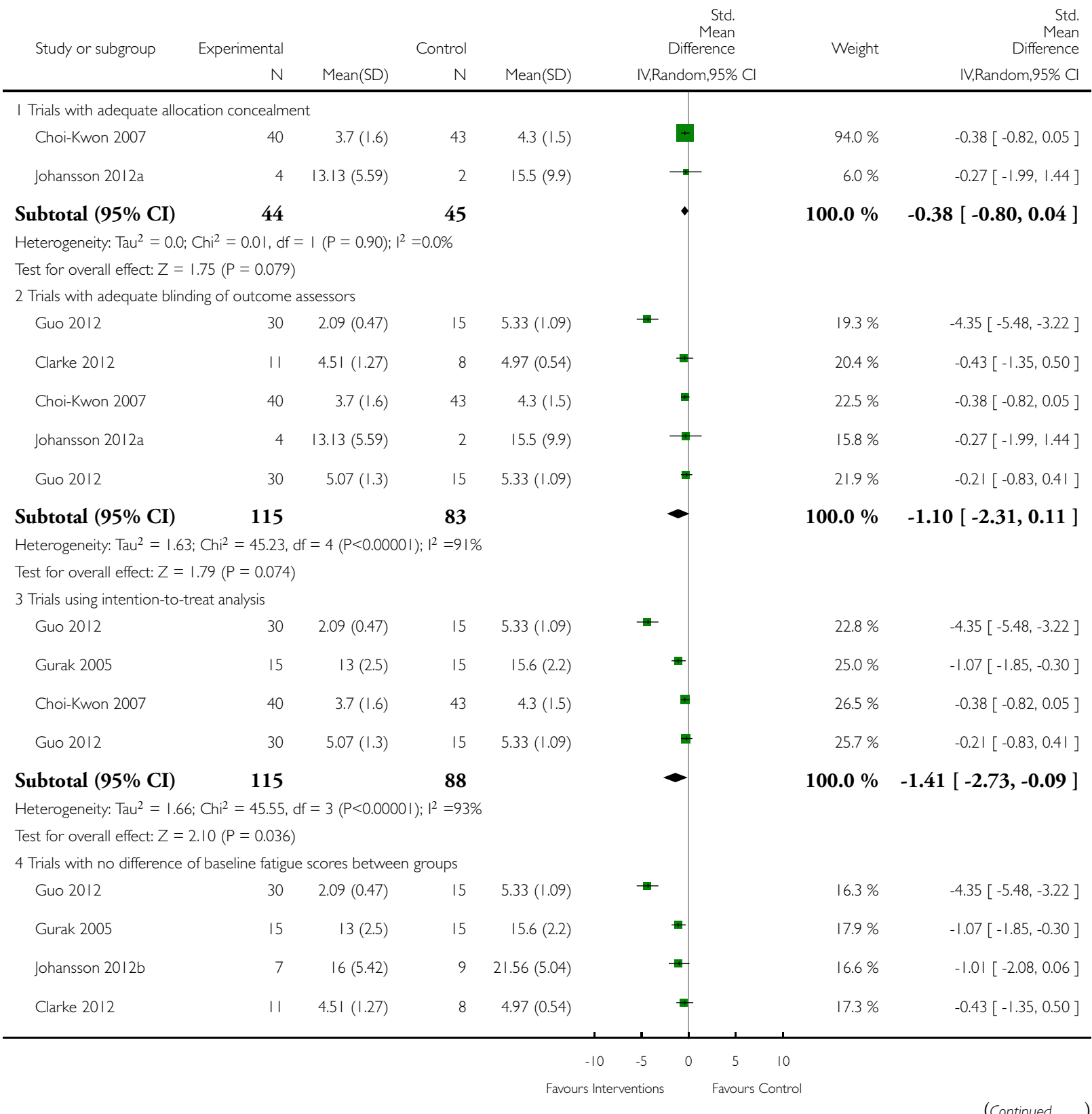




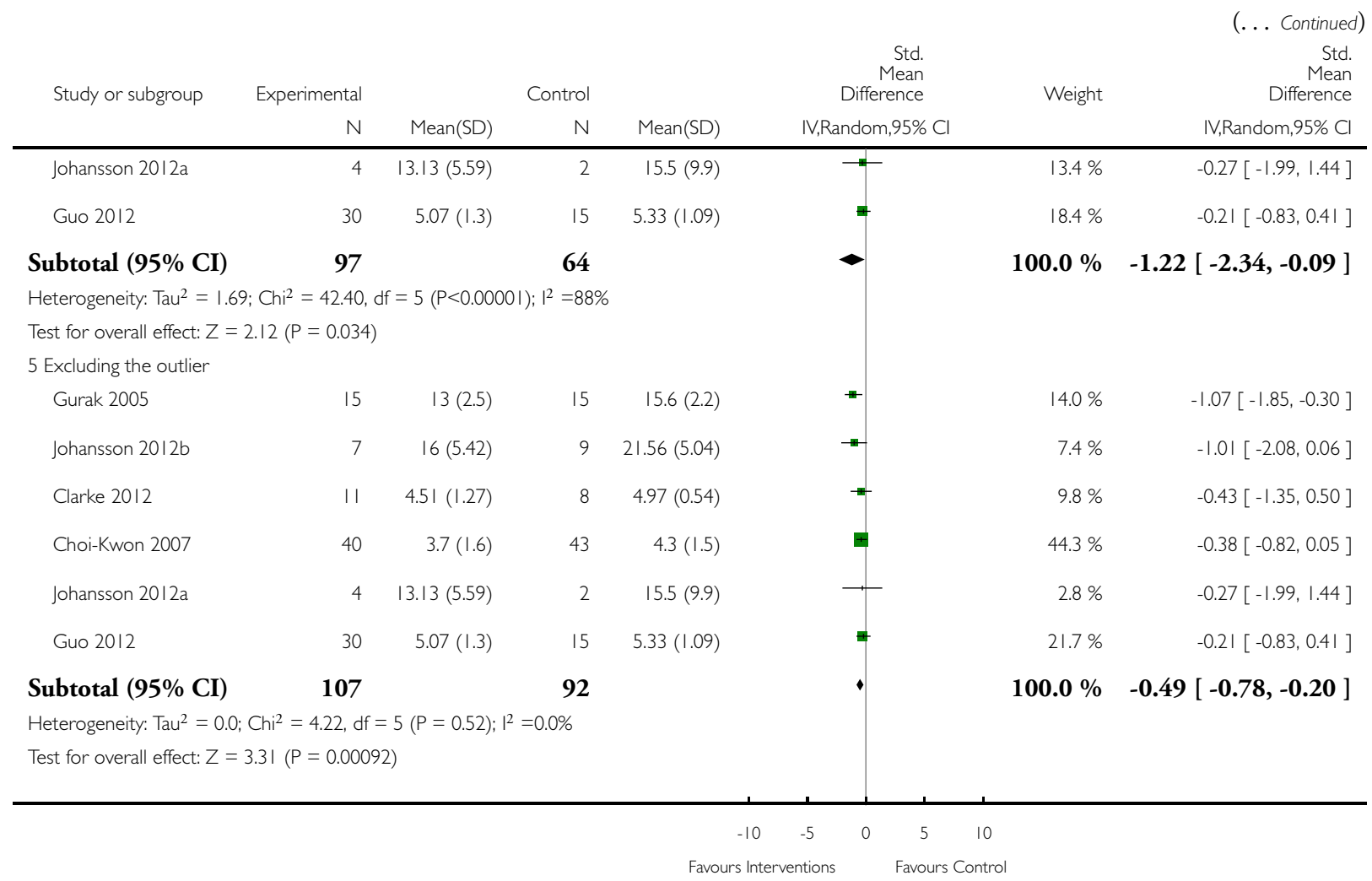


Analysis I.3. Comparison I Trials primarily intended to treat fatigue (intervention versus control), Outcome 3 Dichotomous outcomes.

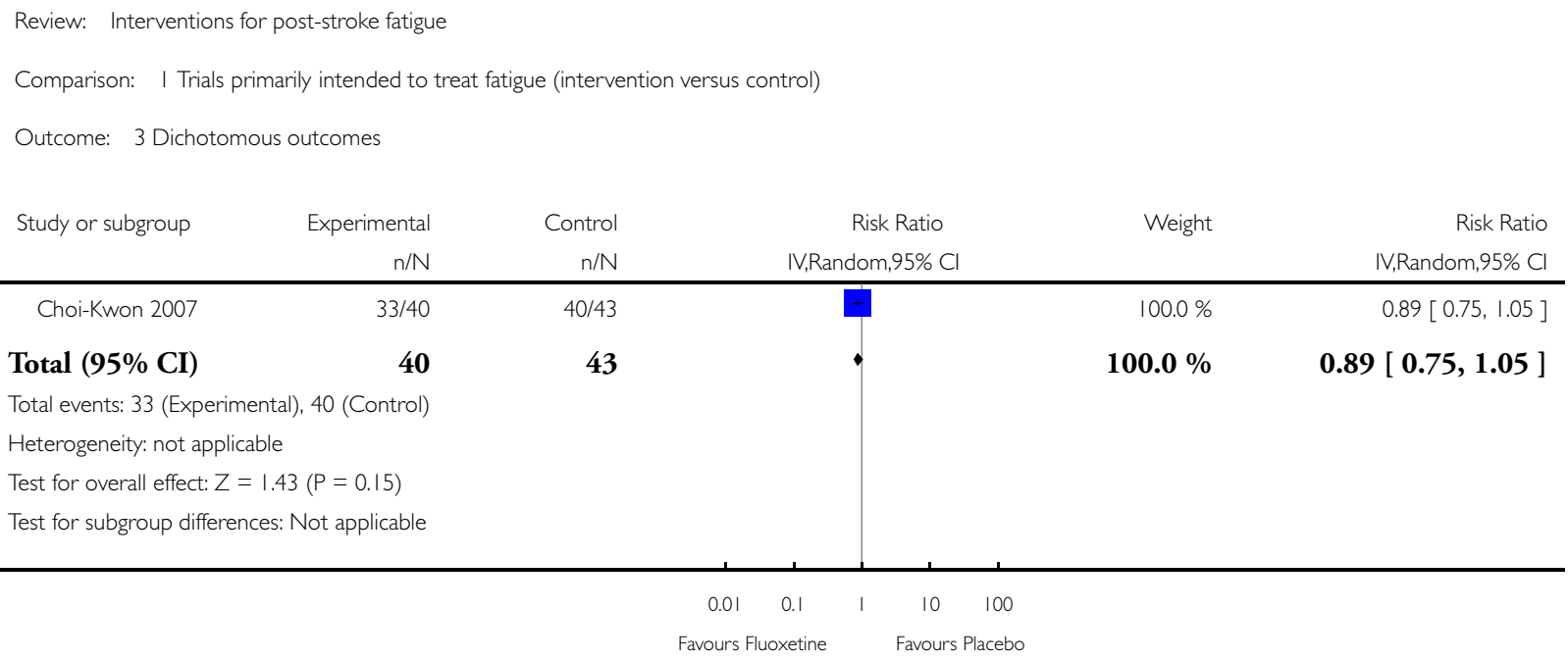

Analysis 3.1. Comparison 3 Trials not primarily intended at post-stroke fatigue (individual results), Outcome I Brown 20 I I (CPAP versus sham, continuous outcome).

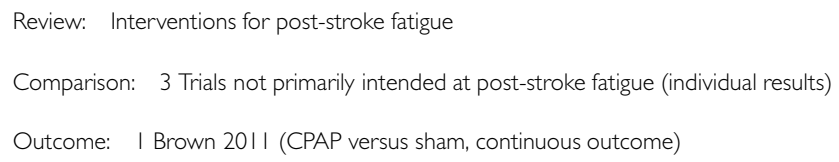

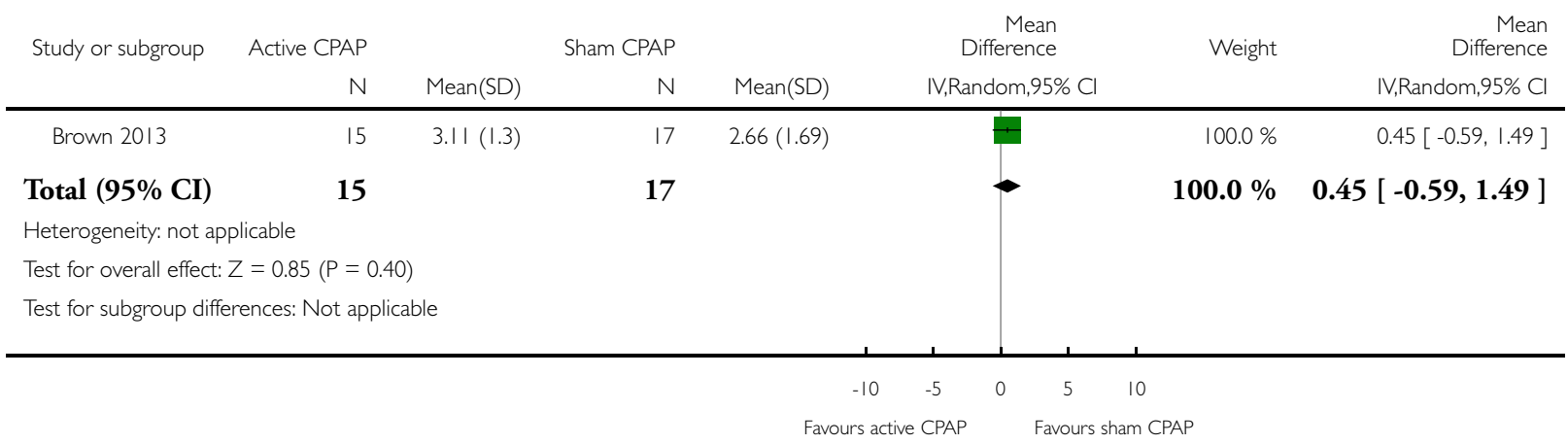


Analysis 3.2. Comparison 3 Trials not primarily intended at post-stroke fatigue (individual results), Outcome 2 Lorig 200 I (CDSMP versus wait-list, continuous outcome).

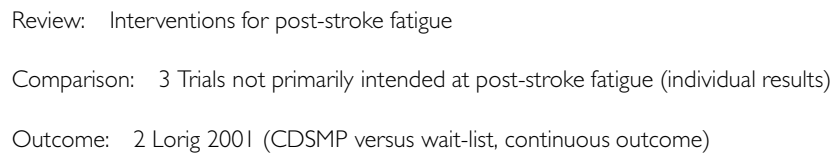

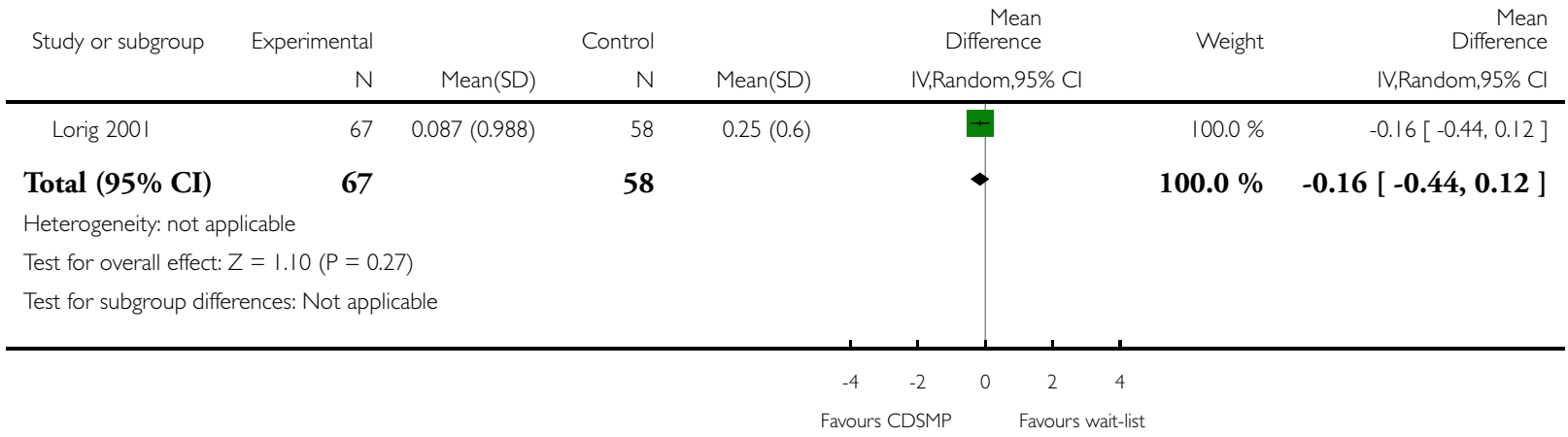

Analysis 3.3. Comparison 3 Trials not primarily intended at post-stroke fatigue (individual results), Outcome 3 Ogden 1998 (tirilazad versus vehicle, dichotomous outcome).

Review: Interventions for post-stroke fatigue

Comparison: 3 Trials not primarily intended at post-stroke fatigue (individual results)

Outcome: 3 Ogden 1998 (tirilazad versus vehicle, dichotomous outcome)

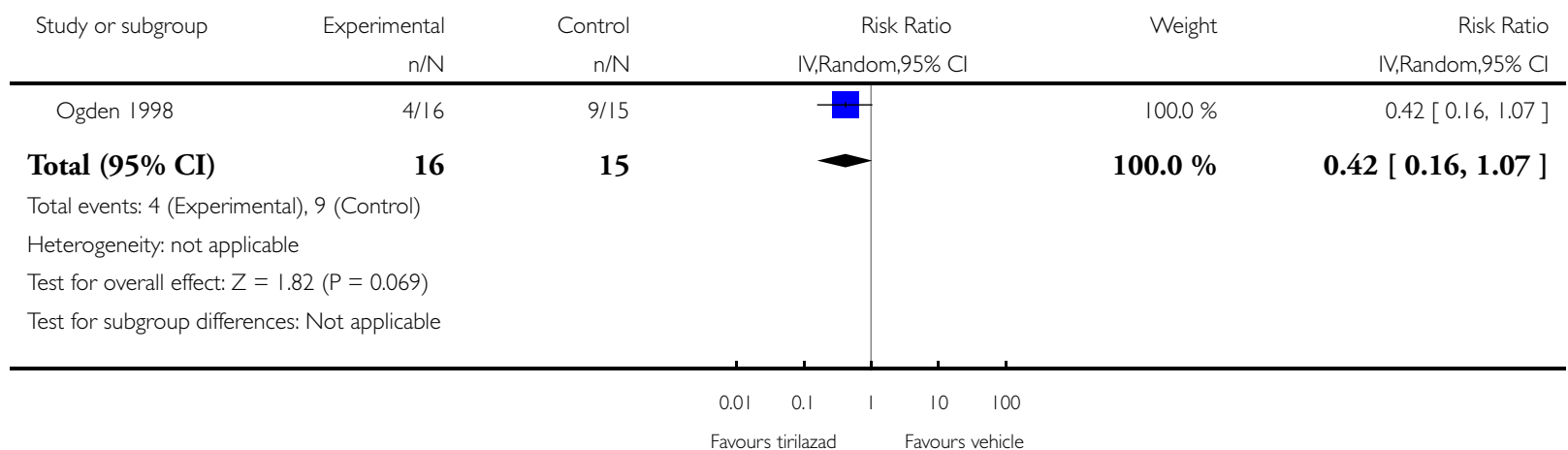


Analysis 3.4. Comparison 3 Trials not primarily intended at post-stroke fatigue (individual results), Outcome 4 Karaiskos 2012 (duloxetine versus citalopram, continuous outcome.

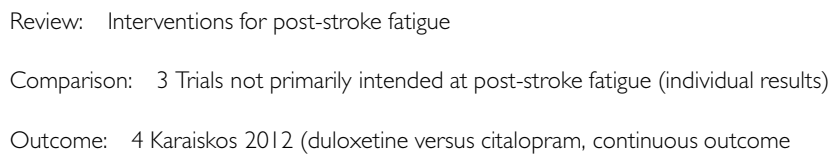

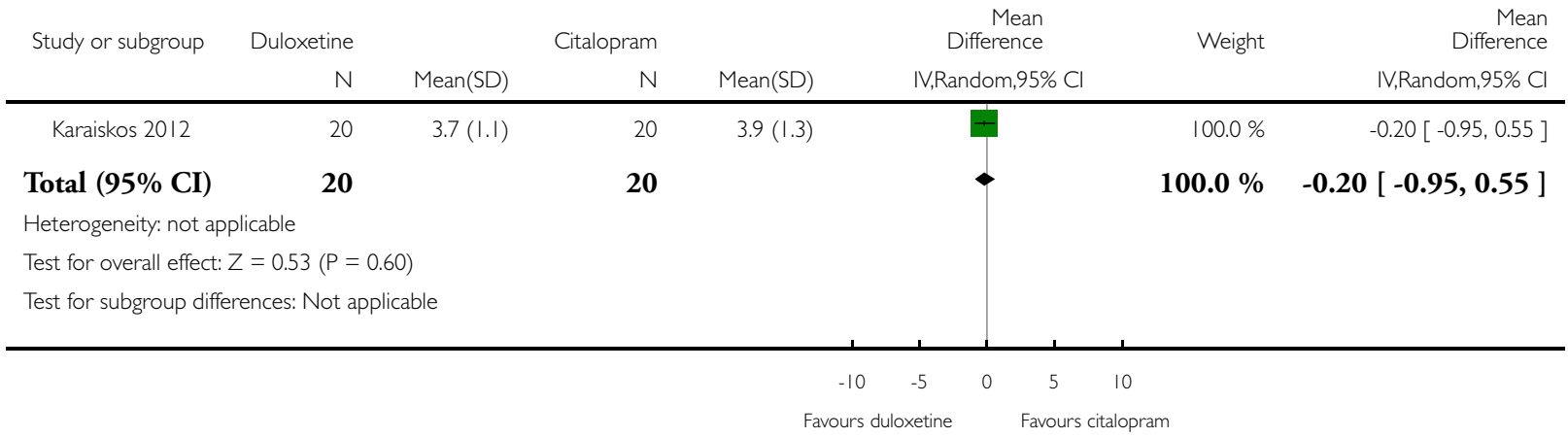

Analysis 3.5. Comparison 3 Trials not primarily intended at post-stroke fatigue (individual results), Outcome 5 Karaiskos 2012 (duloxetine versus sertraline, continuous outcome.

Review: Interventions for post-stroke fatigue

Comparison: 3 Trials not primarily intended at post-stroke fatigue (individual results)

Outcome: 5 Karaiskos 2012 (duloxetine versus sertraline, continuous outcome

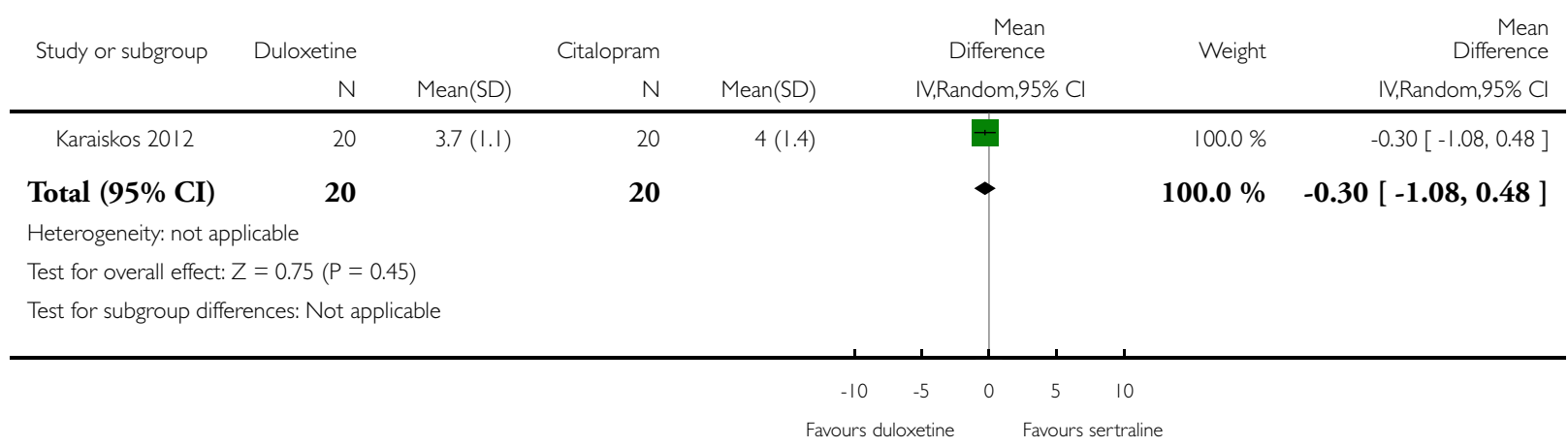


Analysis 3.6. Comparison 3 Trials not primarily intended at post-stroke fatigue (individual results), Outcome 6 Karaiskos 2012 (citalopram versus sertraline, continuous outcome).

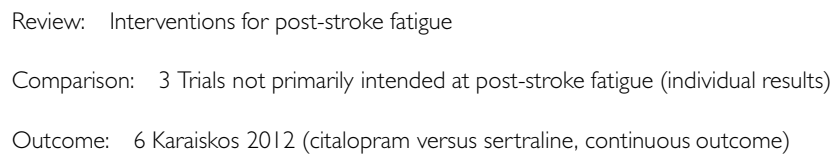

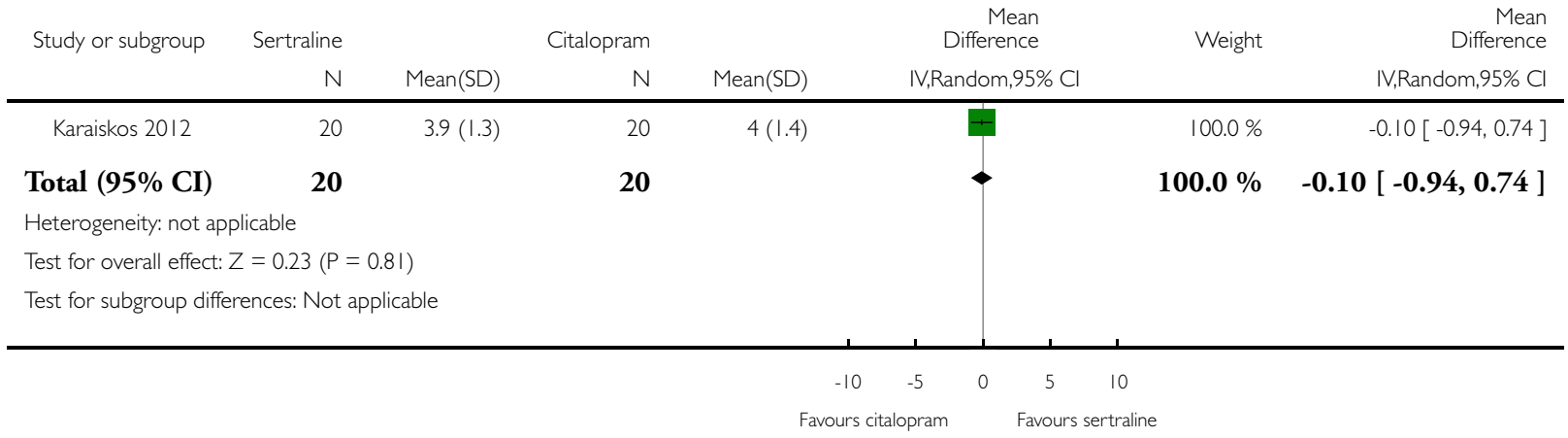

\section{ADDITIONAL TABLES}

Table 1. Participant characteristics and study design of eight trials primarily intended to treat post-stroke fatigue

\begin{tabular}{|c|c|c|c|c|c|c|c|c|}
\hline Studies & Trial design & $\begin{array}{l}\text { Partici- } \\
\text { pants }\end{array}$ & $\begin{array}{l}\text { Treat- } \\
\text { ment inter- } \\
\text { ventions }\end{array}$ & $\begin{array}{l}\text { Control in- } \\
\text { terventions }\end{array}$ & $\begin{array}{l}\text { Duration of } \\
\text { treatment }\end{array}$ & $\begin{array}{l}\text { Measures of } \\
\text { fatigue }\end{array}$ & $\begin{array}{l}\text { Outcomes } \\
\text { at the end of } \\
\text { treatment }\end{array}$ & Follow-up \\
\hline \multicolumn{9}{|c|}{ Pharmacological interventions } \\
\hline $\begin{array}{l}\text { Choi-Kwon } \\
2007\end{array}$ & $\begin{array}{l}\text { Parallel } \\
\text { RCT }\end{array}$ & $\begin{array}{l}\text { Re- } \\
\text { cruitment: } \mathrm{n} \\
=83 \text {, at least } \\
3 \text { months af- } \\
\text { ter stroke } \\
\text { and having } \\
\text { PSF (self re- } \\
\text { ported expe- } \\
\text { rience) } \\
\text { Comple- } \\
\text { tion of treat- } \\
\text { ment: } n=78 \\
\text { Comple- } \\
\text { tion of fol- } \\
\text { low-up: } n= \\
78\end{array}$ & $\begin{array}{l}\text { Flu- } \\
\text { oxetine (a se- } \\
\text { lective sero- } \\
\text { tonin } \\
\text { reuptake in- } \\
\text { hibitor, } \\
20 \mathrm{mg} \text {, daily, } \\
\text { orally) }\end{array}$ & $\begin{array}{l}\text { Placebo (20 } \\
\text { mg, daily, } \\
\text { orally) }\end{array}$ & 3 months & FSS & $\begin{array}{l}\text { FSS scores* } \\
\text { Propor- } \\
\text { tion of par- } \\
\text { ticipants } \\
\text { with fatigue }\end{array}$ & $\begin{array}{l}\text { FSS scores at } \\
3 \text { months af- } \\
\text { ter end of } \\
\text { treatment }\end{array}$ \\
\hline
\end{tabular}




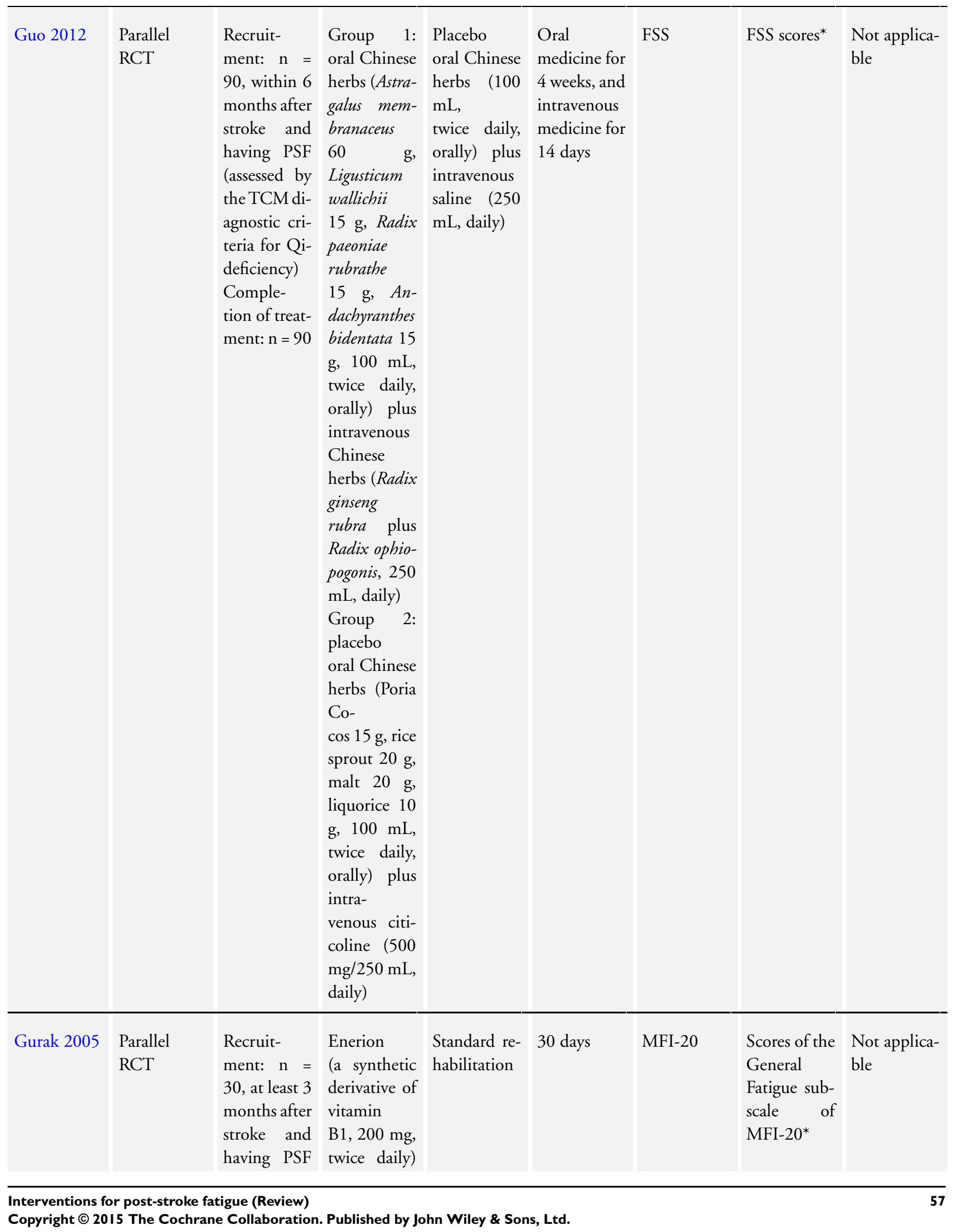




\begin{tabular}{|c|c|c|c|c|c|c|c|c|}
\hline & & $\begin{array}{l}\text { (assessed by } \\
\text { MFI-20) } \\
\text { Comple- } \\
\text { tion of treat- } \\
\text { ment: } \mathrm{n}=30\end{array}$ & $\begin{array}{l}\text { plus stan- } \\
\text { dard out- } \\
\text { patient reha- } \\
\text { bilitation }\end{array}$ & & & & & \\
\hline $\begin{array}{l}\text { Johansson } \\
2012 \mathrm{a}\end{array}$ & $\begin{array}{l}\text { Cross-over } \\
\text { trial }^{2}\end{array}$ & $\begin{array}{l}\text { Recruit- } \\
\text { ment: } \mathrm{n}=6 \text {, } \\
\text { at least } 12 \\
\text { months after } \\
\text { stroke and } \\
\text { having PSF } \\
\text { (assessed by } \\
\text { MFS) } \\
\text { If } \\
\text { a participant } \\
\text { dropped } \\
\text { out, } \\
\text { a new partic- } \\
\text { ipant was in- } \\
\text { cluded } \\
\text { Comple- } \\
\text { tion of treat- } \\
\text { ment: } n=6\end{array}$ & $\begin{array}{l}(-)- \\
\text { OSU6162 } \\
\text { (a } \\
\text { monoamin- } \\
\text { ergic sta- } \\
\text { biliser, } 15 \text { to } \\
45 \mathrm{mg} \text {, twice } \\
\text { daily, orally) }\end{array}$ & $\begin{array}{l}\text { Placebo (15 } \\
\text { to } 45 \mathrm{mg} \text {, } \\
\text { twice daily, } \\
\text { orally) }\end{array}$ & $\begin{array}{l}4 \text { weeks (for } \\
\text { the first } \\
\text { phase) }\end{array}$ & MFS & MFS scores* & $\begin{array}{l}\text { Not applica- } \\
\text { ble }\end{array}$ \\
\hline
\end{tabular}

\section{Non-pharmacological interventions}

\begin{tabular}{|c|c|c|c|c|c|c|c|c|}
\hline Clarke 2012 & $\begin{array}{l}\text { Parallel } \\
\text { RCT }\end{array}$ & $\begin{array}{l}\text { Re- } \\
\text { cruitment: } \mathrm{n} \\
=19,3 \text { to } 18 \\
\text { months after } \\
\text { stroke and } \\
\text { having PSF } \\
\text { (assessed by } \\
\text { FSS) } \\
\text { Comple- } \\
\text { tion of treat- } \\
\text { ment: } \mathrm{n}=16\end{array}$ & $\begin{array}{l}\text { Fatigue } \\
\text { Group Edu- } \\
\text { ca- } \\
\text { tion therapy } \\
\text { (6 weekly } \\
\text { group } \\
\text { sessions, } 60 \\
\text { minutes for } \\
\text { each session) }\end{array}$ & $\begin{array}{l}\text { General } \\
\text { Group Edu- } \\
\text { ca- } \\
\text { tion therapy } \\
\text { (6 weekly } \\
\text { group } \\
\text { sessions, } 60 \\
\text { minutes for } \\
\text { each session) }\end{array}$ & 6 weeks & FSS & FSS scores* & $\begin{array}{l}\text { FSS scores at } \\
3 \text { months af- } \\
\text { ter the end } \\
\text { of treatment }\end{array}$ \\
\hline $\begin{array}{l}\text { Johansson } \\
2012 b\end{array}$ & $\begin{array}{l}\text { Cross-over } \\
\text { trial }^{2}\end{array}$ & $\begin{array}{l}\text { Re- } \\
\text { cruitment: } n \\
=\text { unknown, } \\
\text { at least } 12 \\
\text { months after } \\
\text { stroke and } \\
\text { having PSF } \\
\text { (assessed by } \\
\text { MFS) } \\
\text { Comple- }\end{array}$ & $\begin{array}{l}\text { Mindful- } \\
\text { ness-based } \\
\text { stress reduc- } \\
\text { tion therapy } \\
(8 \quad \text { weekly } \\
\text { group } \\
\text { sessions, } 2 . \\
5 \text { hours for } \\
\text { each session, } \\
\text { plus } 45 \text { min- }\end{array}$ & Wait-list & $\begin{array}{l}8 \text { weeks (for } \\
\text { the first } \\
\text { phase) }\end{array}$ & MFS & MFS scores* & $\begin{array}{l}\text { Not applica- } \\
\text { ble }\end{array}$ \\
\hline
\end{tabular}




\begin{tabular}{|c|c|c|c|c|c|c|c|c|}
\hline & & $\begin{array}{l}\text { tion of treat- } \\
\text { ment: } n=16\end{array}$ & $\begin{array}{l}\text { utes } \\
\text { home prac- } \\
\text { tice for } 6 \\
\text { days a week) }\end{array}$ & & & & & \\
\hline $\begin{array}{l}\text { Zedlitz } \\
2012\end{array}$ & $\begin{array}{l}\text { Parallel } \\
\text { RCT }\end{array}$ & $\begin{array}{l}\text { Recruit- } \\
\text { ment: } \mathrm{n}= \\
83 \text {, at least } 4 \\
\text { months after } \\
\text { stroke and } \\
\text { having PSF } \\
\text { (assessed by } \\
\text { CIS-f) } \\
\text { Comple- } \\
\text { tion of treat- } \\
\text { ment: } \mathrm{n}=73 \\
\text { Comple- } \\
\text { tion of fol- } \\
\text { low-up: } \mathrm{n}= \\
68\end{array}$ & $\begin{array}{l}\text { Group } \\
\text { 1: Cognitive } \\
\text { behavioural } \\
\text { therapy (12 } \\
\text { weekly cog- } \\
\text { nitive treat- } \\
\text { ment } \\
\text { sessions, } \\
2 \text { hours for } \\
\text { each session) } \\
\text { Group } \\
\text { 2: Cognitive } \\
\text { behavioural } \\
\text { therapy plus } \\
\text { graded ac- } \\
\text { tivity train- } \\
\text { ing (tread- } \\
\text { mill walking } \\
\text { and strength } \\
\text { training for } \\
2 \\
\text { hours, twice } \\
\text { a week) }\end{array}$ & None & 12 weeks & $\begin{array}{l}\text { CIS-f and } \\
\text { SOL-f }\end{array}$ & $\begin{array}{l}\text { CIS- } \\
f \text { and SOL-f } \\
\text { scores }\end{array}$ & $\begin{array}{l}\text { CIS-f and } \\
\text { SOL-f scores } \\
\text { at } 6 \text { months } \\
\text { after the end } \\
\text { of treatment }\end{array}$ \\
\hline Zhou 2010 & $\begin{array}{l}\text { Parallel } \\
\text { RCT }\end{array}$ & $\begin{array}{l}\text { Recruit- } \\
\text { ment: } \mathrm{n}= \\
128 \text {, within } \\
3 \text { years after } \\
\text { stroke and } \\
\text { having PSF } \\
\text { (assessed } \\
\text { by SSQOL- } \\
\text { energy) } \\
\text { Comple- } \\
\text { tion of treat- } \\
\text { ment: } \mathrm{n}= \\
128 \\
\text { Comple- } \\
\text { tion of fol- } \\
\text { low-up: } \mathrm{n}= \\
128\end{array}$ & $\begin{array}{l}\text { Group } 1 \text { : } \\
\text { elec- } \\
\text { troacupunc- } \\
\text { ture } \\
(30 \text { minutes } \\
\text { daily, } \\
10 \text { days as } \\
1 \text { cycle, for } \\
3 \text { cycles with } \\
2 \text {-day inter- } \\
\text { vals between } \\
\text { cycles }) \text { plus } \\
\text { cup- } \\
\text { ping at back } \\
\text { (10 minutes, } \\
\text { once every } 2 \\
\text { days) } \\
\text { Group } 2 \text { : } \\
\text { sertra- }\end{array}$ & None & 5 weeks & $\begin{array}{l}\text { SSQOL- } \\
\text { energy }\end{array}$ & $\begin{array}{l}\text { Propor- } \\
\text { tion of par- } \\
\text { ticipants } \\
\text { with PSF } \\
\text { SSQOL-en- } \\
\text { ergy scores** }\end{array}$ & $\begin{array}{l}\text { Propor- } \\
\text { tion of par- } \\
\text { ticipants } \\
\text { with PSF at } \\
2 \text { months af- } \\
\text { ter the end } \\
\text { of treatment }\end{array}$ \\
\hline
\end{tabular}


Table 1. Participant characteristics and study design of eight trials primarily intended to treat post-stroke fatigue (Continued)

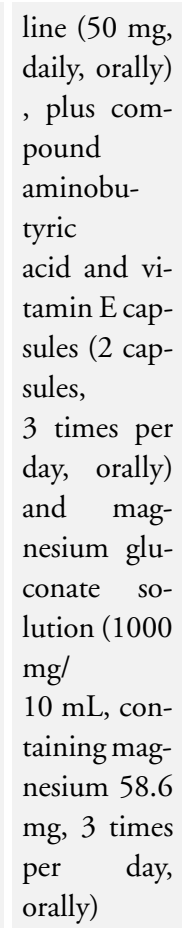

CIS-f: Checklist Individual Strength-fatigue subscale

FSS: Fatigue Severity Scale

MFI-20: Multidimensional Fatigue Inventory-20

MFS: Mental Fatigue Scale

$\mathrm{n}$ : number of participants

PSF: post-stroke fatigue

RCT: randomised controlled trial

SOL-f: Self-Observation List-fatigue subscale

SSQOL-energy: Energy subscale of Stroke-specific Quality of Life

TCM: traditional Chinese medicine

1. For outcomes of fatigue by the end of treatment, review authors calculated the effect size for each outcome according to the type of outcomes, that is, standardised mean difference (SMD) or mean difference (MD) for continuous outcomes and risk ratio (RR) for dichotomous outcomes: *Outcomes from 6 trials were included in meta-analysis, while the other 2 trials that did not have a control arm were not included in meta-analysis; ${ }^{*}$ Zhou 2010 presented SSQOL-energy scores graphically without reporting exact values, thus the review authors were unable to calculate the effect size for this outcome.

2. These two trials enrolled mixed population of participants with stroke or brain injury, and used a cross-over study design. Trial investigators provided unpublished data of results of the first phase (i.e. before the participants were crossed over to the other group) for the subgroup of people with stroke. 
Table 2. Efficacy of interventions not primarily intended for post-stroke fatigue

\begin{tabular}{|c|c|c|c|c|c|c|c|c|}
\hline Studies & $\begin{array}{l}\text { Partici- } \\
\text { pants }\end{array}$ & $\begin{array}{l}\text { Treat- } \\
\text { ment inter- } \\
\text { ventions }\end{array}$ & $\begin{array}{l}\text { Control in- } \\
\text { terventions }\end{array}$ & $\begin{array}{l}\text { Duration of } \\
\text { treatment }\end{array}$ & $\begin{array}{l}\text { Primary } \\
\text { outcomes } \\
\text { of the inter- } \\
\text { vention }\end{array}$ & $\begin{array}{l}\text { Measures of } \\
\text { fatigue and } \\
\text { results } \\
\text { reported by } \\
\text { trial investi- } \\
\text { gators }\end{array}$ & $\begin{array}{l}\text { Ef- } \\
\text { fect size on } \\
\text { fatigue (cal- } \\
\text { culated by } \\
\text { review au- } \\
\text { thors) }{ }^{1}\end{array}$ & Comments \\
\hline \multicolumn{9}{|c|}{ Trials reporting continuous outcomes of fatigue } \\
\hline Brown 2013 & $\begin{array}{l}\text { Re- } \\
\text { cruitment: } n \\
=32 \text {, with } \\
\text { positive re- } \\
\text { sults on tests } \\
\text { of sleep ap- } \\
\text { noea } \\
\text { Comple- } \\
\text { tion of treat- } \\
\text { ment: } n=19\end{array}$ & $\begin{array}{l}\text { Active } \\
\text { CPAP }\end{array}$ & Sham CPAP & 3 months & $\begin{array}{l}\text { Self reported } \\
\text { usage } \\
\text { of CPAP by } \\
\text { participants }\end{array}$ & $\begin{array}{l}\text { Scores } \\
\text { of FSS at the } \\
\text { end of treat- } \\
\text { ment } \\
\text { Ac- } \\
\text { tive CPAP: } \\
\text { mean score } \\
3.11 \text {, SD } 1 . \\
30 \\
\text { Sham } \\
\text { CPAP: } \\
\text { mean score } \\
2.66, \text { SD } 1 . \\
69\end{array}$ & $\begin{array}{l}\text { MD } 0.45, \\
95 \% \text { CI }-0 . \\
59 \text { to } 1.49\end{array}$ & $\begin{array}{l}\text { Trial inves- } \\
\text { tigators only } \\
\text { provided } \\
\text { data for the } \\
19 \text { partic- } \\
\text { ipants who } \\
\text { completed } \\
\text { the trial. } \\
\text { They found } \\
\text { no between- } \\
\text { group differ- } \\
\text { ence } \\
\text { of scores of } \\
\text { either sleep } \\
\text { apnoea (Ep- } \\
\text { worth } \\
\text { Sleepiness } \\
\text { Scale) or fa- } \\
\text { tigue after } \\
\text { treatment }\end{array}$ \\
\hline Lorig 2001 & $\begin{array}{l}\text { Recruit- } \\
\text { ment: } \mathrm{n}= \\
125 \text {, people } \\
\text { with stroke } \\
\text { Comple- } \\
\text { tion of treat- } \\
\text { ment: } \mathrm{n}= \\
104\end{array}$ & CDSMP & Wait-list & 6 months & $\begin{array}{l}\text { Health } \\
\text { behaviours, } \\
\text { health status } \\
\text { and health } \\
\text { service utili- } \\
\text { sation }\end{array}$ & $\begin{array}{l}\text { Changes of } \\
\text { scores of en- } \\
\text { ergy/fatigue } \\
\text { scale from } \\
\text { the long- } \\
\text { form Medi- } \\
\text { cal Out- } \\
\text { comes Study } \\
\text { CDSMP: } \\
\text { mean de- } \\
\text { crease of en- } \\
\text { ergy score } 0 . \\
087 \text {, SD 0. } \\
988 \text { Wait-list: } \\
\text { mean de- } \\
\text { crease of en- }\end{array}$ & $\begin{array}{l}\text { MD }-0.16, \\
95 \% \text { CI }-0 . \\
44 \text { to } 0.12\end{array}$ & $\begin{array}{l}\text { Higher } \\
\text { energy score } \\
\text { in- } \\
\text { dicates lower } \\
\text { fatigue } \\
\text { severity; de- } \\
\text { crease of en- } \\
\text { ergy score } \\
\text { indicates in- } \\
\text { crease of fa- } \\
\text { tigue } \\
\text { severity; the } \\
\text { greater } \\
\text { decrease of } \\
\text { energy score } \\
\text { indicates the } \\
\text { greater in- }\end{array}$ \\
\hline
\end{tabular}


Table 2. Efficacy of interventions not primarily intended for post-stroke fatigue (Continued)

\begin{tabular}{|c|c|c|c|c|c|c|c|c|}
\hline & & & & & & $\begin{array}{l}\text { ergy score } 0 . \\
246 \text {, SD } 0 . \\
600\end{array}$ & & $\begin{array}{l}\text { crease of fa- } \\
\text { tigue sever- } \\
\text { ity }\end{array}$ \\
\hline $\begin{array}{l}\text { Karaiskos } \\
2012\end{array}$ & $\begin{array}{l}\text { Re- } \\
\text { cruitment: } n \\
=60 \text {, with a } \\
\text { clinical diag- } \\
\text { nosis of de- } \\
\text { pression af- } \\
\text { ter stroke } \\
\text { Comple- } \\
\text { tion of treat- } \\
\text { ment: } \mathrm{n}=60\end{array}$ & $\begin{array}{l}\text { Group 1: } \\
\text { duloxetine } \\
\text { Group 2: } \\
\text { citalopram } \\
\text { Group 3: } \\
\text { sertraline }\end{array}$ & None & 3 months & $\begin{array}{l}\text { Depression } \\
\text { and anxiety }\end{array}$ & $\begin{array}{l}\text { Scores } \\
\text { of FSS at the } \\
\text { end of treat- } \\
\text { ment }\end{array}$ & 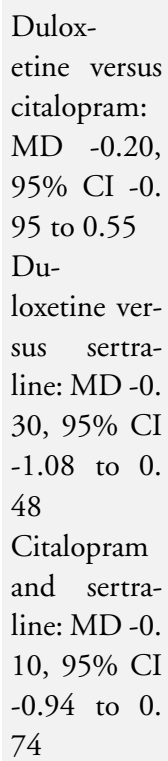 & $\begin{array}{l}\text { Trial investi- } \\
\text { gators found } \\
\text { significant } \\
\text { improve- } \\
\text { ment of de- } \\
\text { pression and } \\
\text { anxiety after } \\
\text { treatment in } \\
\text { each of the } 3 \\
\text { groups, but } \\
\text { no signif- } \\
\text { icant change } \\
\text { of fatigue } \\
\text { scores dur- } \\
\text { ing the treat- } \\
\text { ment in any } \\
\text { group }\end{array}$ \\
\hline
\end{tabular}

Trials reporting dichotomous outcomes of fatigue

\begin{tabular}{|c|c|c|c|c|c|c|c|c|}
\hline Ogden 1998 & $\begin{array}{l}\text { Recruit- } \\
\text { ment: } \mathrm{n}=31 \\
\text { women with } \\
\text { subarach- } \\
\text { noid haem- } \\
\text { orrhage } \\
\text { Comple- } \\
\text { tion of treat- } \\
\text { ment: } \mathrm{n}=18\end{array}$ & $\begin{array}{l}\text { Tirilazad } \\
\text { mesylate }\end{array}$ & Placebo & 3 months & GOS & $\begin{array}{l}\text { Self } \\
\text { report of de- } \\
\text { bilitating fa- } \\
\text { tigue by par- } \\
\text { ticipants }\end{array}$ & $\begin{array}{l}\text { RR } 0 . \\
42,95 \% \text { CI } \\
0.16 \text { to } 1.07\end{array}$ & $\begin{array}{l}\text { Trial inves- } \\
\text { tigators only } \\
\text { provided } \\
\text { data for the } \\
18 \text { partici- } \\
\text { pants who } \\
\text { completed } \\
\text { the trial. } \\
\text { They found } \\
\text { no between- } \\
\text { group dif- } \\
\text { ference in } \\
\text { either GOS } \\
\text { scores or } \\
\text { cognitive } \\
\text { impairment, } \\
\text { but con- } \\
\text { centration, } \\
\text { sustained at- } \\
\text { tention, psy- } \\
\text { chomotor }\end{array}$ \\
\hline
\end{tabular}


Table 2. Efficacy of interventions not primarily intended for post-stroke fatigue (Continued)

speed and debilitating fatigue were worse in placebo group

CDSMP: Chronic Disease Self-management Programme

CI: confidence interval

CPAP: continuous positive airway pressure

GOS: Glasgow Outcome Scale

MD: mean difference

$\mathrm{n}$ : number of participants

RR: risk ratio

SD: standard deviation

${ }^{1}$ We calculated the effect size using the intention-to-treat analysis, that is, based on the number of participants and their grouping at recruitment.

\section{A P PENDICES}

\section{Appendix I. CENTRAL search strategy}

1. [mh “"cerebrovascular disorders"] or [mh "basal ganglia cerebrovascular disease"] or [mh "brain ischemia”] or [mh "carotid artery diseases"] or [mh "cerebrovascular trauma”] or [mh "intracranial arterial diseases"] or [mh "intracranial arteriovenous

malformations"] or [mh "intracranial embolism and thrombosis"] or [mh "intracranial hemorrhages"] or [mh ^stroke] or [mh "brain infarction"] or [mh “"vertebral artery dissection”]

2. (stroke or poststroke or "post-stroke" or cerebrovasc* or brain next vasc* or cerebral next vasc* or cva* or apoplex* or SAH):ti,ab

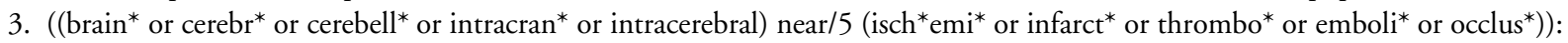
ti,ab

4. ((brain* or cerebr* or cerebell* or intracerebral or intracranial or subarachnoid) near/5 (haemorrhage* or hemorrhage* or haematoma* or hematoma* or bleed*)):ti,ab

5. [mh ^hemiplegia] or [mh paresis] or [mh "Gait Disorders, Neurologic"]

6. (hemipleg* or hemipar* or paresis or paretic):ti,ab

7. \#1 or \#2 or \#3 or \#4 or \#5 or \#6

8. [mh ^fatigue] or [mh “fatigue syndrome, chronic"] or [mh âsthenia] or [mh ^"mental fatigue”] or [mh ^"muscle fatigue”] or [mh ^lethargy]

9. (fatigue* or astheni* or neurastheni* or tired or tiredness or weary or weariness or exhausted or exhaustion or lassitude or listlessness or letharg* or apath* or malaise):ti,ab

10. ((low or lack) near/5 energy):ti,ab

11. \#8 or \#9 or \#10

12. \#7 and \#11

Interventions for post-stroke fatigue (Review)

Copyright ( 2015 The Cochrane Collaboration. Published by John Wiley \& Sons, Ltd. 


\section{Appendix 2. MEDLINE search strategy}

The trial search co-ordinator (BT) of the Cochrane Stroke Group developed the search strategies for the 2008 review and amended them for the 2014 review. The following search strategy was used for MEDLINE and adapted for other databases in the 2014 review.

1. cerebrovascular disorders/ or exp basal ganglia cerebrovascular disease/ or exp brain ischemia/ or exp carotid artery diseases/ or exp cerebrovascular trauma/ or exp intracranial arterial diseases/ or exp intracranial arteriovenous malformations/ or exp "intracranial embolism and thrombosis"/ or exp intracranial hemorrhages/ or stroke/ or exp brain infarction/ or vertebral artery dissection/

2. (stroke or poststroke or post-stroke or cerebrovasc $\$$ or brain vasc $\$$ or cerebral vasc $\$$ or cva $\$$ or apoplex $\$$ or SAH).tw.

3. ((brain $\$$ or cerebr $\$$ or cerebell $\$$ or intracran $\$$ or intracerebral) adj5 (isch?emi $\$$ or infarct $\$$ or thrombo $\$$ or emboli $\$$ or occlus\$)).tw.

4. ((brain $\$$ or cerebr $\$$ or cerebell $\$$ or intracerebral or intracranial or subarachnoid) adj5 (haemorrhage $\$$ or hemorrhage $\$$ or haematoma $\$$ or hematoma $\$$ or bleed $\$)$ ).tw.

5. hemiplegia/ or exp paresis/ or exp Gait Disorders, Neurologic/

6. (hemipleg\$ or hemipar\$ or paresis or paretic).tw.

7. 1 or 2 or 3 or 4 or 5 or 6

8. fatigue/ or fatigue syndrome, chronic/ or asthenia/ or mental fatigue/ or muscle fatigue/ or lethargy/

9. (fatigue $\$$ or astheni $\$$ or neurastheni $\$$ or tired or tiredness or weary or weariness or exhausted or exhaustion or lassitude or listlessness or letharg\$ or apath\$ or malaise).tw.

10. ((low or lack) adj5 energy).tw.

11. 8 or 9 or 10

12. 7 and 11

13. exp animals/ not humans.sh.

14. 12 not 13

15. Randomized Controlled Trials as Topic/

16. random allocation/

17. Controlled Clinical Trials as Topic/

18. control groups/

19. clinical trials as topic/ or clinical trials, phase i as topic/ or clinical trials, phase ii as topic/ or clinical trials, phase iii as topic/ or clinical trials, phase iv as topic/

20. double-blind method/

21. single-blind method/

22. Placebos/

23. placebo effect/

24. cross-over studies/

25. Drug Evaluation/

26. randomized controlled trial.pt.

27. controlled clinical trial.pt.

28. (clinical trial or clinical trial phase i or clinical trial phase ii or clinical trial phase iii or clinical trial phase iv).pt.

29. (random\$ or RCT or RCTs).tw.

30. (controlled adj5 (trial\$ or stud\$)).tw.

31. (clinical\$ adj5 trial\$).tw.

32. ((control or treatment or experiment\$ or intervention) adj5 (group\$ or subject\$ or patient\$)).tw.

33. (quasi-random $\$$ or quasi random $\$$ or pseudo-random $\$$ or pseudo random $\$$ ).tw.

34. ((control or experiment $\$$ or conservative) adj5 (treatment or therapy or procedure or manage $\$)$ ).tw.

35. ( (singl $\$$ or doubl\$ or tripl\$ or trebl $\$$ ) adj5 (blind $\$$ or mask $\$)$ ).tw.

36. (cross-over or cross over or crossover).tw.

37. (placebo $\$$ or sham).tw.

38. trial.ti.

39. (assign $\$$ or allocat $\$$ ).tw.

40. controls.tw.

41. or $/ 15-40$

42. 14 and 41

Interventions for post-stroke fatigue (Review)

Copyright () 2015 The Cochrane Collaboration. Published by John Wiley \& Sons, Ltd. 


\section{Appendix 3. EMBASE search strategy}

1. stroke/ or cerebrovascular disease/ or exp basal ganglion hemorrhage/ or exp brain hematoma/ or exp brain hemorrhage/ or exp brain infarction/ or exp brain ischemia/ or carotid artery disease/ or cerebral artery disease/ or exp cerebrovascular accident/ or exp cerebrovascular malformation/ or exp intracranial aneurysm/ or exp occlusive cerebrovascular disease/

2. stroke unit/ or stroke patient/

3. (stroke or poststroke or post-stroke or cerebrovasc $\$$ or brain vasc $\$$ or cerebral vasc $\$$ or cva $\$$ or apoplex $\$$ or SAH).tw.

4. ((brain $\$$ or cerebr $\$$ or cerebell $\$$ or intracran $\$$ or intracerebral) adj5 (isch?emi $\$$ or infarct $\$$ or thrombo $\$$ or emboli $\$$ or occlus $\$))$.tw.

5. (brain $\$$ or cerebr $\$$ or cerebell $\$$ or intracerebral or intracranial or subarachnoid) adj5 (haemorrhage $\$$ or hemorrhage $\$$ or haematoma $\$$ or hematoma $\$$ or bleed\$)).tw.

6. hemiplegia/ or paresis/ or exp neurologic gait disorder/

7. (hemipleg\$ or hemipar\$ or paresis or paretic).tw.

8. 1 or 2 or 3 or 4 or 5 or 6 or 7

9. fatigue/ or chronic fatigue syndrome/ or exhaustion/ or lassitude/ or muscle fatigue/ or Fatigue Impact Scale/ or Fatigue Severity Scale/

10. lethargy/ or listlessness/ or malaise/ or apathy/ or dysthymia/ or asthenia/ or neurasthenia/

11. (fatigue $\$$ or astheni $\$$ or neurastheni $\$$ or tired or tiredness or weary or weariness or exhausted or exhaustion or lassitude or listlessness or letharg $\$$ or apath $\$$ or malaise).tw.

12. ((low or lack) adj5 energy).tw.

13. 9 or 10 or 11 or 12

14. 8 and 13

15. (exp animals/ or exp invertebrate/ or animal experiment/ or animal model/ or animal tissue/ or animal cell/ or nonhuman/) not (human/ or normal human/ or human cell/)

16. 14 not 15

17. Randomized Controlled Trial/

18. Randomization/

19. Controlled Study/

20. control group/

21. clinical trial/ or phase 1 clinical trial/ or phase 2 clinical trial/ or phase 3 clinical trial/ or phase 4 clinical trial/ or controlled clinical trial/

22. Crossover Procedure/

23. Double Blind Procedure/

24. Single Blind Procedure/ or triple blind procedure/

25. placebo/

26. (random $\$$ or RCT or RCTs).tw.

27. (controlled adj5 (trial\$ or stud $\$)$ ).tw.

28. (clinical\$ adj5 trial\$).tw.

29. ((control or treatment or experiment $\$$ or intervention) adj5 (group $\$$ or subject $\$$ or patient $\$)$ ).tw.

30. (quasi-random $\$$ or quasi random $\$$ or pseudo-random $\$$ or pseudo random $\$$ ).tw.

31. ((control or experiment $\$$ or conservative) adj5 (treatment or therapy or procedure or manage $\$)$ ).tw.

32. ((singl\$ or doubl\$ or tripl\$ or trebl\$) adj5 (blind $\$$ or mask\$)).tw.

33. (cross-over or cross over or crossover).tw.

34. (placebo $\$$ or sham).tw.

35. trial.ti.

36. (assign $\$$ or allocat $\$$ ).tw.

37. controls.tw.

38. or/17-37

39. 16 and 38

Interventions for post-stroke fatigue (Review) 


\section{Appendix 4. CINAHL search strategy}

- S1 .(MH "Cerebrovascular Disorders”) OR (MH "Basal Ganglia Cerebrovascular Disease+") OR (MH “Carotid Artery Diseases+”) OR (MH “Cerebral Ischemiat”) OR (MH “Cerebral Vasospasm”) OR (MH “Intracranial Arterial Diseasest”) OR (MH "Intracranial Embolism and Thrombosis") OR (MH "Intracranial Hemorrhage+”) OR (MH "Stroke”) OR (MH "Vertebral Artery Dissections")

- S2 .(MH "Stroke Patients") OR (MH “Stroke Units")

- S3 .TI ( stroke or poststroke or post-stroke or cerebrovasc* or brain vasc* or cerebral vasc or cva or apoplex or SAH ) or AB ( stroke or poststroke or post-stroke or cerebrovasc* or brain vasc* or cerebral vasc or cva or apoplex or SAH )

- S4 .TI ( brain* or cerebr* or cerebell* or intracran* or intracerebral ) or AB ( brain* or cerebr* or cerebell* or intracran* or intracerebral )

- S5 .TI ( ischemi* or ischaemi* or infarct* or thrombo* or emboli* or occlus* ${ }^{*}$ ) or AB (ischemi* or ischaemi* or infarct* ${ }^{*}$ thrombo* or emboli* or occlus*

- S6.S4 and S5

- S7 .TI ( brain* or cerebr* or cerebell* or intracerebral or intracranial or subarachnoid ) or AB ( brain* or cerebr* or cerebell* or intracerebral or intracranial or subarachnoid )

- S8 .TI ( haemorrhage* or hemorrhage* or haematoma* or hematoma* or bleed*) or AB ( haemorrhage* or hemorrhage* or haematoma* or hematoma* or bleed*)

- S9 .S7 and S8

- S10.(MH "Hemiplegia")

- S11 .TI ( hemipleg* or hemipar* or paresis or paretic) or AB ( hemipleg* or hemipar* or paresis or paretic)

- $\mathrm{S} 12 . \mathrm{S} 1$ or S2 or S3 or S6 or S9 or S10 or S11

- S13 .(MH "Fatigue") OR (MH "Fatigue Syndrome, Chronic") OR (MH “Asthenia”)

- S14 .(MH "Fatigue (NANDA)") OR (MH "Fatigue (Saba CCC)”)

- S15.(MH "Muscle Fatigue")

- S16 .TI ( fatigue* or astheni* or neurastheni* or tired or tiredness or weary or weariness or exhausted or exhaustion or lassitude or listlessness or letharg* or apath* or malaise ) or $\mathrm{AB}$ ( fatigue* or astheni* or neurastheni* or tired or tiredness or weary or weariness or exhausted or exhaustion or lassitude or listlessness or letharg* or apath* or malaise )

- S17 .TI ( (low N5 energy) or (lack* N5 energy) ) or AB ( (low N5 energy) or (lack* N5 energy) )

- $S 18 . S 13$ or $S 14$ or $S 15$ or $S 16$ or S17

- S19.S12 and S18

\section{Appendix 5. AMED search strategy}

1. cerebrovascular disorders/ or cerebral hemorrhage/ or cerebral infarction/ or cerebral ischemia/ or cerebrovascular accident/ or strokel

2. (stroke or poststroke or post-stroke or cerebrovasc $\$$ or brain vasc $\$$ or cerebral vasc $\$$ or cva $\$$ or apoplex $\$$ or $S A H)$.tw.

3. ( (brain $\$$ or cerebr $\$$ or cerebell $\$$ or intracran $\$$ or intracerebral) adj5 (isch?emi $\$$ or infarct $\$$ or thrombo $\$$ or emboli $\$$ or occlus\$)).tw.

4. ((brain $\$$ or cerebr $\$$ or cerebell $\$$ or intracerebral or intracranial or subarachnoid) adj5 (haemorrhage $\$$ or hemorrhage $\$$ or haematoma $\$$ or hematoma $\$$ or bleed\$)).tw.

5. hemiplegia/

6. (hemipleg\$ or hemipar\$ or paresis or paretic).tw.

7. 1 or 2 or 3 or 4 or 5 or 6

8. fatigue/ or fatigue mental/ or fatigue syndrome chronic/ or muscle fatigue/

9. (fatigue $\$$ or astheni $\$$ or neurastheni $\$$ or tired or tiredness or weary or weariness or exhausted or exhaustion or lassitude or listlessness or letharg\$ or apath\$ or malaise).tw.

10. ((low or lack) adj5 energy).tw.

11. 8 or 9 or 10

12. 7 and 11

Interventions for post-stroke fatigue (Review) 


\section{Appendix 6. Psyclnfo search strategy}

1. cerebrovascular disorders/ or cerebral hemorrhage/ or exp cerebral ischemia/ or cerebrovascular accidents/ or subarachnoid hemorrhage/

2. (stroke or poststroke or post-stroke or cerebrovasc $\$$ or brain vasc $\$$ or cerebral vasc $\$$ or cva $\$$ or apoplex $\$$ or $S A H)$.tw.

3. ((brain $\$$ or cerebr $\$$ or cerebell $\$$ or intracran $\$$ or intracerebral) adj5 (isch?emi $\$$ or infarct $\$$ or thrombo $\$$ or emboli $\$$ or occlus\$)).tw.

4. ((brain $\$$ or cerebr $\$$ or cerebell $\$$ or intracerebral or intracranial or subarachnoid) adj5 (haemorrhage $\$$ or hemorrhage $\$$ or haematoma $\$$ or hematoma $\$$ or bleed $\$)$ ).tw.

5. hemiplegia/

6. (hemipleg\$ or hemipar\$ or paresis or paretic).tw.

7. 1 or 2 or 3 or 4 or 5 or 6

8. fatigue/ or chronic fatigue syndrome/ or hypersomnia/ or sleepiness/ or asthenia/ or neurasthenia/ or apathy/ or dysthymic disorder/

9. (fatigue $\$$ or astheni $\$$ or neurastheni $\$$ or tired or tiredness or weary or weariness or exhausted or exhaustion or lassitude or listlessness or letharg\$ or apath\$ or malaise).tw.

10. ((low or lack) adj5 energy).tw.

11. 8 or 9 or 10

12. 7 and 11

\section{Appendix 7. ProQuest search strategy}

all(stroke OR poststroke OR post-stroke OR cerebrovasc* OR brain vasc* OR cerebral vasc* OR cva* OR apoplexy* OR subarachnoid OR hemipleg* OR hemipar* OR paresis OR paretic) AND all(fatigue OR hypersomnia OR sleepiness OR asthenia OR neurasthenia OR apathy OR dysthymic disorder OR tired OR tiredness OR weary OR weariness OR exhausted OR exhaustion OR lassitude OR listlessness OR lethargy* OR apathy* OR malaise OR low NEAR/3 energy OR lack* NEAR/3 energy)

\section{Appendix 8. British Nursing Index search strategy}

1. (“cerebrovascular disorder" OR "cerebrovascular disorders" OR ("cerebral hemorrhage" or "cerebral haemorrhage”) OR ("cerebral ischemia" or "cerebral ischaemia”) OR (“cerebrovascular accident" or "CVA") OR (("subarachnoid hemorrhage” or "subarachnoid haemorrhage") OR ("subarachnoid hemorrhages" or "subarachnoid haemorrhages"))) OR (cerebrovascular disorder OR cerebral hemorrhage OR cerebral haemorrhage OR cerebral ischemia OR cerebral ischaemia OR cerebrovascular accident OR subarachnoid hemorrhage)

2. (SU.EXACT.EXPLODE(“Stroke”) OR “Stroke” OR Stroke) OR (poststroke OR “poststroke” OR “post-stroke” OR poststroke) OR cerebrovasc* OR (brain vasc*) OR (cerebral vasc*) OR cerebrovasc* OR cerebro-vasc* OR (CVA or "CVA”) OR apoplex* OR (SAH or "SAH")

3. (brain* or cerebr* or cerebell* or intracran* or intracerebral) NEAR/5 (isch?emi* or infarct* or thrombo* or emboli* or occlus*)

4. (brain* or cerebr* or cerebell* or intracerebral or intracranial or subarachnoid) NEAR/5 (haemorrhage* or hemorrhage* or haematoma* or hematoma* or bleed*)

5. hemiplegia OR "hemiplegia"

6. hemipleg* OR hemipar* OR paresis OR paretic

7. 1 or 2 or 3 or 4 or 5 or 6

8. "hypersomnia” OR “sleepiness" OR “asthenia” OR "neurasthenia” OR "apathy” OR "dysthymic disorder" OR

(SU.EXACT.EXPLODE(“Chronic Fatigue Syndrome”) OR SU.EXACT.EXPLODE(“Fatigue”))

9. fatigue* or astheni* or neurastheni* or tired or tiredness or weary or weariness or exhausted or exhaustion or lassitude or listlessness or letharg* or apath* or malaise

10. (low or lack) NEAR/5 energy

11. 8 or 9 or 10

12. 7 and 11

Interventions for post-stroke fatigue (Review) 


\section{WHAT'S NEW}

Last assessed as up-to-date: 13 May 2014.

\begin{tabular}{l|l|l}
\hline Date & Event & Description \\
\hline 1 March 2015 & New citation required and conclusions have changed & $\begin{array}{l}\text { This current version of the review found a marginally sta- } \\
\text { tistically significant effect of pharmacological interventions } \\
\text { (but not non-pharmacological interventions) on fatigue af- } \\
\text { ter stroke. However, there is no robust evidence to guide } \\
\text { the prevention or treatment of fatigue after stroke, because } \\
\text { the existing trials were small and heterogeneous, and some } \\
\text { had a high risk of bias. The delivery of some non-pharma- } \\
\text { cological interventions was feasible in stroke patients, but } \\
\text { efficacy should be investigated in further trials with more } \\
\text { robust study design }\end{array}$ \\
\hline \multirow{2}{*}{ 1 March 2015} & New search has been performed & $\begin{array}{l}\text { We have added nine new published trials (of which two were } \\
\text { ongoing trials in the previous review). We identified nine } \\
\text { ongoing trials (compared with two in the previous review) } \\
\text { We included } 12 \text { published trials in total with a total of } \\
\text { 703 participants (compared with three trials in the previous } \\
\text { version). Of these 12 trials, six trials provided data suitable } \\
\text { for pooling and six did not }\end{array}$ \\
\cline { 2 - 4 }
\end{tabular}

\section{H I S T O R Y}

Protocol first published: Issue 2, 2008

Review first published: Issue 3, 2009

\begin{tabular}{l|l|l}
\hline Date & Event & Description \\
\hline 1 March 2015 & New search has been performed & There has been a change of authorship. \\
\hline
\end{tabular}

\section{CONTRIBUTIONSOFAUTHORS}

For the 2008 review, Gillian Mead, Martin Dennis, Michael Sharpe and Susan Lewis wrote the protocol. Elizabeth Keane, Gillian Mead, Alex Pollock and Lorraine Smith performed the searches, selected studies fulfilling the inclusion criteria and extracted data. Susan Lewis provided advice on statistical analysis and interpretation. Elizabeth Keane and Gillian Mead drafted the review. All authors edited the review and all approved the final version.

For this updated review, Alex Pollock, Malcolm Macleod, Martin Dennis and Gillian Mead provided advice on review methods and Simiao Wu clarified aspects of the protocol. Simiao Wu, Eileen Cowey and Mansur Kutlubaev performed the searches. Simiao Wu, Ho-Yan Yvonne Chun, Eileen Cowey, Mansur Kutlubaev and Gillian Mead selected studies. Simiao Wu, Ho-Yan Yvonne Chun and Mansur Kutlubaev extracted data. Simiao Wu analysed data. Simiao Wu and Gillian Mead drafted the review. Alex Pollock, Eileen Cowey, Malcolm Macleod, Michael Sharpe and Mansur Kutlubaev edited the review. All authors approved the final version.

Interventions for post-stroke fatigue (Review)

Copyright @ 2015 The Cochrane Collaboration. Published by John Wiley \& Sons, Ltd. 


\section{DECLARATIONSOF INTEREST}

Simiao Wu: none known.

Mansur A Kutlubaev: none known.

Ho-Yan Y Chun: none known.

Eileen Cowey: none known.

Alex Pollock: none known.

Malcolm Macleod: is an employee of the University of Edinburgh and the Medicines \& Healthcare products Regulatory Agency (MHRA), and receives honoraria relating to book and journal publishing.

Martin Dennis: none known.

Elizabeth Keane: none known.

Michael Sharpe: for the 2008 review, Michael Sharpe received a research grant from the Scottish Government Chief Scientist Office to carry out research on a related topic. He is currently employed by the University of Oxford. He has no competing interests.

Gillian Mead: has been awarded a project grant from the Scottish Government Chief Scientist Office to perform a longitudinal study of fatigue after stroke. The preliminary results of this Cochrane review were used in the application for funding to justify the need for further studies in this area. She has developed a course on exercise after stroke, which was licensed to Later Life Training who pay royalties for the course. She has received expenses for speaking at conferences on exercise and fatigue after stroke.

\section{SOURCES OF SUPPORT}

\section{Internal sources}

- University of Edinburgh, UK.

(Simiao Wu, Ho-Yan Yvonne, Gillian Mead, Malcolm Macleod, Martin Dennis)

- Nursing, Midwifery and Allied Health Professions Research Unit, Glasgow Caledonian University, UK.

(Alex Pollock)

- Nursing and Health Care School, College of Medical, Veterinary and Life Sciences, University of Glasgow, UK.

(Eileen Cowey)

- University of Oxford, UK.

(Michael Sharpe)

- NHS Lothian, UK.

(Gillian Mead, Susan Lewis, Martin Dennis, Elizabeth Keane)

- Chief Scientist Office, Scottish Government, UK.

(Alex Pollock)

\section{External sources}

- Scottish Branch of the British Geriatrics Society, UK.

Small project grant to Elizabeth Keane for searches and retrieval of articles for the 2008 review

Interventions for post-stroke fatigue (Review) 


\section{DIFFERENCES BETWEEN PROTOCOLANDREVIEW}

\section{Clarification of types of studies and types of participants included in this review}

In the 2008 review, we stated that we would include trials "where the interventions were aimed at treating fatigue". However, we included some trials that were not primarily intended to treat fatigue but reported fatigue as an outcome (e.g. Lorig 2001). Thus, in the current review, we clarified this inclusion criterion by listing all eligible types of studies: 1 . trials primarily intended to treat fatigue, 2. trials primarily intended to prevent fatigue and 3. trials not primarily intended to treat or prevent fatigue but which reported fatigue as an outcome.

In the 2008 review, we stated that we would include "relevant randomised controlled trials in patients with a clinical diagnosis of stroke", but we included some trials that had recruited mix populations of participants with difference diseases including stroke (e.g. Lorig 2001), where we were able to obtain data on just the participants with stroke. Thus, in the current review, we clarified that we also included studies "which reported mixed populations of participants if more than $75 \%$ of the people were stroke or separate data for people with stroke were obtained".

\section{Measures of treatment effects}

In the 2008 review, we stated that if a study used a number of different measures for fatigue, we preferred the dichotomous measures as primary outcomes to the continuous measures. In the current review, we performed different analyses for dichotomous outcomes and for continuous outcomes.

\section{Assessment of publication bias}

We added methods for assessing the publication bias.

\section{Synthetic analysis and effect size}

We had planned to calculate standardised mean difference (SMD) for continuous outcomes and pool the results using a random-effects model. However, we did not pool the results from trials that were too diverse in participant characteristics and interventions. This is because a meta-analysis is particularly interested in the effect of a specific intervention (compared with an adequate control) on a specific outcome in a specific population.

Furthermore, for trials not in the meta-analysis, we calculated mean difference (MD) rather than SMD for continuous outcomes as the individual effect size. This is because SMD was used to facilitate the pooling of results from trials using different scales for a same outcome, but for individual trials MD is preferable as it is more interpretable than SMD.

\section{Subgroup analyses}

In the 2008 review, we had planned to perform a subgroup analysis for 'duration of treatment'. In the current review, we changed this to the 'amount of intervention'. The latter is a better expression to quantify an intervention, as it involves both dose/intensity and duration of the intervention.

In the 2008 review, we planned to perform a subgroup analysis for 'length of follow-up'. In the current review, we did not perform this subgroup analysis but performed separate analyses for outcomes assessed at different time points after treatment.

In the current review, we added an analysis for time window from stroke onset to recruitment. This is based on our hypothesis that different factors may contribute to PSF along its natural history, thus the efficacy of the same intervention may be different for participants at different time points after stroke.

We had intended to perform subgroup analyses for different types of interventions, but each identified intervention was tested in a single trial, thus we could only broadly categorise them as pharmacological interventions and non-pharmacological interventions. We also summarised the individual results for each intervention in a separate section.

We had intended to perform subgroup analyses for sources of participants, amount of intervention and time of recruitment since stroke, but this was not achieved because these subgroups were pre-specified to be performed under a same type intervention, but the included trials each used a different intervention. 


\section{Sensitivity analyses}

In the 2008 review, we planned to perform a sensitivity analysis for publication types. We did not perform this analysis in the current review, because we do not think publication status related to any risk of bias.

\section{N DEX TERMS}

\section{Medical Subject Headings (MeSH)}

Antidepressive Agents [therapeutic use]; Drugs, Chinese Herbal [therapeutic use]; Fatigue [etiology; *therapy]; Mindfulness [methods]; Randomized Controlled Trials as Topic; Stress, Psychological [prevention \& control]; Stroke [ ${ }^{*}$ complications; psychology]

\section{MeSH check words}

Female; Humans; Male 